\title{
UAB
}

Universitat Autònoma de Barcelona

\section{IMPLEMENTATION OF OCCULT HEPATITIS SCREENING IN THE SPANISH COHORT OF HIV-INFECTED PEDIATRIC PATIENTS}

\author{
Marta Dapena Archilés
}

ADVERTIMENT. L'accés als continguts d'aquesta tesi queda condicionat a l'acceptació de les condicions d'ús

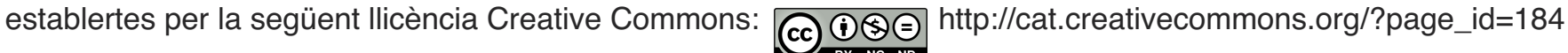

ADVERTENCIA. El acceso a los contenidos de esta tesis queda condicionado a la aceptación de las condiciones de uso establecidas por la siguiente licencia Creative Commons: (c) (i) @ http://es.creativecommons.org/blog/licencias/

WARNING. The access to the contents of this doctoral thesis it is limited to the acceptance of the use conditions set by the following Creative Commons license: (c) (i) () $@$ https://creativecommons.org/licenses/?lang=en 


\section{UAB \\ Universitat Autònoma \\ de Barcelona}

Dr. PERE SOLER I PALACÍN, Senior consultant at the Pediatric Infectious Diseases and Immunodeficiencies Unit of the Hospital Universitari Vall d'Hebron and adjunct professor of the Universitat Autònoma de Barcelona, and Prof. ANTONIO CARRASCOSA LEZCANO, Head of Pediatric Department in the Faculty of Medicine of the Universitat Autònoma de Barcelona.

HEREBY CERTIFY that the PhD Thesis presented by MARTA DAPENA ARCHILÉS, entitled: “IMPLEMENTATION OF OCCULT HEPATITIS SCREENING IN THE SPANISH COHORT OF HIV-INFECTED PEDIATRIC PATIENTS", has been prepared under our supervision in the PhD Program of the Department of Pediatrics, Obstetrics and Gynecology and Preventive Medicine and meets the required standard for defense as a doctoral dissertation to obtain the degree of Doctor of Medicine.

Bellaterra (Barcelona, Spain), September 8, 2016 
IMPLEMENTATION OF OCCULT HEPATITIS SCREENING IN THE SPANISH COHORT OF 2011 HIV-INFECTED PEDIATRIC PATIENTS 
It is better to debate a question without settling it than to settle a question without debating it. Joseph Joubert 
IMPLEMENTATION OF OCCULT HEPATITIS SCREENING IN THE SPANISH COHORT OF 2011 HIV-INFECTED PEDIATRIC PATIENTS 
IMPLEMENTATION OF OCCULT HEPATITIS SCREENING IN THE SPANISH COHORT OF 2011 HIV-INFECTED PEDIATRIC PATIENTS

To Daniel, Bruna and Lola 
IMPLEMENTATION OF OCCULT HEPATITIS SCREENING IN THE SPANISH COHORT OF 2011 HIV-INFECTED PEDIATRIC PATIENTS 


\section{ACKNOWLEDGMENTS}

The completion of a doctoral thesis requires effort, motivation and perseverance by the doctoral candidate, as well as the collaboration and constant support of many people. I would therefore like to thank and show my appreciation to everyone who, direct or indirectly, has supported me through the long writing of this thesis.

Firstly, my sincere thanks to Dr. Pere Soler, director of this thesis, for his invaluable help, guidance and support, for introducing me to the pediatric infectious diseases and transmitting his love and enthusiasm of the subject, and for all those articles, abstracts, mails and enquiries at odd hours and to Prof. Antonio Carrascosa, codirector of this project, for his support and lead.

To Red de Investigación en SIDA (RIS) for financial support (see disclosures) and to all the researchers that participated in the development of this study.

To Dr. Concepció Figueras for her expertise and knowledge and for being a role model in the field of pediatric infectology, and to Dr. Andrea Martin for her trust, friendship and affection.

To Dr. Antoinette Frick and Dr. Maria Espiau, the CoRISPe Node 2 coordinators, for their help and advice. 
To Dr. Xavier Martínez-Gómez, Santiago Pérez Hoyos and Francisco Rodríguez-Frias who provided help, without which it would not have been possible to develop this thesis.

To my good friend Dr. Leticia González for her friendship, advice and support with statistics, and to my dear friend Dr. Laia Gifre for her valuable advice on writing this thesis and for all we have been thorough since our first days at Medical School.

Thanks also to Dr. Ton Noguera for his "red pen" review of the preliminary version of the manuscript.

Not least, thanks to my family: to my parents Maricarmen and Paco for their trust and unconditional support and motivation, to Daniel for his comprehension and unconditional daily love, and to Bruna, my daughter, whose happiness and energy over these months encouraged me to complete this project.

Lastly, thanks to all those who helped me with the blueprint that gave rise to this PhD Thesis. 


\section{TABLE OF CONTENTS}

2. ABBREVIATIONS.

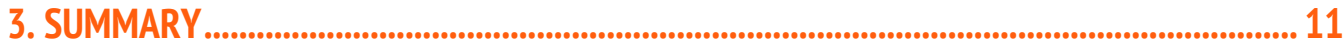

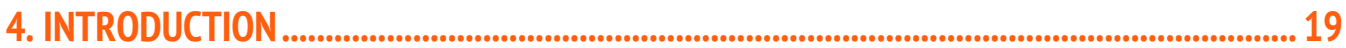

4.1. Epidemiology of hepatitis B virus infection............................................................................22

4.2. Epidemiology of hepatitis C virus infection...........................................................................2

4.3. Epidemiology of viral hepatitis in HIV-infected adults........................................................ 27

4.4. Epidemiology of viral hepatitis in HIV-infected pregnant women ........................................ 30

4.5. Epidemiology of viral hepatitis in HIV-infected children...................................................... 34

4.5.1. Hepatitis B virus monoinfection .......................................................................................... 34

4.5.2. Hepatitis C virus monoinfection ...................................................................................... 42

4.5.3. Viral hepatitis in HIV-infected pediatric patients.......................................................... 45

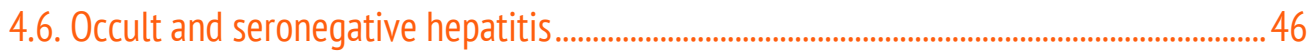

4.6.1. Occult hepatitis B infection ................................................................................................. 47

4.6.2. Seronegative hepatitis C infection..................................................................................50

4.6.3. Occult hepatitis in HIV-infected patients..........................................................................51

4.6.4. Occult hepatitis in HIV-infected pediatric patients........................................................52

4.7. Assessment of liver fibrosis ..................................................................................................... 53

4.7.1. Invasive assessment of liver fibrosis ............................................................................... 53

4.7.2. Noninvasive assessment of liver fibrosis ........................................................................... 54

4.8. Vaccination against hepatitis B virus in children .................................................................. 59

4.8.1 Vaccination against hepatitis B virus in the HIV-negative population........................60

4.8.2 Vaccination against hepatitis B virus in the HIV-infected patients..............................61 
5. AIMS, PATIENTS AND METHODS

5.1. Aims 65

5.1.1. Primary objectives 65

5.1.2. Secondary objectives 65

5.2. Patients and study design .65

5.2.1. Study. 65

5.2.2. Human aspects. Informed consent. 66

5.3. Clinical data 66

5.4. Analytical data. 67

5.5. Outcomes and definitions 69

5.6. Statistical analysis. 70

6. RESULTS 73

6.1. Baseline characteristics ................................................................................................................... 73

6.2. Prevalence of overt hepatitis $B$ virus coinfection .................................................................. 77

6.3. Prevalence of overt hepatitis C virus coinfection................................................................... 79

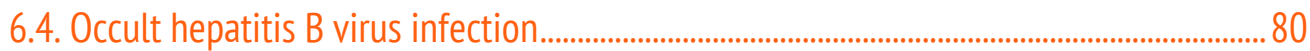

6.5. Seronegative hepatitis C virus infection................................................................................ 84

6.6. Noninvasive assessment of liver fibrosis in overt hepatitis $B$ and $C$ virus infection......85

6.7. Noninvasive assessment of liver fibrosis in occult hepatitis infection ..............................87

6.8. Noninvasive assessment of liver fibrosis in HIV-monoinfected patients ..........................89

6.9. Hepatitis B virus vaccine response .......................................................................................... 90

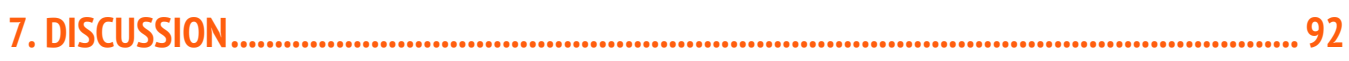

7.1. HBV/HIV coinfection in children .............................................................................................. 92 
7.2. HCV/HIV coinfection in children .......................................................................................... 94

7.3. Occult hepatitis in HIV-positive children.................................................................................. 97

7.3.1. Occult hepatitis B virus infection .......................................................................................... 97

7.3.2. Seronegative hepatitis C virus infection ......................................................................103

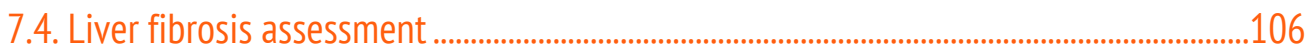

7.4.1 AST/ALT ratio ...............................................................................................................................107

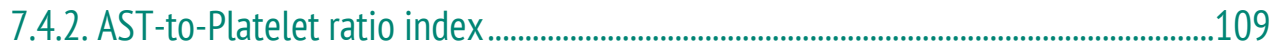

7.4.3. Fibrosis-4 score ...................................................................................................................111

7.5. Hepatitis B virus vaccine response ..............................................................................................113

8. STUDY LIMITATIONS ..................................................................................................................117

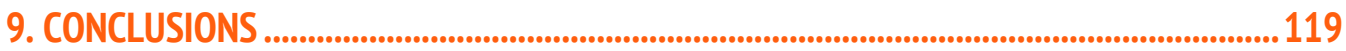

10. FURTHER RESEARCH ........................................................................................121

11. DISCLOSURES

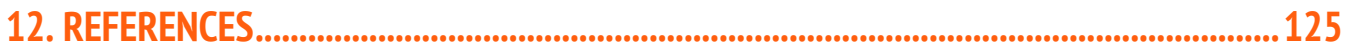

13. APPENDIX 1: INFORMATION SHEET FOR PARENTS/GUARDIANS ..................................151

14. APPENDIX 2: INFORMED CONSENT..................................................................................155

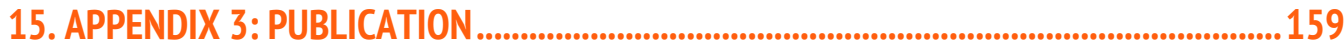


IMPLEMENTATION OF OCCULT HEPATITIS SCREENING IN THE SPANISH COHORT OF

2011 HIV-INFECTED PEDIATRIC PATIENTS 


\section{ABBREVIATIONS}

\begin{tabular}{|c|c|}
\hline Abbreviation & Meaning \\
\hline $3 T C$ & Lamivudine \\
\hline AIDS & Acquired Immune Deficiency Syndrome \\
\hline ALT & Alanine Amino transferase \\
\hline Anti-HBc & Hepatitis B Core Antibody \\
\hline Anti-HBe & Hepatitis B Envelope Antibody \\
\hline Anti-HBs & Hepatitis B Surface Antibody \\
\hline APRI & AST- to- Platelet Ratio Index \\
\hline AST & Aspartate Amino transferase \\
\hline AUC & Area under receiver operating characteristic curve \\
\hline $\mathrm{cHCV}$ & Chronic Hepatitis C virus infection \\
\hline CHIVA & Children's HIV Association \\
\hline CoRISPe & Spanish Cohort of HIV-Infected pediatric patients \\
\hline d4T & Stavudine \\
\hline ddl & Didanosine \\
\hline DNA & Deoxyribonucleic Acid \\
\hline EASL & European Association for the Study of the Liver \\
\hline ECDC & European Centre for Disease Prevention and Control \\
\hline EPHN & European Pediatric HCV Network \\
\hline
\end{tabular}


EIA

ELISA

FIB-4

FTC

HAART

HAV

$\mathrm{HBcAg}$

HBeAg

HBsAg

HBV

HCC

HCV

HDV

HIV

HOMA-IR

$\lg G$

$\lg M$

INF- $\alpha$

IOR

$\mathrm{kPa}$

LDUO

MTCT
Enzyme immunosorbent assay

Enzyme linked immunosorbent assay

Fibrosis-4 score

Emtricitabine

Highly active antiretroviral therapy

Hepatitis A Virus

Hepatitis B Core Antigen

Hepatitis B Envelope Antigen

Hepatitis B Surface Antigen

Hepatitis B Virus

Hepatocellular carcinoma

Hepatitis C Virus

Hepatitis Delta Virus

Human Immunodeficiency Virus

Homeostatic model assessment for insulin resistance

Immunoglobulin $\mathrm{G}$

Immunoglobulin M

Interferon alpha

Interquartile range

Kilopascals

Liver disease of uncertain origin

Mother-to-Child Transmission 
Non-AIDS related events

NAFLD

NASPGHAN

NITs

OBI

$\mathrm{OCl}$

PCR

PENTA

RIBA

RIS

RNA

TDF

TLE

ULN

VL

WHO
Nonalcoholic fatty liver disease

North American Society for Pediatric Gastroenterology, Hepatology and Nutrition

Noninvasive Tests

Occult Hepatitis B Infection

Occult Hepatitis C Infection

Polymerase Chain Reaction

Paediatric European Network for Treatment of AIDS

Recombinant Immunoblot Assay

Spanish AIDS Research Network (Red Española de Investigación en SIDA)

Ribonucleic Acid

Tenofovir disoproxil fumarate

Transient Liver Elastography

Upper limit of normal

Viral Load

World Health Organization 
IMPLEMENTATION OF OCCULT HEPATITIS SCREENING IN THE SPANISH COHORT OF

2011 HIV-INFECTED PEDIATRIC PATIENTS 


\section{SUMMARY}

Background: The management of human immunodeficiency virus (HIV) has changed during the last decade in the developed setting, due to early implementation of combined antiretroviral therapy (CART) as the standard of care. HIV-infected patients can now enjoy a longer life expectancy with almost no acquired immune deficiency syndrome (AIDS) defining episodes if diagnosed promptly, as is the case for most vertically-infected children in our setting. The question is whether this longer life expectancy is free of comorbidities or whether other medical conditions will appear. In fact, the generalization of CART in rich income countries has led to the emergence of certain pathologies and disorders encompassed under the term nonAIDS events (NAEs) that were not so evident and prevalent at the beginning of the epidemic, in the pre-HAART (highly active antiretroviral therapy) era. Liver disease is a good example of this epidemiological change.

Hepatotropic virus coinfection is now a well-known factor of poor prognosis in adult HIV patients. A worse outcome of liver disease is expected through both the direct action of the virus and the effect of the antiretroviral drugs. Moreover, HIV itself is considered a risk factor that contributes to increased mother-to-child transmission (MTCT) of the hepatitis virus. Furthermore, the infection rates of the hepatitis B and C viruses (HBV and HCV respectively) are considerably higher in patients living with HIV, as they share most of the transmission routes. For both 
types of virus (HIV and hepatitis), the main acquisition route in childhood is MTCT. This can take place in utero but is particularly prevalent in the perinatal period, especially in endemic areas. The earlier the hepatitis virus is acquired, whether HBV or HCV, the higher the risk of chronicity and further complications in adulthood, such as liver fibrosis, cirrhosis and hepatocellular carcinoma (HCC).

Also, the immunosupression conferred by the virus itself, among other factors, makes HIV-infected patients prone to uncommon variations of hepatotropic coinfections which are serologically silent, namely, occult hepatitis B infection (OBI) and seronegative HCV infection. These entities bring an increased risk of disease reactivation, progression and evolution to chronic and severe liver damage, especially in children who acquire the virus early in life, as stated above.

Because of these particularities, current regular screening methods may miss the diagnosis of these coinfections in immunocompromised patients. As in many other pathologies clinical and laboratory data regarding this issue are lacking in HIV-infected children and adolescents.

The inclusion of screening for $\mathrm{OBI}$ and seronegative hepatitis $\mathrm{C}$ in routine HIV patient monitoring would be a useful tool to identify those patients at risk of hepatic decompensation in the event of additional immunosuppression, and would give the clinician the opportunity to reach an early coinfection diagnosis and to take appropriate action. In HIV- 
infected children who face the prospect of a lifetime coinfection, this possibility would be of particular interest, and highly beneficial, as it would become possible to anticipate secondary clinical conditions and future complications.

\section{Objectives:}

\section{Primary objectives:}

1. To assess the prevalence of HBV and HCV infection among the HIVinfected pediatric population in the Spanish Cohort of HIV-infected pediatric patients (CoRISPe).

2. To address $\mathrm{OBI}$ and seronegative hepatitis $C$ virus infection in the same population and discover whether it would be useful to include occult hepatitis markers in the routine screening of these patients for hepatotropic virus infection, in order to increase the ability to diagnose these entities and allow early diagnosis, treatment and/or prevention of HBV reactivation in $\mathrm{OBI}$ cases.

3. If possible, retrospectively to investigate maternal serostatus to include occult hepatitis screening.

\section{Secondary objectives:}

1. To ascertain the rate of $\mathrm{HBV}$ vaccination and vaccine response in these children. 
2. To assess noninvasive liver fibrosis through biochemical serum markers and detect, if possible, those patients at higher risk of liver disease due to liver fibrosis.

Patients and methods: This is an observational, cross-sectional study conducted in 2011 among CoRISPe. Demographic, clinical, immunological and virological data were examined, as well as the CART and HBV vaccination status recorded in the collective shared database. At one of the scheduled quarterly visits the following HBV and HCV infection markers were measured, with no additional blood extraction: aminotransferase levels (AST and ALT), hepatitis B surface antigen (HBSAg), hepatitis B antibody (anti-HBs), hepatitis B core antibody immunoglobulin $G$ and immunoglobulin M (anti-HBc IgG, anti-HBc IgM), polymerase chain reaction (PCR) for HBV deoxyribonucleic acid (DNA) testing, enzyme linked immunoblot assay (ELISA) and recombinant immunoblot assay (RIBA) antibodies, and PCR for HCV ribonucleic acid (RNA) testing. Additionally, maternal HBV and HCV infection serological markers (HBsAg and RIBA HCV antibodies and PCR for HBV DNA and HCV RNA) were included retrospectively in order to establish the prevalence rate of maternal HCV and HBV coinfection and seronegative HCV or OBI. In addition, noninvasive tests (NITs) for liver fibrosis assessment using the AST/ALT ratio, the ASTto-platelet index (APRI) and the fibrosis-4 score (FIB-4) were conducted in all patients; HIV-monoinfected children, those found to be chronically HBV and HCV coinfected and those with seronegative HCV and OBI coinfection. 
The available data about HBV vaccination schedules were recorded and correlated with protective anti-HBs levels.

The statistical analyses were performed using Stata/SE 11.2 software (StataCorp College Station, TX, USA).

Results: Of the 572 patients below 18 years of age comprising CoRISPe at that point, a total of 254 patients, from 14 participating centers all of which are members of the national health system were included in this study. The median age of the study cohort was 14 years. Half were girls. The majority ethnic group was Caucasian (70.5\%) while Black African and Latin American were respectively the second (19.3\%) and third (7\%) most frequent ethnicities. Regarding the HIV transmission route, $94.9 \%$ of these children were vertically-infected and there were small minorities of other acquisition routes. The children included in the study appeared to be under good immunological and virological control, with a median CD4+ Tlymphocyte count of 840 cells/mm3, and in a good Centers for Disease control and Prevention (CDC) clinical category: $40 \%$ were in category N/A with only $26 \%$ in category C (AIDS). Regarding antiretroviral therapy, 8 patients were naïve to any antiretroviral therapy, 90\% had current or prior exposure to lamivudine (3TC) or emtricitabine (FTC) and 30\% also had exposure to tenofovir disoproxil fumarate (TDF).

Three (1.2\%) and $13(5 \%)$ patients respectively had serological markers compatible with overt chronic HBV (cHBV) and HCV (cHCV) infection. Two 
patients showed spontaneous clearance of HCV infection. Triple HCV/HBV/HIV coinfection was not observed in any patient.

Six children were considered probable OBI cases, 2 presenting with anti$\mathrm{HBc}$ alone and 4 with an anti-HBc+/anti-HBs+ serological pattern, although blood HBV DNA testing was negative in all cases. Two patients $(0.8 \%)$ had seronegative HCV infection.

$90 \%$ of the patients had followed a complete HBV vaccination schedule prior to the study but almost $50 \%$ of the patients showed no protective antibody response following the regular scheduled vaccinations against HBV.

Regarding noninvasive assessment of liver fibrosis at least one score was pathological in all 3 with overt cHBV and in 7 out of 13 with overt $\mathrm{CHCV}$, warning of a possible underlying fibrosis and the need for further liver function assessment and monitoring. One HCV-infected patient showed simultaneous alteration of the three scores included in the study. All 6 probable OBI cases appeared to have altered ALT/AST ratio, APRI index was high in 2 out of 6 and FIB-4 scores were normal in all probable OBI cases. Both cases of seronegative HCV infection showed abnormal APRI index values. Among HIV-monoinfected children, 77\% showed raised ALT/AST ratios, while $5.7 \%$ presented APRI abnormal values. Just one patient showed FIB-4 score abnormality. 
Regarding maternal HBV and HCV infection, 3.9\% of the mothers were chronic HBV carriers and $24.4 \%$ were infected by HCV. Retrospective maternal occult hepatitis infection screening could not be performed because some of the mothers had passed away years before the present study and hepatitis molecular assays had not been performed on others. Only two of the mothers of the children identified as having probable OBI were known to be HBV-infected and both mothers of the children with seronegative HCV infection were HCV-positive. Conversely, the mothers of the three patients with overt cHBV infection had unknown serology for HBV, as did 3 out of the 13 mothers of HCV-infected patients. Moreover, one of these mothers had negative serology for HCV.

Conclusions: The HBV and HCV prevalence coinfection rates in this cohort appear to be in keeping with previously published data, in the absence of wider prevalence coinfection data for the HIV-infected pediatric population, whereas the global rate of occult hepatitis coinfection cases detected in this cohort was low (3.1\%). However, molecular diagnosis assays may be indicated to increase the sensitivity of detection and minimize the risk of under-diagnosis and its clinical implications in adulthood.

Although $90 \%$ of the patients had followed a complete HBV vaccination schedule, only half of them reached protective levels. In view of the responsiveness rate in this population, serological verification, review of 
the immunization schedules and revaccination, when indicated, should be considered as recommended by current guidelines.

Noninvasive liver assessment thorough biochemical scores shows abnormal figures in HIV-infected patients with otherwise normal transaminase levels, allowing an early approach to liver disease management in the HIV coinfected patient. However, correlation with transient liver elastography (TLE) data was not measured because TLE was not performed at the time of the study, as the pediatric probe was not available in all the participating centers. Nor were any biopsies performed, either due to the invasive nature of this procedure. Further research is needed to assess the suitability of using biochemical scores in these populations in order to approach good levels of sensitivity and specificity, and to correlate this method to liver fibrosis assessed by imaging and/or biopsy.

It is both a challenge and responsibility for pediatricians skilled in pediatric HIV infection to look for and stay alert to any hint of liver disease that might already be present in childhood and could emerge in adult life, when complications are irreversible. 


\section{INTRODUCTION}

Of the forty million HIV-infected people worldwide, fifteen million are on CART, particularly in resource-rich countries. Since access to and implementation of CART became widespread, the mortality and morbidity of HIV infection have decreased dramatically, to the extent that it is now considered a chronic disease in both adult and pediatric patients. In the pre-HAART era, around 15\% of untreated HIV-infected children would die or present an AIDS-defining illness during their first year of life. This progression would slow down after they were 5 years old, when they acquired a steady stage infection. Nowadays, this pattern of disease evolution in children has changed extraordinarily in our setting, as the widespread application of effective HIV MTCT prevention policies have dramatically decreased pediatric HIV infections and universal CART has turned HIV into a chronic infection involving a chronic latent condition that induces extensive damage to the immune system through both virusrelated and indirect pathogenic mechanisms (1-3).

As a consequence of the extended life expectancy, a series of NAEs have emerged as important causes of morbidity and mortality in HIV-infected individuals. They include cardiovascular, bone, metabolic and neurocognitive disorders, and liver disease is currently one of the leading causes of hospitalization and death. The advent of these disorders is thought to respond to a multifactorial origin, with CART drug toxicity, low 
CD4+ T-lymphocyte counts, older age and lifestyle playing important roles $(4-10)$.

A recent study among newly diagnosed HIV-infected adult patients followed-up over 2 years found hepatic, psychiatric and malignant diseases to be the three most frequent NAEs associated with age, immunosuppression and lack of virological control. In the same study, one third of the deaths were attributed to NAEs, especially neoplasms and liver disease (8).

Thus, liver disease has emerged as one of the main cause of death among adult HIV-infected individuals, who are known to have a faster progression of the disease alongside a worse outcome of the liver condition. Several causes are known to have a place in the causality of liver disease in the adult HIV-infected population: the direct action of the HIV virus itself, the toxicity of antiretroviral drugs such as didanosine (ddl) and stavudine (d4T) and alcohol abuse. Besides, it has been reported recently that HIV-infected patients may present with a liver disease of uncertain origin (LDUO), which may also lead to developing a chronic disease such as fibrosis, or cirrhosis, or even terminal liver disease. A recent prospective longitudinal study in Spain tried to shed light on this by following liver stiffness for a year and a half in 210 adult HIV-infected patients who were known to be free of liver disease and not HBV/HCV coinfected. Twenty percent of these patients developed LDUO, which was independently associated with metabolic risk 
factors (higher HOMA-IR and body mass index). The leading cause of LDUO was found to be non-alcoholic fatty liver disease (NAFLD) $(5,6,11,12)$.

Nevertheless, with almost 300 million worldwide living with cHBV and 180 million with $\mathrm{CHCV}$, viral hepatitis are now deemed a worldwide epidemic and remain the most frequent liver diseases in adult HIV-infected patients and an important factor in poor prognosis and end-stage hepatic illness. Moreover, HCV/HIV coinfection is known to confer risk for other non-liver related events like insulin-resistance, chronic kidney disease, hematological malignancies and neurocognitive disorders (4,7,13-19).

Both acute and chronic infections are of increasing concern because they are mostly asymptomatic and because a considerable and rising number of people are infected with a hepatitis virus. Two years ago, a group of experts and researchers working in the field of HIV and viral hepatitis gathered at HepHIV 2014 in Barcelona to discuss new approaches to reduce the impact of such infections in Europe, basically through enhanced screening programs and diagnostic testing and mainly addressing the adult population. In the same way as there is a definition for late diagnosis of HIV infection, the conference created a definition for late diagnosis hepatitis B and C infection. New public health strategies were urged, highlighting the importance of wide coverage, easy access and early diagnosis. This is particularly relevant in relation to HCV because the arrival of new treatments has been a major step in tackling HCV and now the 
primary goal of therapy is to cure the infection, especially in cases of monoinfection but also for HIV/HCV coinfected patients $(18,20)$.

As the extent of the whole situation is unclear in coinfected children, only limited and heterogeneous pediatric-specific data are available. A few studies in the pediatric HIV population can be found, but the results are not at all conclusive (21-23).

\subsection{Epidemiology of hepatitis B virus infection}

cHBV is considered globally the main cause of liver disease, cirrhosis and HCC. Almost one third of the population worldwide has been exposed to the virus and the gross burden of cHBV is estimated at around 240 million people chronically infected (5\% of the general population). In the United States, the estimated incidence is 50,000 new cases per year. The World Health Organization (WHO) has reported that the number of deaths from HBV infection exceeds 600,000 per year (16,24-28).

Although the geographic distribution of HBV is universal, prevalence varies depending on the degree of introduction of preventive vaccination schedules for HBV and on the control of the different acquisition mechanisms, such as systematic control of blood donations and serological screening of pregnant women. However, HBV is considered endemic in sub-Saharan Africa, Southeast Asia, China and India, which have prevalences of between $10 \%$ and $20 \%$ and where most infections occur during childhood due to MTCT. 
According to the 2012 Hepatitis Surveillance Report of the European Centre for Disease Prevention and Control (ECDC), 17,329 cases were reported in 29 European Union Member States, of which 71\% were chronic, $16 \%$ acute and $10.8 \%$ unknown. Regarding transmission, MTCT was the most common route for chronic cases globally (67\%) and heterosexual (31.2\%) and nosocomial (20.6\%) were most commonly reported for acute infections. However, in countries with low prevalence the sexual route is the most prevalent. The 2012 ECDC's report summarized these transmission categories as shown in Figure 1 (29).

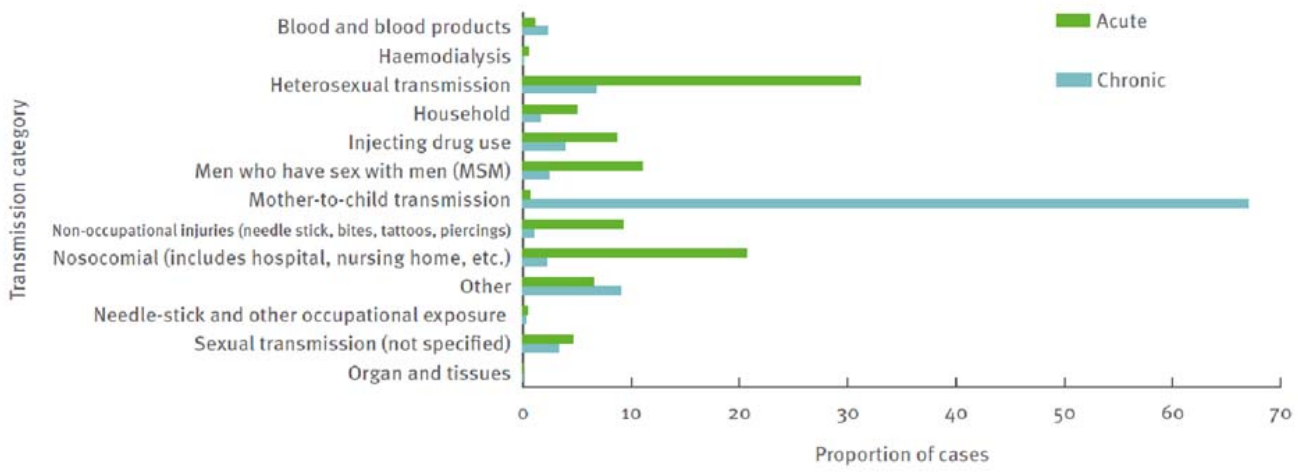

Figure 1. HBV transmission category in the EU, 2012(29).

The data for HBsAg seropositivity prevalence in Europe according to ECDC Hepatitis Surveillance Report are represented in Figure 2. In the Western European setting, the ECDC considers Spain a country with intermediate 
prevalence (2-8\%). However, recent publications indicate that the figures might have decreased considerably in keeping with other European data, to adult prevalence rates of around $1.69 \%$ in certain areas of Catalonia and $0.5 \%$ in school-age children under 15 years old, probably because of universal vaccination campaigns and good screening and perinatal care of the newborn infants of HBV-infected mothers (29-32).
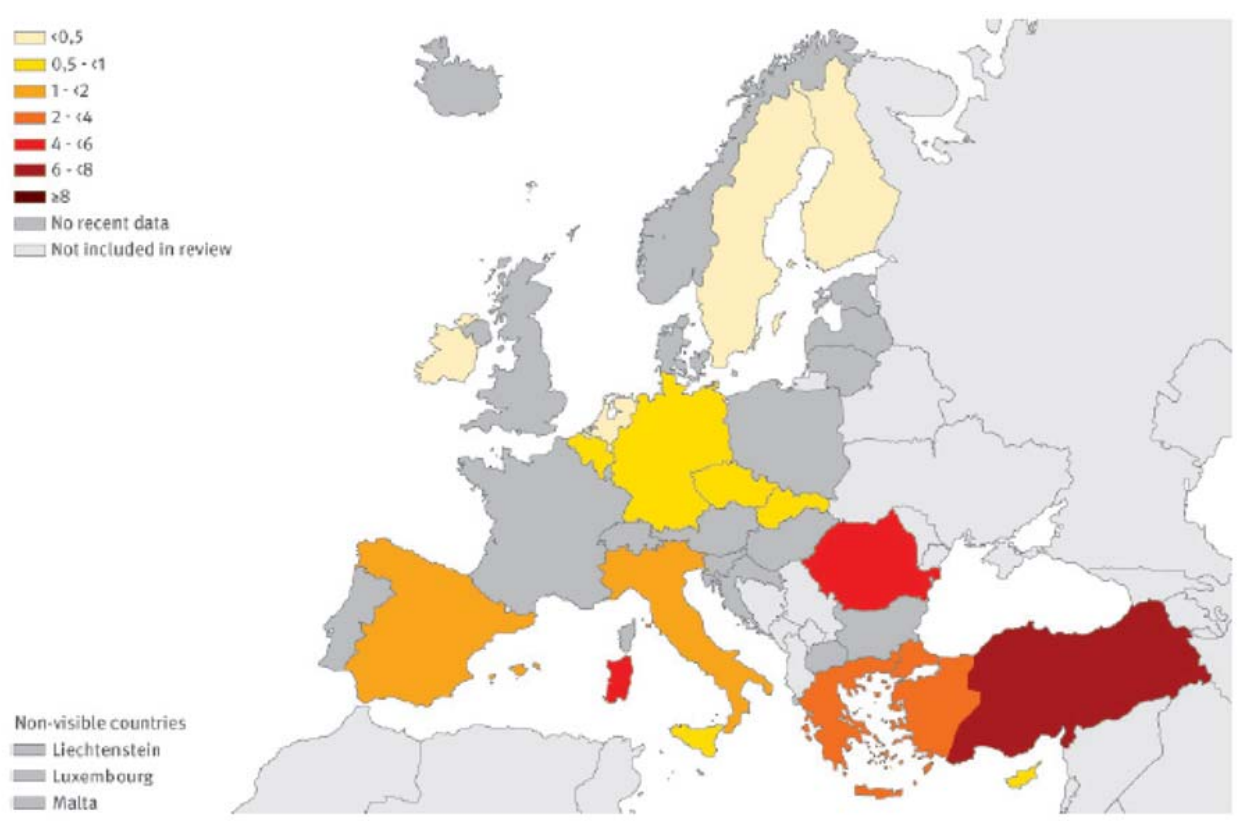

Figure 2. Hepatitis B (HBsAg) prevalence in the general population in Europe (27). 


\subsection{Epidemiology of hepatitis C virus infection}

Recent data estimate the prevalence of HCV at around 130-150 million people infected globally (3\% of the global population). The prevalence of antibodies against $\mathrm{HCV}$ is between $1.6 \%$ and $2.6 \%$ in the general population, with variations depending on age and region. The highest rates of chronic HCV infection are found in Egypt (15.0\%), Pakistan (4.8\%) and China (3.2\%). As for HBV, the WHO has reported that the number of HCVrelated deaths is more than 350,000 per year $(24,26,27,29,33)$.

The ECDC hepatitis surveillance in 2012, reported 30,607 cases of HCV infection in the European Union. Data on HCV seroprevalence in the general population can be viewed in Figure 3. Overall the most commonly reported route of infection was injecting drug use, accounting for $76.5 \%$ of all cases. However, there has been a continued rise in acute HCV cases associated with HIV-positive men who have sex with men, and outbreaks have been reported throughout Europe. Data regarding HCV MTCT is missing in this report (29). 

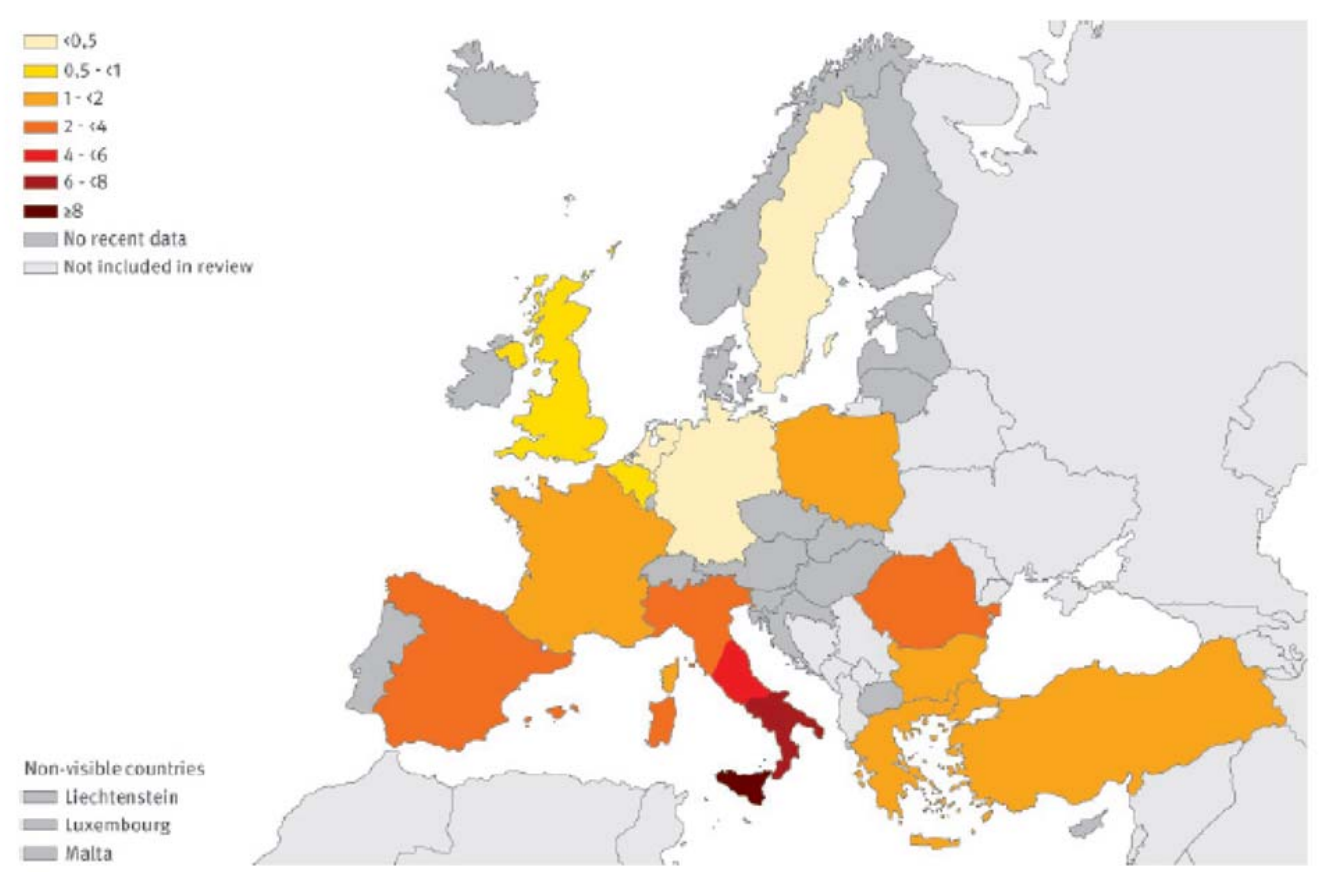

Non-visible countries Liechtenstein Luxembourg Malta

Figure 3. HCV seroprevalence in the general population in Europe (27).

HCV infection in healthy children and adolescents in Spain is estimated to be between $0 \%$ and $0.7 \%$ but increases significantly with age, depending on the population and the risk factors. The estimated prevalences in North America are $0.17 \%$ in children between 6 and 11 years old and $0.39 \%$ in the 12 to 19 year old range $(26,34)$.

The burden of chronic disease is high, even higher than for HBV and trends in HCV infection are not showing a similar decline to that for HBV due to several factors, mostly the route of transmission (drug injection and outbreaks in men who have sex with other men) and the lack of a 
preventive vaccine. However, since significant strides have been made in developing new treatments for $\mathrm{HCV}$, the prevalence is expected to move downward in the coming years. Indeed, the emergence of new treatments consisting of direct-acting drugs confers cure rates exceeding 90\%, including in HIV-positive patients, who seem to present a better response compared to the former interferon-based regimes. In fact, international guidelines for HCV infection treatment recommend treating regardless of HIV status, which obviously causes concern about CART interactions $(18,35,36)$.

\subsection{Epidemiology of viral hepatitis in HIV-infected adults}

The HIV-infected population, who have experienced a changing hepatic virus coinfection epidemiology over the last decade, present totally different figures from those mentioned above (16).

The shared risk factors and modes of transmission explain why the overall rate of hepatitis virus is significantly higher in the adult HIV-individual with coinfection rates of around 10\% for HBV and 30\% for HCV, and, not surprisingly and as expected, higher coinfection rates in areas of high prevalence of the three viruses (Southeast Asia and West Africa, for instance).

Three out of the 35 million people living with HIV are coinfected with HBV and it is estimated that between $40 \%$ and $60 \%$ of HIV-positive individuals 
have been exposed to HBV. The EuroSIDA cohort found a prevalence of HBV dual infection in HIV cases of around 9\% in 2005 (17,35).

HCV/HIV coinfection is estimated at between 5 and 10 million depending on the series, and the risk of HCV coinfection is up to 6 times higher in HIV individuals than in the general population as highlighted by Clausen et al. (Figure 4) (37).

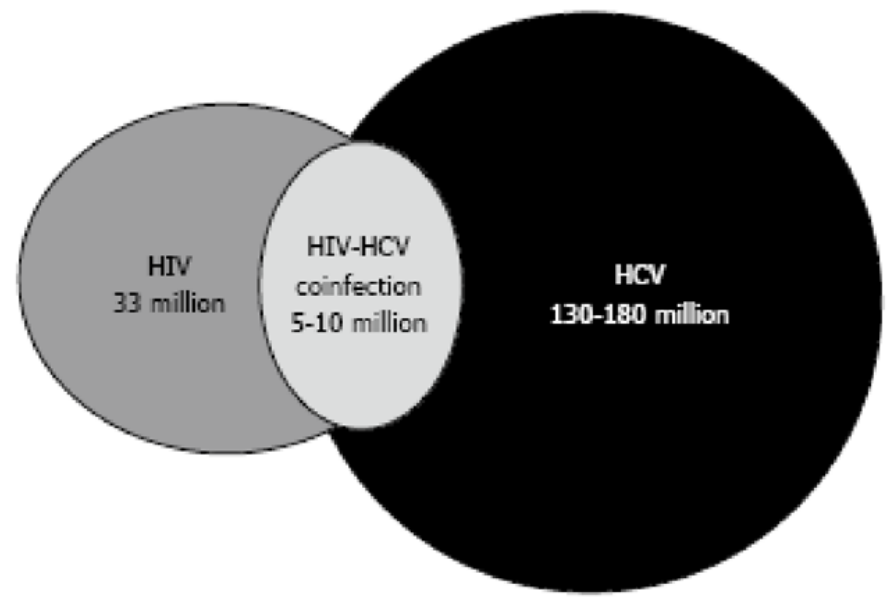

Figure 4. Worldwide numbers of HIV, HCV and HIV/HCV coinfected individuals (37).

Recent data from the EuroSIDA cohort on HCV dual infection in HIV reflected the variations in prevalence across different European regions plus Argentina and Israel, with prevalences of around 30\% in the countries of southern Europe (Figure 5). It may be highlighted that in this cohort of 
18,786 patients, a quarter of the deaths in a ten-year period were attributable to HCV infection (17,33).

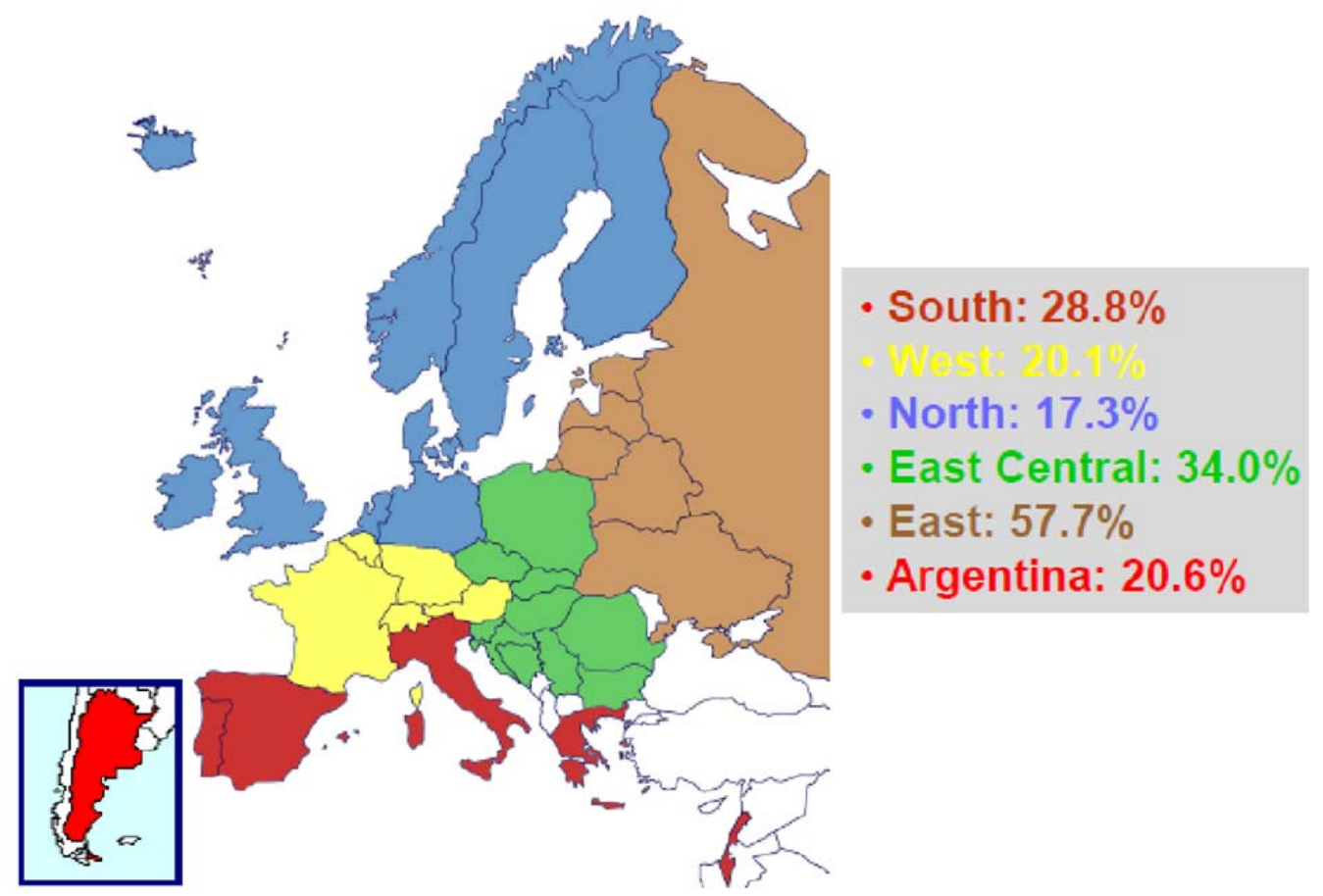

Figure 5. Anti-HCV antibody prevalence in EuroSIDA regions (17).

Triple coinfection with HIV, HBV and HCV has also been described, the most frequent HCV superinfection being of a chronic HBsAg carrier in whom HBV DNA is usually low or undetectable, although it can fluctuate over time, and the determinant of the severity of the progression of liver disease is HCV infection (25). 
HIV hepatitis coinfection management can be considered a global challenge, with the warning that the majority of the HIV-hepatitis coinfected population currently has limited access to testing, assessment or treatment. For this reason, international policies are focused on universal, easy-to-access screening in the interests of developing strategies to battle the hepatitis epidemic $(20,24)$.

\subsection{Epidemiology of viral hepatitis in HIV-infected pregnant women}

MTCT is the main route of acquisition for both viruses -HIV and viral hepatitis- in childhood, especially in endemic countries but also worldwide. Data about intrauterine hepatitis transmission rates and associated risk factors are uncertain and, although data about hepatitis coinfection in HIVpositive mothers are not as exhaustive as might be desired, epidemiology shows that the effect of HIV on HBV/HCV increases MTCT 2-to 3-fold $(3,22,38)$.

As Papaeva et al. pointed out, HIV-infected infants may have early humoral and cell-mediated immunity defects that may lead to a higher risk of HCV infection after being exposed to small amounts of the virus perinatally. In addition, recent studies on HCV exposure in utero hint at a relative fetal suppression of immune activation after HCV-exposure that could shed light in the pathogenesis of HCV MTCT $(22,39)$.

In Spain, HBV infection prevalence markers during pregnancy have declined over time. The prevalence of HBV among pregnant women was 
estimated at around 1.2\% in 1991 (Figure 6). Twenty years later, these figures had dropped to $0.1-0.8 \%$. This substantial reduction is directly related to universal vaccination in our country and to the special care of the newborn infants of HBV-infected mothers, who receive post-exposure immunoprophylaxis consisting of a first dose of HBV vaccine at birth plus a dose of HBV immunoglobulin within the first 72 hours. The same management is provided in cases of unknown maternal serostatus $(26,30,40,41)$.
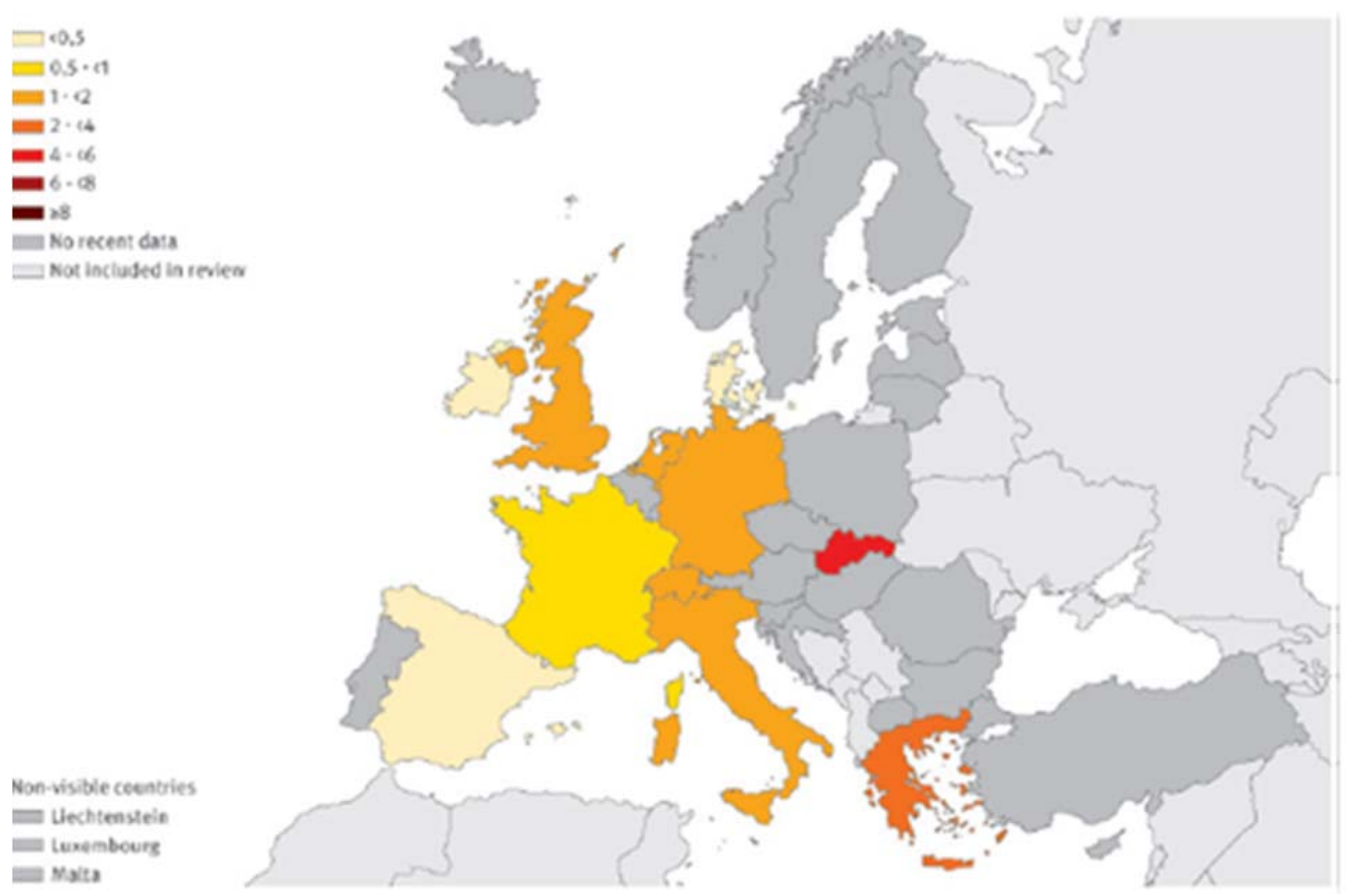

Figure 6. HBsAg prevalence in pregnant women in Europe (27). 
Although HBV has been isolated in breast milk, concentrations are low and are not associated with an increased risk of transmission.

Regarding HCV prevalence among pregnant women, the ECDC's 2010 technical report on Hepatitis B and C in the EU zone did not disclose recent data. However, recent papers estimate a similar prevalence to that for HCV in the general population, which varies between $0.5 \%$ and $1.4 \%$ (Figure 7).

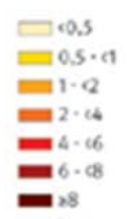

No recent dass

Kot included in revien

Nonvisible countries

E Uechitensteic

E texembeurg Mat:a

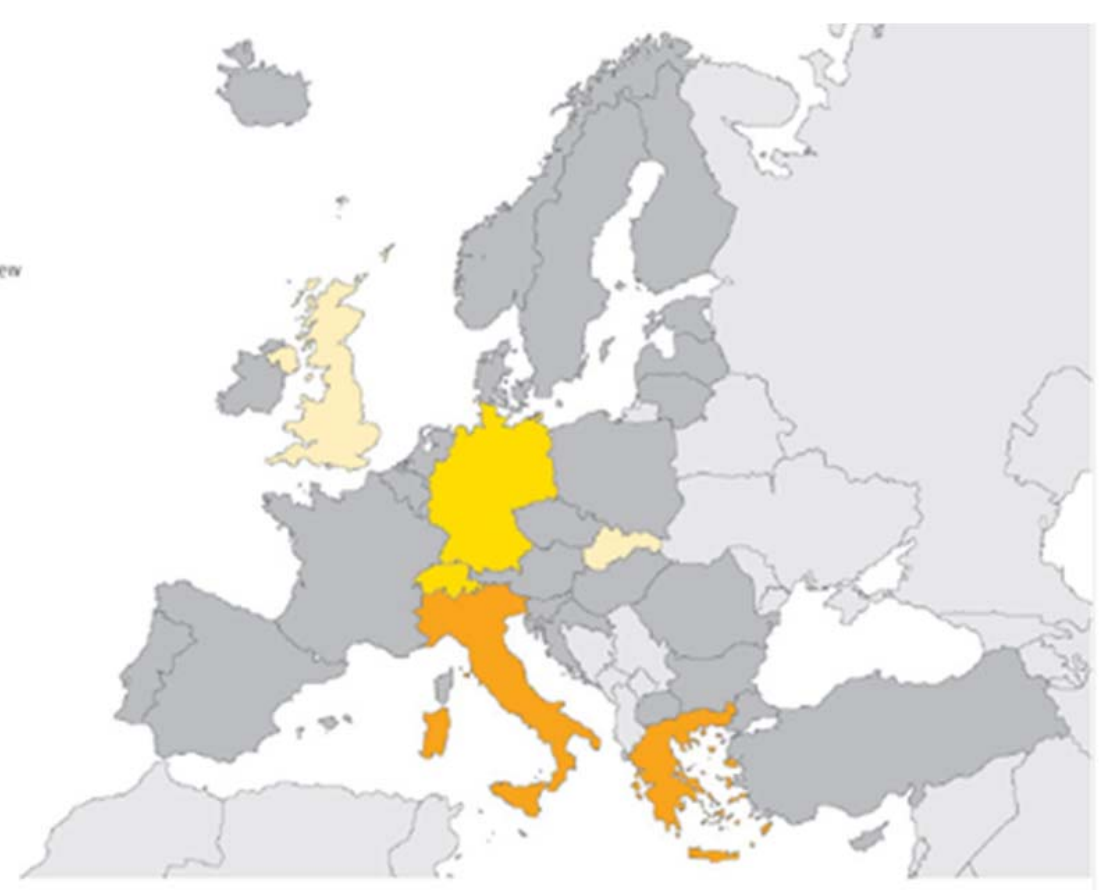

Figure 7. Hepatitis C prevalence in pregnant women in Europe: anti-HCV (27). 
Ward et al. found an overall prevalence of HCV infection of $0.8 \%$ and viremia of $0.6 \%$ among 4852 women attending antenatal clinics in an inner city hospital in London in 2000. In the United States, the estimated prevalence of $\mathrm{HCV}$ infection among pregnant women is around $0.75 \%$ $(26,27,34,40,42,43)$.

Perinatal HCV infection prevention in Spain follows the national recommendations: avoiding premature membrane rupture and invasive obstetric procedures that can increase the exposure to maternal and fetal blood. Again, perinatal HCV transmission is associated with higher maternal HCV VL and HIV coinfection as stated at the beginning of this subsection. However, contrary to what was previously thought, the consensus document of the European Paediatric HCV Network stated that despite the fact that several risk factors for HCV MTCT have been identified, none are considered to be modifiable and there are no current interventions available to prevent vertical HCV transmission. Thus, elective cesarean delivery, avoiding prolonged membrane rupture and invasive procedures during pregnancy and avoiding breastfeeding do not seem to be associated with lower HCV vertical transmission and are not recommended for HCV-monoinfected mothers. The estimated risk for HCV transmission is $5-7 \%$ per pregnancy if the mother is not coinfected with HIV, in which case the risk is increased 2-to 3-fold (34,43-46). 
On the other hand, although a high proportion of infected women are first diagnosed in pregnancy, routine antenatal HCV serological screening is not widely recommended. However, ultimately this might be reassessed in view of the latest developments in active drugs against HCV that offer a curative alternative. In addition, antenatal screening also ensures that vertically-infected children are identified before the onset of symptoms $(43,45)$.

In HIV mothers, viral hepatitis coinfection assessment is made only through serologic screening and intrapartum management is based on HIV guidelines recommendations, which advocate elective cesarean section and avoiding breastfeeding in settings where formula milk is available $(35,45,47)$.

\subsection{Epidemiology of viral hepatitis in HIV-infected children}

\subsubsection{Hepatitis B virus monoinfection}

cHBV is defined as HBsAg positivity for at least 6 months. The natural history of the disease in children remains a complex and dynamic process. The majority of chronically HBV-infected children are asymptomatic with normal growth and physical examinations and normal liver function tests. This is the reason why HBV infection in children has been thought of traditionally as a benign disease, or at least not an aggressive disease. However, $5 \%$ of children may develop long-term liver complications, 
between $1.7 \%$ and $4.5 \%$ of children infected vertically show histological changes compatible with cirrhosis, and $0.03 \%$ may develop HCC before adulthood (48).

The age of acquisition is the major determinant of chronicity, which is highest in children infected within the first year of life. Figure 8 represents the outcome of HBV infection according to age at infection from the recent WHO Guidelines for the screening, care and treatment of persons with CHBV (49).

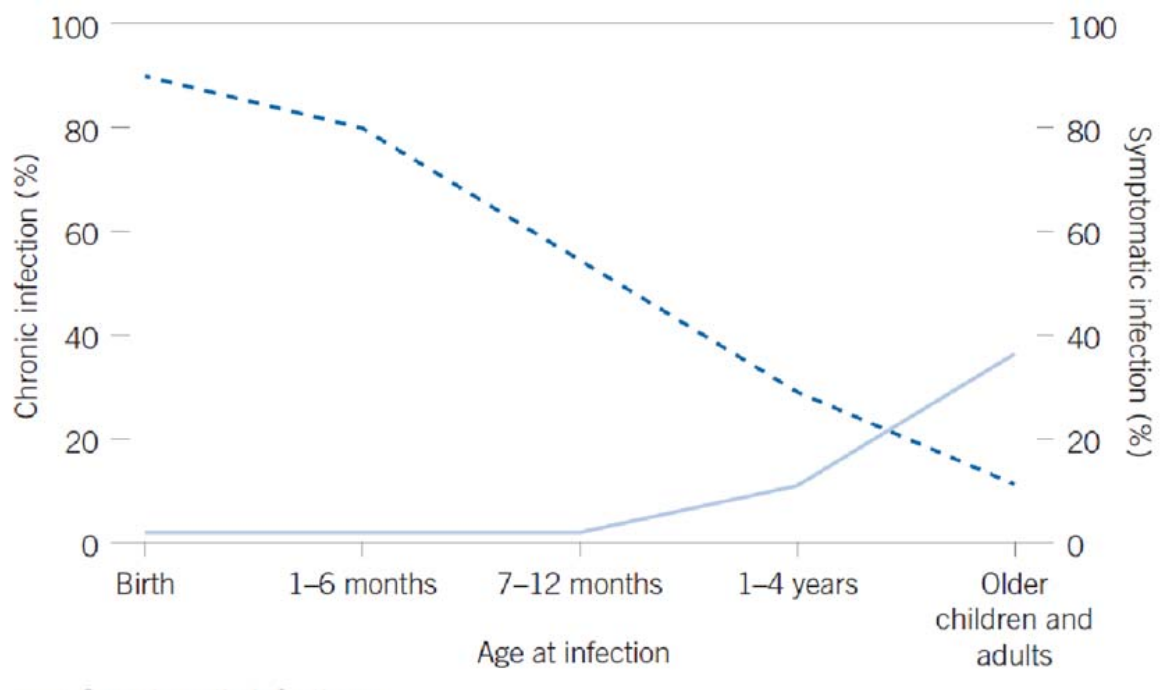

- Symptomatic infections

--- Chronic infections

Figure 8. Outcome of Hepatitis B infection by age at infection (49). 
Worldwide prevalence of cHBV in children is represented in the 2015 WHO's Guidelines for the screening, care and treatment of persons with hepatitis B infection in Figure 9 (49).

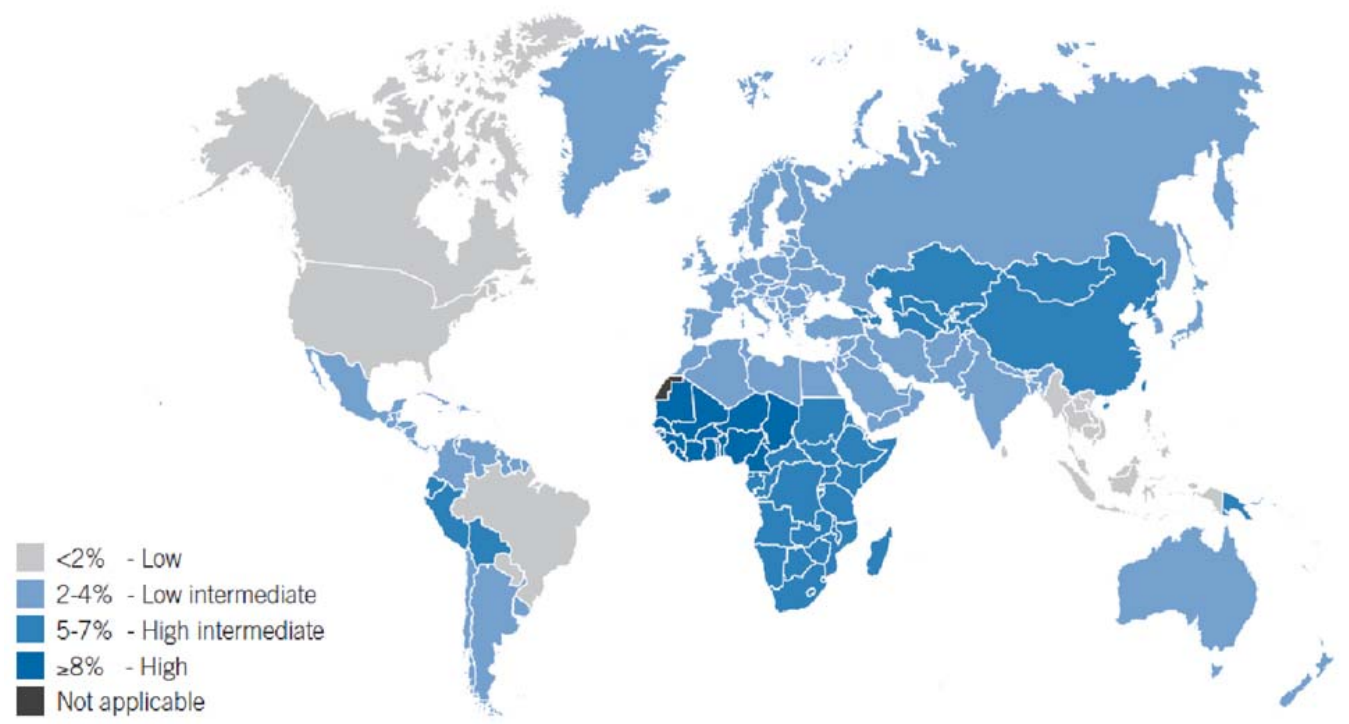

Figure 9. Worldwide prevalence of HBV in 5-9 year old children (49).

More than $90 \%$ of infected infants become chronic carriers, compared with $6-10 \%$ of children older than 6 years old that become infected. Spontaneous clearance and resolution of HBV infection (loss of HBsAg and appearance of anti-HBs) is rarely observed in perinatally infected children ( $<1 \%$ per year) in comparison to horizontal acquisition of the virus (50-52). 
Intrauterine infection is reported as below $5 \%$ and it is known that in newborn infants born from chronically HBV-infected mothers, HBeAg can cross the placenta and induce hyporesponsiveness of $T$ helper lymphocytes to maternal HBeAg and HBsAg. This may cause an immune tolerant phase in the neonate who has an immature immune system, leading to chronicity which is hypothesized to be the cause of the high rate of perinatal infection in the absence of secondary prophylaxis found on comparing infection in adults and in babies born from HBeAg-positive mothers (53).

Transmission differs depending on geographic variations. In highly endemic areas, mainly Asian countries, MTCT accounts globally for approximately half of the cHBV infections in childhood, although intrauterine does not seem to be the major route, as stated in the previous paragraph. Vertical infection has been related to placental tears, invasive intrapartum procedures or trauma during delivery resulting in contact with infected maternal fluids. Maternal HBeAg positivity results in a higher risk of MTCT, with $70-90 \%$ more infectivity, and infants born from viremic mothers are at risk of breakthrough infection despite a correct postexposure management and immunization program, which is considered to be $98 \%$ effective. Household horizontal transmission is also prevalent in endemic areas through child to child transmission, mainly in African countries. In areas with low endemicity, infection occurs mainly in adult life 
through sexual or parenteral transmission (blood transfusion, surgery, dental care, body piercing, tattooing...) $(51,54)$.

The risk factors associated with progressive hepatic damage are HBV genotype, persistent viremia (immune-active phase) and specific mutations in the HBV genome.

There are eight HBV genotypes, from $\mathrm{A}$ to $\mathrm{H}$, with differences in chronicity and severity and in geographic distribution. Genotypes B and C are prevalent in Asia while genotypes $A$ and $D$ are found more commonly in cHBV in Africa, the Middle East, India and Europe. Genotype C infection in children is related to lower rates of HBeAg seroconversion than genotype B. However, genotype B has a higher association with HCC in children, whereas the association is with genotypes $\mathrm{C}$ and $\mathrm{F}$ in adults (48).

HBV infection proceeds in three phases: the immune-tolerant phase, immune-active phase and inactive carrier phase. An understanding of the serological dynamics over the acute and chronic infection stages and of HBV serological profile interpretation is essential. However, they might be confusing in the pediatric population, especially in the immunocompromised patient. Figures 10 and 11 respectively, summarize this information. 

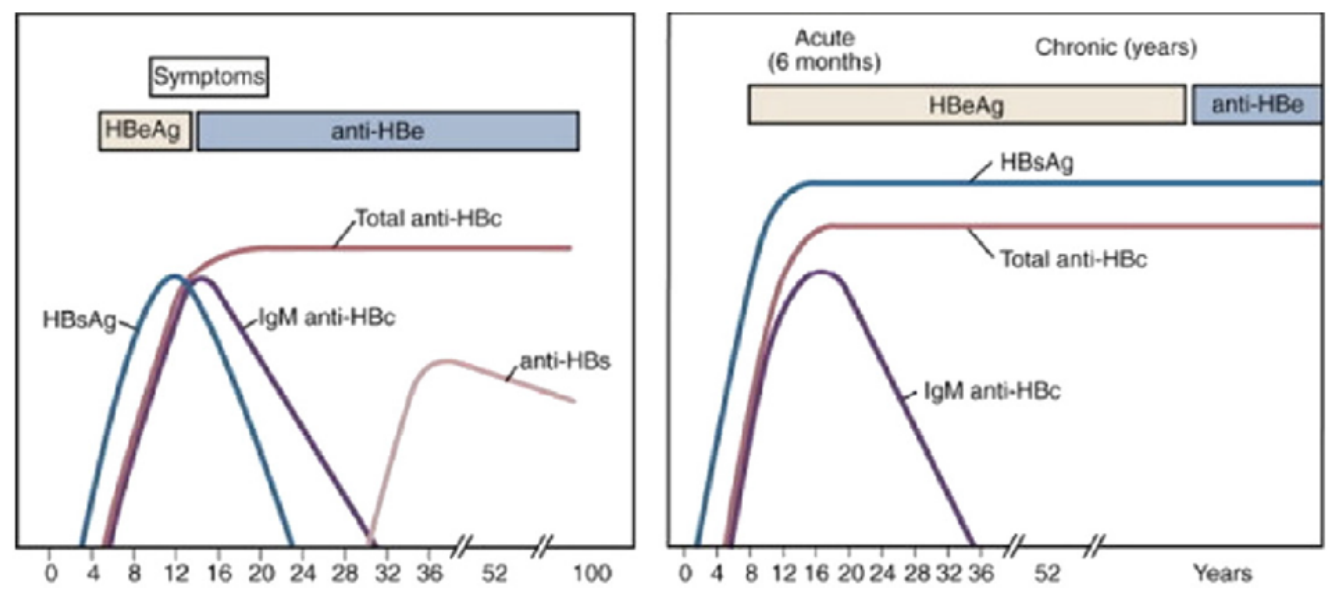

Figure 10. HBV serological dynamics over acute and chronic infection (adapted from Mandell, Douglas, and Bennett's Principles and practice of infectious diseases, 8th edition, figures 119-1 and 119-2. Copyright Elsevier 2015) (55).

Most children are immune-tolerant and this status lasts for 10 or 30 years long into adulthood. This phase is defined by HBsAg-positivity, high viral replication $\left(10^{6}\right.$ copies $\left./ \mathrm{mL}\right)$ and positive $\mathrm{HBeAg}$ with normal or minimum aminotransferase level elevation. Surprisingly, regardless of active HBV replication there is minimum liver inflammation with a normal liver biopsy, because HBV is a virus that does not attack hepatocytes directly. Rather, it is the immune response that is hepatotoxic. In adulthood, high DNA serum levels have been reported as an independent risk factor for cirrhosis and HCC, however (50). 


\begin{tabular}{|l|c|c|c|c|}
\hline HBsAg & $\begin{array}{c}\text { Anti- } \\
\text { HBC }\end{array}$ & $\begin{array}{c}\text { Anti- } \\
\text { HBs }\end{array}$ & HBV DNA & Interpretation \\
\hline Negative & Negative & Negative & $\begin{array}{c}\text { Not } \\
\text { considered }\end{array}$ & Never infected \\
\hline Negative & Negative & Positive & $\begin{array}{r}\text { Not } \\
\text { considered }\end{array}$ & Immune due to vaccination \\
\hline
\end{tabular}

\begin{tabular}{|c|c|c|c|c|}
\hline Positive & Positive & Negative & $\begin{array}{c}\text { Not } \\
\text { considered }\end{array}$ & Acutely infected \\
\hline Negative & Positive & Negative & $\begin{array}{c}\text { Not } \\
\text { considered }\end{array}$ & $\begin{array}{l}\text { 1. Resolved infection (most common) } \\
\text { 2.False-positive anti-HBc } \\
\text { 3.Low level chronic infection } \\
\text { 4. Resolving acute infection }\end{array}$ \\
\hline Negative & Positive & Positive & $\begin{array}{c}\text { Not } \\
\text { considered }\end{array}$ & Immune due to prior natural infection \\
\hline Positive & Positive & Negative & $\begin{array}{c}\text { Not } \\
\text { considered }\end{array}$ & $\mathrm{cHBV}$ \\
\hline
\end{tabular}

\begin{tabular}{|c|c|c|c|c|} 
Negative & $\begin{array}{c}\text { Positive } \\
\text { or } \\
\text { negative }\end{array}$ & $\begin{array}{c}\text { Positive } \\
\text { or } \\
\text { negative }\end{array}$ & Positive & OBI \\
\hline
\end{tabular}

Figure 11. HBV serological markers and clinical interpretation (adapted from Mortensen) (28).

The immune-tolerant phase usually persists until adulthood. However, some children may present with an immune-active or immune-clearance 
phase with elevation of aminotransferases, which indicates the underlying liver inflammation and the consequent risk of fibrosis over time.

In the immune-active or seroconversion phase there is a T-cell mediated inflammation response leading to cell necrosis and hepatic inflammation. It is characterized by an acute exacerbation and marked inflammation, with a subsequent elevation of transaminases which results in the clearance of HBeAg in $60-95 \%$ of patients. Although spontaneous seroconversion may occur in childhood it rarely appears before 3 years of age and is more common in adolescence and youth between the ages of 15 and 30 years. Recent Caucasian and Asian data estimate a spontaneous seroconversion rate in children of $17 \%$ and $12 \%$, respectively $(48,56,57)$.

Spontaneous seroconversion is lower in countries where HBV is endemic and HBV is acquired vertically, and, has been reported to be higher in children infected horizontally. Seroconversion diminishes the risk of HCC over time. However, spontaneous HBeAg seroconversion does not mean histological remission of chronic hepatitis. In fact, it seems to be a bad prognosis factor, and early anti-HBe conversion in very young children has been associated with a higher risk of HCC. Another subgroup is the $10 \%$ of antiHBe-positive pediatric patients who show active replication with histologically active hepatitis $(54,58,59)$.

The last phase leads to the anti-HBe positivity status of inactive carrier, with low aminotransferase levels and low HBV DNA (<104 copies/mL). It is 
known that $7-25 \%$ of inactive carriers lose HBsAg and become anti-HBs over time, and that the HBsAg clearance rate is significantly higher in children who are already anti-HBe-positive compared to those who are HBeAg-positive. However, this is considered a rare event in pediatrics, with 0.6-1\% of cases/year. Horizontal transmission is more prone to anti-HBepositivity than vertical transmission as stated before $(56,60)$.

Anti-HBs seroconversion marks the resolution of HBV infection, but due to its complex life cycle HBV can persist indefinitely in the nucleus of infected hepatocytes as a covalently closed circular DNA (cccDNA), and a certain level of replication in case of immunosuppression is always possible, which is the reason that lifetime follow-up is warranted. Indeed, HBV DNA integrates into the host genome and exerts an oncogenic effect, increasing the risk of HCC.

\subsubsection{Hepatitis C virus monoinfection}

The history of cHCV in children differs from that of adults in several respects. Since the advent of universal screening of blood products, the mode of infection is mainly MTCT. Transmission from viremic mothers is estimated at between $4 \%$ and $6 \%$, and approximately 10,000 to 60,000 of newborns are infected with HCV worldwide each year (39).

Although hypothetically the earlier the acquisition the higher the risk of long-term liver-related complications, the spontaneous resolution is a relatively frequent $\mathrm{HCV}$ infection outcome in children. The rate of 
spontaneous resolution in the pediatric age-bracket is high, between 25$40 \%$, especially for vertically-infected children. The placenta is known to play a protective role and if neonatal HCV infection takes place, spontaneous resolution frequently occurs. In a child with confirmed infection, with two PCR tests after one month of age or two positive tests, either PCR or antibody, after 18 months of age, spontaneous clearance might occur. The reason it is much more prevalent in children than in adults remains unknown, but it usually occurs during the first 3 years of life (34).

Spontaneous resolution of a neonatal HCV infection with high ALT levels is often seen in the first year of life, and it remains unclear whether the infection is just a transient viremia. This pattern of clearance is seen irrespective of whether the child was infected vertically or through a blood donation (34).

Chronically infected children, defined as 6 months of HCV RNA positive detection, generally have a mild disease with normal liver histology. Children are usually asymptomatic and growth is not impaired, as per HBV. HCC and liver transplantation are extremely rare in children with $\mathrm{CHCV}$. Even so, $1-2 \%$ of chronically infected children develop cirrhosis and $\mathrm{cHCV}$ represents a 26-fold increased risk of liver-related death according to NASPGHAN data (34). 
Extrahepatic manifestations such as membranoproliferative glomerulonephritis and executive cognitive impairment have been reported in children, although much less frequently than in adulthood. However, neither lymphoma nor cryoglobulinemia have been identified in pediatrics (61).

Pediatric HCV infection rates vary from 0.05 to $0.36 \%$ in Europe and the United States, whereas in developing countries the rates can be around 6\%. According to Muñoz-Gomez et al., HCV prevalence among Spanish children is around $0.07 \%(26,62)$.

There are host factors and factors related to HCV itself that play a role in the clearance or persistence of the virus. HLA DR 13 is known to confer MTCT protection and the Rs12979860 CC genotype for IL28B polymorphism is related to spontaneous resolution. HCV genotypes have important implications in determining outcome and liver disease progression. Genotype 3 is likely to resolve spontaneously and genotypes 1 and 4 are more resistant to treatment compared to genotypes 2 and 3 . However, MTCT seems to be independent of genotype. Genotypes present geographic variation. The most common is genotype 1, although it is distributed worldwide, it is found predominantly in North America and Europe. Genotypes 2 and 3 also have worldwide spread. Genotype 4 is prevalent in Africa and the Middle East, genotype 5 in South Africa and genotype 6 in Asia. However, HCV presents a high mutation rate and this 
generates quasi-species that may explain the varying clinical pictures and the difficulty of developing an effective vaccine (62).

\subsubsection{Viral hepatitis in HIV-infected pediatric patients}

Recent European and Spanish guidelines on pediatric HIV management promote universal screening of viral hepatitis coinfection. The exact prevalence data on chronic viral hepatitis in HIV-positive children in this setting are hovering around coinfection rates of $1 \%$ for HBV and 3.3\% for HCV, while data on the adult population show coinfection rates of $30 \%$ and $10 \%$ for HCV and HBV, respectively, depending on endemicity $(4,16,25,47,63-$ $66)$.

HBV coinfection figures from a Romanian study in HIV-infected adolescents showed a prevalence of $43 \%$. These data were higher because the period of time analyzed was prior to universal HBV immunization, whereas in the United States, prevalences of $2.6 \%$ have been found, similar to a study conducted in perinatally HIV-infected Thai children. Recent data from Nigeria, an endemic country for both viruses, show a seroprevalence rate of $6 \%$ among HBV/HIV coinfected children. In an extensive review of HBV/HIV coinfected children, one African study showed that in the long term, anti-HBe seroconversion did not result in virological control, contrary to patients with HBV monoinfection, and, as expected, that those with lower CD4+T-lymphocyte counts were unable to sustain a virological response for HBV and showed higher VHB DNA levels (67-71). 
In a national retrospective study on vertically-acquired HCV/HIV coinfection in children within CoRISPe, 43\% showed high ALT levels and 30\% had advanced fibrosis in the last liver test (biopsy/fibroscan). Of note was that $13 \%$ of the patients were seronegative for HCV, showing both negative antibodies with positive RNA HCV (72).

As discussed in the introduction, viral hepatitis and HIV coinfection is a dangerous combination, especially for children, who face a lifelong risk of HIV infection progression, accelerated liver disease progression and higher rates of liver failure and death. These are the main reasons why an active search for viral hepatitis/HIV coinfection by pediatricians caring for HIVinfected children is warranted.

\subsection{Occult and seronegative hepatitis}

Occult HBV infection (OBI) and seronegative HCV infection are serosilent forms of viral hepatitis that are detectable with virological assays but may be misdiagnosed by routine serological screening methods. Their clinical relevance and clinical impact lie in their infectivity and the silent long-term progression of liver disease to cirrhosis and HCC. Transmission through blood products, hemodialysis and both solid organ and bone marrow transplantation have been reported as inducing a classic acute HBV infection leading to clinically significant liver damage in recipients. Interestingly but also worrisome for pediatricians, occult hepatitis may also be implicated in MTCT (73-85). 
Reactivation of occult infection with the emergence of a typical HBV infection serological profile has also been reported in hematological malignancies and other states of immunosuppression, in which cytotoxic Tcell-mediated hepatitis and viral reactivation are associated with immune reconstitution syndrome (25,86-90).

\subsubsection{Occult hepatitis B infection}

$\mathrm{OBI}$ is defined as undetectable HBsAg with low rate viral replication outside the acute phase window period. HBV DNA might be found peripherally and/or in the hepatocyte. The molecular basis of OBI relies on the life cycle of HBV, in which a stable cccDNA survives for a lengthy period in hepatocyte nuclei and perpetuates HBV gene transcription and the production of new virions in the infected cells of the host. Thus, after an acute hepatitis, HBV can persist for decades despite an effective down regulation of the memory $\mathrm{T}$-cell dependent antiviral protective immune response. The complex HBV life cycle is captured in Figure 12. 


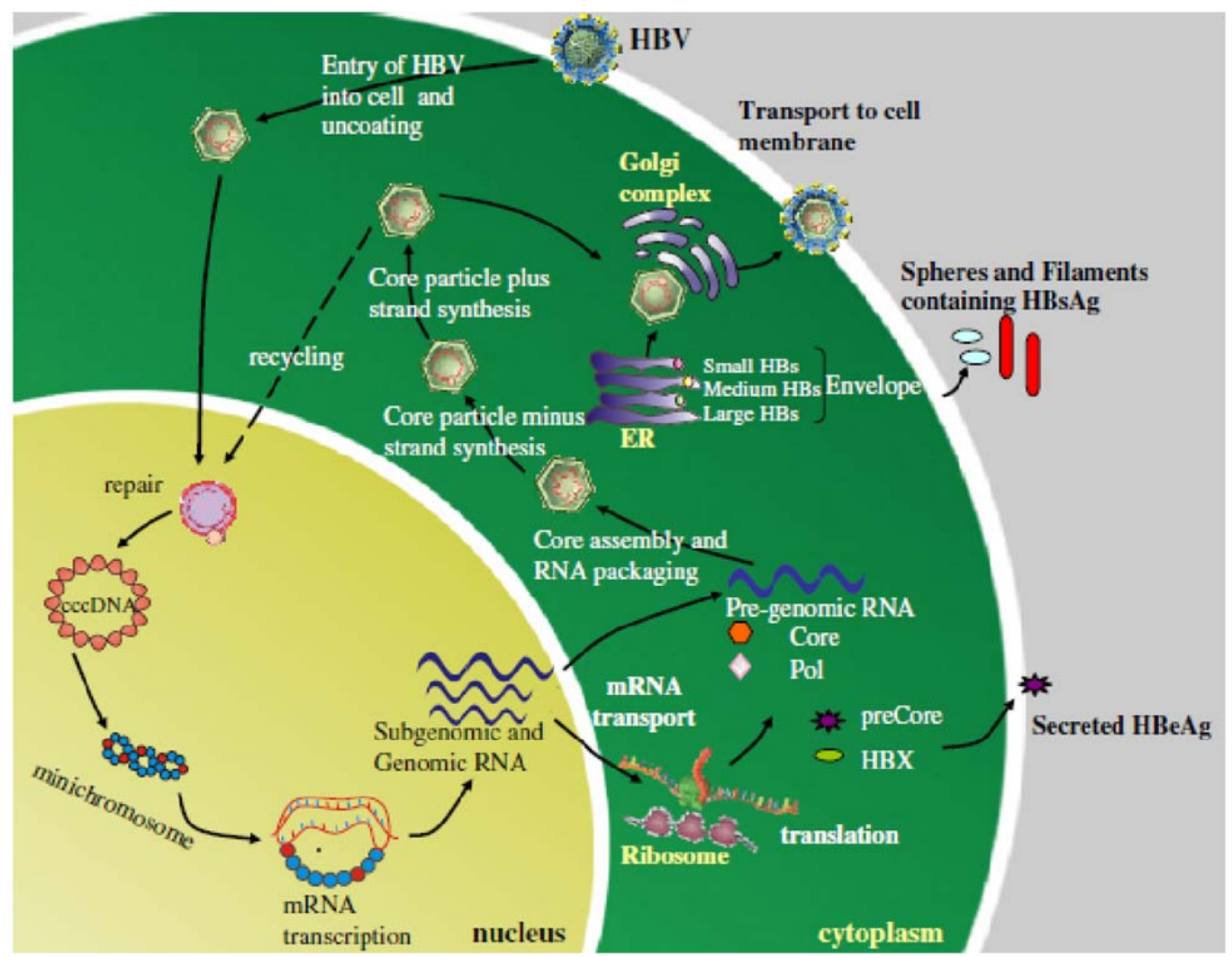

Figure 12. HBV life cycle (adapted from Raimondo) (91).

The mechanism of this infection is fascinating, particularly in the immunosuppressed patient, and a complete natural history of HBV infection is not understood because occult infection can represent the last phase of resolved infection in which viral particles that have not been cleared out from the liver persist, or a low-dose infection in a situation of partial or total lack of proper immune response. 
Prevalence in patients with HCV coinfection has been assumed to be up to $30 \%$, but remains unknown in the general population $(80,90,92,93)$.

Studies of liver tissues of $\mathrm{OBI}$ patients warn that HBV genomic heterogeneity consisting in modified HBV S protein not detected by conventional screening methods, or in viral mutations that impair S gene expression, is similar to that in overt HBV infection and does not explain why HBsAg negativity typifies OBI. The hypothesis is that $\mathrm{OBI}$ is the result of strong viral replication suppression and gene expression, although the underlying mechanisms remain unclear. The host's immune response based on T-cell response and cytokine synthesis in the liver has been proposed as the main determining factor, but down-regulation by coinfection with other infectious agents such as HCV and hepatitis delta virus (HDV) and epigenetic factors also play a role in the physiopathology of OBI $(91,92,94)$.

It should be noted that although $\mathrm{OBI}$ is characterized by a low level of viremia, quantification of HBV DNA in the liver might show comparable figures to classic infection. Serum viremia in OBI is below $200 \mathrm{IU} / \mathrm{mL}$ by definition and higher viral loads comparable to overt HBV-infected patients and considered false $\mathrm{OBI}$, are usually considered to be due to HBV escape mutants $(73,95)$.

Several OBI serological patterns might be found, depending on which antiHBV antibodies (anti-HBc and anti-HBsAg) are present simultaneously in 
OBI. The anti-HBc alone or isolated anti-HBc pattern, although controversial, is considered a surrogate marker of HBV infection itself. Seronegative OBI refers to chronic carriage without any serological marker or detectable HBV DNA and can be found up to $20 \%$ of OBI carriers $(73,91,92)$.

\subsubsection{Seronegative hepatitis C infection}

The hallmark of cHCV infection is the positivity of antibodies against HCV plus HCV RNA serum positivity. False negative serological results can occur during the period following exposure to HCV-specific antibody seroconversion in acute infection, and in patients with cHCV. Natural infection does not confer protective immunity since HCV infection persists despite the presence of virus-specific cytotoxic T-cells and circulating antibodies to HCV proteins (96).

Analogously to $\mathrm{OBI}, \mathrm{HCV}$ seronegative HCV infection is characterized by negative HCV antibodies with detectable RNA in serum. The low total number of quiescent HCV infections reported in population studies hampers insight into the risk factors and the conditions associated with this entity. The HIV-infected population is one of the most studied, and shows higher seronegative HCV infection subsets of patients with a history of drug injection, patients with higher ALT levels and patients with more immunosuppression, with CD4+T-lymphocyte counts lower than 200 cells/ $\mu \mathrm{L}(37,72,81,97)$. 
RNA testing for HIV and HCV screening in potential blood donors are another blood panel to which attention has been paid due to the risk of transmission if they donate during the window period before seroconversion. In a large 3-year study in the United States, 139 HCV seronegative individuals were found among 37 million donations. Although the HCV seronegative was low, HCV nucleic acid screening prevented the release of 1 viremic donation for every 350,000 screened (98).

Experimental studies on HCV infection in the animal model may give advance warning of the dynamics of the serologic profile in humans. If rapid loss of antibodies occurs, like in chimpanzees, the time in which HCV infection could be detected would be rapidly reduced, so the chances of a proper diagnosis and viral clearance may be underestimated (96).

\subsubsection{Occult hepatitis in HIV-infected patients}

Cellular immune response is essential for maintaining viral hepatitis under tight control. In the HIV-infected patient the impairment of CD4+Tlymphocyte is accountable for the insufficient T-cell help to core-specific B cells, with a lack of detectable anti-HBV antibodies in the serum of these patients $(79,81,92,99,100)$.

In fact, in HIV/HBV-infected patients particular attention must be paid to any shift in the cART containing an active drug against HBV (3TC, FTC, TDF), due to the risk of HBV breakthrough. Moreover, the aging of the HIV 
population signifies a greater likelihood of developing a non-AIDS event such as malignancy, gastroenterological, rheumatic or dermatologic disorder which will require immunomodulatory therapies such as anti-TNF drugs, monoclonal antibodies (especially rituximab), high doses of corticosteroids, or systemic chemotherapy, and increases the risk of reactivation due to a loss of immune control, warranting preemptive HBV therapy. Even patients with a past history of resolved HBV infection are at risk of reactivation in case of immunosuppression because even in resolved infection, HBV cccDNA persists in the hepatocyte nuclei, as stated before (101).

\subsubsection{Occult hepatitis in HIV-infected pediatric patients}

Little attention has been paid to the true prevalence and clinical significance of occult hepatitis infection in children. A large body of information has been produced in recent years regarding occult hepatitis in adults, but data describing the clinical impact of these infections are still limited or at least are not given the public recognition they deserve, and most of the studies are of case series $(78,82,89,90,102,103)$.

Because of the lack of standardization of diagnostic methods and the small number of prospective studies, the real prevalence of occult hepatitis infections in HIV-infected patients is controversial. As usual, and as seen in relation to other issues, data concerning HIV-infected children are particularly lacking. 
Inclusion of screening for $\mathrm{OBI}$ and seronegative hepatitis $\mathrm{C}$ virus infection in routine patient monitoring might detect new coinfected pediatric HIV patients at risk of hepatic failure when additional immunosuppression or a CART switch for immune-virological failure is required. To determine the status of pediatric patients in this regard, this study was designed to investigate the value of including $\mathrm{OBI}$ and HCV seronegative infection markers in the routine hospital-based screening protocol for HIV-infected pediatric patients, starting with assessing the prevalence of occult HBV and seronegative HCV infection in a large cohort of vertically HIV-infected Spanish children which is CoRISPe.

\subsection{Assessment of liver fibrosis}

Chronic hepatitis, despite its etiology, is a common cause of liver dysfunction and usually is the background for cirrhosis progression and HCC, both monoinfected as in those with HIV coinfection. This is why liver fibrosis is one of the main prognostic factors of progression, as the grade of fibrosis is correlated with the risk of cirrhosis and other liver-related complications such as HCC.

\subsubsection{Invasive assessment of liver fibrosis}

Liver biopsy traditionally has been and still is the gold standard for liver fibrosis assessment. The histological Metavir Score has been used to assess the degree of activity and fibrosis based on a 5-point scale. The 
grades of fibrosis are scored as follows: no fibrosis (F0), portal fibrosis with no septae (F1), portal fibrosis with septae (F2), numerous septae with no cirrhosis (F3) and cirrhosis (F4). F1-F2 indicate mild fibrosis whereas F3 and F4 are markers of advanced fibrosis (104).

Apart from precise fibrosis assessment in terms of morphology, liver biopsy provides additional functional information through immunohistochemical evaluation. However, it is not exempt from inaccuracy due to the lack of a good sample size and, besides technical problems; it is an invasive and costly procedure. These limitations have led to changes in the way that adult patients are assessed and liver disease is staged. Thus, for applicability, and widespread use and for minimum variation between laboratories, invasive procedures have been replaced by noninvasive fibrosis assessment methods.

\subsubsection{Noninvasive assessment of liver fibrosis}

These novel procedures are endorsed by the WHO 2015 guidelines for screening, care and treatment of persons with HBV infection. The APRI index is recommended as the preferred NITs to check for the presence of cirrhosis in resource-limited settings where biopsy is not feasible (APRI score $>2$ in adults), and TLE which are described below may be the preferred NIT in settings where it is available and cost is not a major constraint. 
Basically, there are two kinds of panels of tests: those that include simple fibrosis scores and advanced biochemical serum markers, and then imaging techniques as a surrogate for liver stiffness measurement $(105,106)$.

For fibrosis scores, originally the APRI index, Forns index, Fibrotest ${ }^{\circledR}$ (BioPredictive, Paris, France) and Fibrometer ${ }^{\circledR}$ (Echosens, Paris, France) were designed for HCV-monoinfected patients and FIB-4 and SHASTA for HIV/HCV coinfection, all in the adult population. The cut-off values for each noninvasive liver assessment score are summarized in Figure 13 (105).

\begin{tabular}{|c|c|c|}
\hline AST/ALT ratio & APRI index & FIB-4 score \\
\hline$\geq 1$ & $\geq 0.5$ & $\geq 1.3$ \\
\hline AST/ALT & [AST level/AST ULN] / platelet & age $\times$ AST level / \\
& count $\times 100$ & platelet count $\times \sqrt{ } / \mathrm{ALT}$ \\
\hline
\end{tabular}

Figure 13. Cut-off values for each noninvasive liver assessment score.

APRI and FIB-4 consist of indirect markers of fibrosis such as platelet count, ALT and AST levels, and are much more readily available and feasible in the outpatient setting. Others like Fibrometer ${ }^{\circledR}$ are patented and need to be performed by laboratories that meet certain quality standards, so are less readily available and more expensive (49). 
These tests are well validated for adult patients with chronic viral hepatitis, especially for HCV and the results seem to be better for cirrhosis than for significant fibrosis. Shah et al. compared the FIB-4 index score with 6 other indices in 541 adults with NAFLD and found that a FIB-4 value of $<1.3$ showed $90 \%$ negative predictive value while a value of $\geq 2.67$ showed $80 \%$ positive predictive value. Moreover, interestingly, FIB-4 has been postulated as an important predictor factor for HCC in adults (107).

Some of these scores have been applied to the pediatric population. The APRI index score has been studied in several pathologies such as chronic viral hepatitis, biliary atresia and intestinal failure, for instance. NAFLD emerged as a common cause of pediatric liver disease with the epidemic of obesity in the last decade. In fact, only two scores have been published for diagnosing and monitoring liver fibrosis in this context: the pediatric NAFLD fibrosis index and the pediatric NAFLD fibrosis score. Both indices have shown good AUC values for detecting advanced fibrosis but have not been externally validated for their widespread implementation. However, as Mansoor et al. recently proposed, adult scores cannot be applied to the pediatric population with NAFLD and possibly the same would occur when assessing liver fibrosis in HIV-positive pediatric patients.

The APRI score has been validated in children with chronic viral hepatitis. McGoogan et al. applied the APRI index and compared its results with the histological METAVIR score, setting APRI scores of over 0.5 and over 1.5 to 
identify liver fibrosis with sensitivities of $47 \%$ and $18 \%$ and specificities of $90 \%$ and $100 \%$, respectively (108-112).

The advanced biochemical markers include cytokeratin 18 fragment level measurement, hyaluronic acid, and the enhanced liver fibrosis test, which detects fibrogenesis and extracellular matrix products through sophisticated enzyme immunoassay techniques. Hyaluronic acid has proved a strong predictor of liver fibrosis in both HBV and HCV coinfected patients from the EuroSIDA cohort, while the enhanced liver fibrosis test has shown promising results in a cohort of children and adolescents with $\operatorname{NAFLD}(17,113)$.

Radiological studies include elastography-based measurements, magnetic resonance elastography and acoustic force impulse imaging. TLE (Fibro Scan(R), Echosens, Paris, France) consists of a one-dimension ultrasound which detects the velocity of a low-frequency shear wave through a transducer directly located in the 9th to 11 th intercostal spaces, in the same zone as a liver biopsy. It is performed in a supine position with the right arm elevated. The results are expressed in kilopascals ( $\mathrm{kPa}$ ). For the adult population range from 1.5 to $75 \mathrm{kPa}$, with around $5 \mathrm{kPa}$ being considered a normal value. The faster the wave, the more fibrotic the tissue. The correlation between elastometry and liver fibrosis in the HCVmonoinfected adult population is shown in Figure 14. 


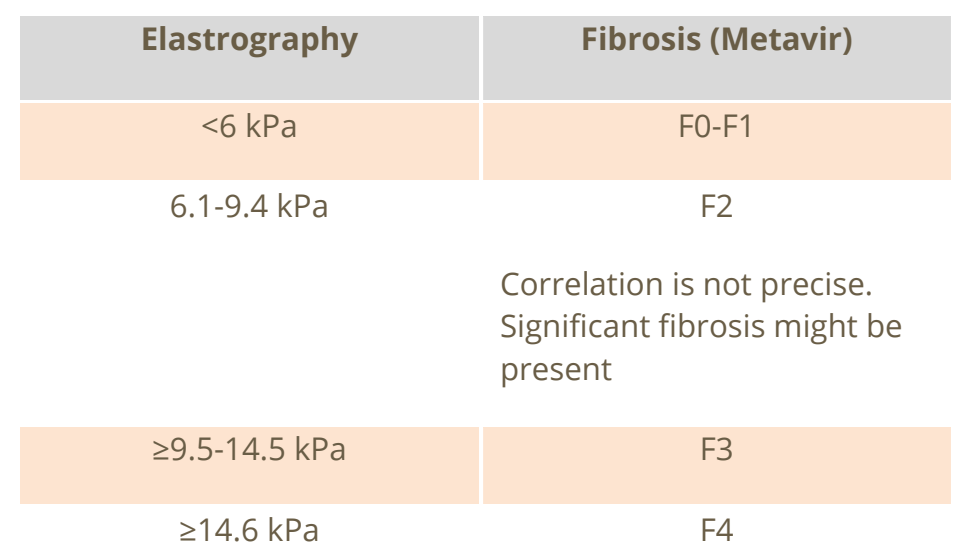

Figure 14. Correlation between elastometry and liver fibrosis in the HCVmonoinfected adult population (35).

The benefits of this technique are speed, because it is performed in realtime, feasibility and reproducibility, and the fact that measurements can be made in the outpatient clinic or at the bed-side. In addition, it is known to perform better than the biochemical scores because is not influenced by CART, HIV VL, CD4+ lymphocyte cell count or extrahepatic inflammatory processes, although the images can be impaired by recent food intake, alcohol abuse, obesity, narrow intercostal space, acute hepatitis, ascites and congestive heart failure (114).

In the adult HCV-monoinfected population, national guidelines recommend yearly TLE for liver stiffness assessment and a value of $\geq 14.6$ has been validated as a diagnostic cut-off for cirrhosis in HIV/VHC coinfected patients. Values of $\geq 9.5 \mathrm{kPa}$ correspond to advanced liver fibrosis (METAVIR $\mathrm{F} \geq 3$ ) in monoinfected patients, but this has not been validated in HIV/HCV 
coinfection. However, TLE makes it possible to predict the probability of decompensation with a high level of reliability compared to liver biopsy, and subjects with initial TLE values of $<9.5 \mathrm{kPa}$ seem to have a very low risk of decompensation (35).

As for some simple liver fibrosis scores, TLE is known to present higher median AUC values for cirrhosis than for fibrosis, so combining both biological serum markers and imaging assessment is fundamental for an accurate approach both for an early diagnosis and for following the progression of the liver fibrosis $(114,115)$.

This is of great importance in children in whom invasive procedures preferably are avoided if there is no extreme need. None of the existing NITs have had their performance in HIV-positive pediatric patients evaluated so far, except for a few recent papers, the first to try to tackle this issue among perinatally HIV-infected children. Accordingly, more studies are needed to set pediatric cut-off serum biomarker values and standardized measurements for TLE in HIV-infected children $(23,116-118)$.

\subsection{Vaccination against hepatitis B virus in children}

In Spain, the Interterritorial Health Council enforced vaccination in adolescents in risk groups in 1982 and introduced gradual inclusion from birth in a universal immunization program following the WHO recommendations for universal vaccination in 1992. As a result of these 
policies, in 2002 all the regions already included vaccination against HBV in infants. Vaccination rates for HBV are currently about $96.2 \%$ throughout the country $(119,120)$.

\subsubsection{Vaccination against hepatitis B virus in the HIV-negative population}

Over the past decade, vaccination against HBV has shown itself to be extremely effective and safe. However, the evidence of waning HBV immunity over time in a recent paper about the impact of vaccination against HBV over the last 20 years in Spain has led to the modification of the pediatric vaccination schedule (120).

The current national pediatric guidelines of the Spanish Pediatrics Association's Advisory Committee on Vaccines recommend a 2+1 strategy of three conventional pediatric doses $(10 \mu \mathrm{g})$ at 2,4 and 11 or 12 months with hexavalent vaccines (DTPa-IPV-Hib-HB) for the general healthy pediatric population depending on the region. For the newborn infants of HBV infected mothers or mothers with unknown HBV serology, a monovalent HBV vaccine immediately after birth is recommended (121).

It is known that vaccination against HBV is highly protective despite the loss of detectable anti-HBs in the healthy population, and postvaccinal response assessment is not routinely required except in children at higher risk of HBV infection (from 9 months of life for babies born of HBV infected mothers, hemodialysis, household contacts, celiac disease, HIV infection, any condition requiring immunosuppression), in whom it is advisable to 
determine the anti-HBs levels in order to assess the minimum protective level of $10 \mathrm{mlU} / \mathrm{mL}$. In case of a low response rate, repeat vaccination with recall pediatric doses of $10 \mu \mathrm{g}$ at 0,1 and 6 months and a seroconversion test within a month are needed $(120,121)$.

\subsubsection{Vaccination against hepatitis B virus in the HIV-infected patients}

Although vaccination against $\mathrm{HBV}$ is highly protective in the general population and inactivated vaccines are well tolerated and safe and effective, HIV immunosuppressed patients are known to present worse responses despite complete vaccination schedules. Thus even with good vaccination policies and despite vaccination, children living with HIV are at risk of immunopreventable infectious diseases compared to uninfected children because HIV-positive patients show responsiveness even when receiving CART and in immune recovery status $(122,123)$.

While it is true that early ART initiation when the CD4+T-lymphocyte count is still high is associated with better immunity improvement and, accordingly, with a more efficient response, it is known that the magnitude of the antibody protection might be insufficient and might wane with time due to lymphocyte dysfunction, with an impaired ability to produce memory cells and their loss due to HIV infection. In addition, in HIVinfected children the CD4+T-lymphocyte nadir does not predict the robustness of vaccine response. The CD4+T-lymphocyte counts and virological suppression at the time of vaccination seem to show better 
positive correlation. In fact, the response is known to be dependent on the number of CD4+T-lymphocytes and HIV viral load (VL), with an inverse relationship, denoting that ongoing viremia hampers the success of vaccination $(124,125)$.

When planning the schedule of vaccinations in children living with HIV, their age, immune status and ART must be considered. This is the reason why international guidelines on vaccine management in HIV-positive children tend to recommend early primary immunization even before starting CART, bearing in mind that although is not going to restore full immunity, the earlier CART is started, the better the immunological response, due to preservation of the memory function (123).

Current guidelines recommend vaccination for all HIV-positive infants (under one year old), regardless of whether or not they are receiving CART, and of their clinical, immunological and virological status, because of the increased risk of progression to AIDS and death, since CD4+T-lymphocyte counts are not good markers of progression in these infants. The schedule for HIV-infected children differs from that for uninfected children in general and a three-dose strategy, at 0,1, and 6 months, is preferred due to its more efficient immunogenicity. Special care must be taken with HIVinfected children born from HIV/HBV coinfected mothers because coinfection is extremely frequent, as stated before. In older children, as in adults, vaccination is recommended after immunoreconstitution has been 
achieved, ideally with CD4+T-lymphocyte $>15 \%$ for children under 6 years old and over 200 cells/mm3 in adults $(25,125)$.

Regular seroconversion testing is advisable, especially in children who present a steady immunological situation but were vaccinated before reconstitution. However, there is no unanimous opinion on the whether vaccinated children who do not have protective titres should be given only a pediatric booster dose only or a full 3-dose course, although the latter option seems to ensure greater protection (122).

Neither is there a current consensus on the HBV vaccine dosage for children over two years of age. For instance, the Spanish national guidelines point slightly to the possibility of vaccination with double doses in HIV-infected children aged over two years, while the European guidance on vaccination in HIV-infected children published in 2012 and endorsed by the Paediatric European Network for Treatment of AIDS (PENTA) Vaccines Group and the Steering Committee and Children's HIV Association (CHIVA) advocates using a schedule based on three adult doses (20 $\mu \mathrm{g})$ even in numerically immunocompetent children. National guidelines for adult HIVinfected patients recommend an initial schedule of double doses of $40 \mu \mathrm{g}$ $(35,41,122,123)$.

Subsequent seroconversion assessment is also convenient and the European recommendations advocate adherence to the following response classification: $<10 \mathrm{mlU} / \mathrm{mL}$ : complete revaccination course 
advised, $10-100 \mathrm{mIU} / \mathrm{mL}$ : one booster dose if the patient is immunereconstituted on CART, but if the patient is immunocompromised, defer until 6 months post-immune reconstitution, >100mlU/mL: confers longterm protection; re-check every 5 years, increasing the frequency to annually if the patient becomes immunocompromised (123).

Apart from HBV vaccination, it is desirable to protect the general HIVpositive population against hepatitis A virus (HAV), especially those coinfected with $\mathrm{HBV}$ or $\mathrm{HCV}$, due to the risk of decompensation and fulminant hepatic failure in the event of primoinfection by HAV. The standard vaccination of two doses at an interval of 6-18 months is not always effective, and measuring antibody titres one month after the last dose is also recommended. Vaccine efficacy can be increased by administering a third dose. Also three doses of combined HBV/HAV preparations can be administered in order to minimize the number of injections in the schedule at 0,1 and 6 months $(122,123)$. 


\section{AIMS, PATIENTS AND METHODS}

\subsection{Aims}

\subsubsection{Primary objectives}

To ascertain the prevalence of HBV and HCV in CoRISPe. To investigate the $\mathrm{OBI}$ and seronegative HCV infection in the same population in order to assess the feasibility of including occult hepatitis markers in the regular screening for hepatotropic infection. Additionally and retrospectively, to investigate maternal serostatus with regard to occult hepatitis, if possible.

\subsubsection{Secondary objectives}

To assess the rate of vaccination against HBV and the vaccine response in the study cohort. To assess the level of liver fibrosis in the CoRISPe population through NITs.

\subsection{Patients and study design}

\subsubsection{Study}

This is an observational, descriptive, cross-sectional, multicenter study, in a cohort of pediatric patients infected by HIV. The CoRISPe database collates comprehensive longitudinal data and was the source of the data for this study. 
CoRISPe, launched in 2008, is an open, retrospective-prospective, multicenter cohort of HIV-infected Spanish patients aged 18 years or under, in which pediatricians participate voluntarily. It currently includes 304 patients treated in 56 centers in Spain, divided into two nodes. Node 2 covers Catalonia and the Balearic Islands and Node 1 covers the rest of Spain. The following inclusion criteria were applied: children and adolescents living with confirmed HIV infection and aged $\leq 18$ years old.

\subsubsection{Human aspects. Informed consent}

The study was approved by the Ethics Committees of all the participating centers, which enrolled voluntarily. A written information sheet was given to the parents and guardians and informed consent to use their data was obtained from all the subjects and their parents or legal guardians, as applicable (see Appendices 1 and 2). The study was designed in accordance with the Declaration of Helsinki principles and carried out in compliance with the International Conference on Harmonization /WHO Good Clinical Practice standards. The present study was approved by the Ethics Committee of Hospital Universitari Vall d'Hebron on June 1, 2010 (register number PR (AMI) 50/2010).

\subsection{Clinical data}

At enrolment, the following information was retrieved from the CoRISPe database: demographic characteristics, hepatitis B vaccination status, 
maternal serostatus for HCV and HBV infection, and a complete history of past and current antiretroviral drug use, including agents that are active against HBV: 3TC, FTC and TDF. The clinical and immunological stages were assessed in keeping with the CDC classification criteria (126).

\subsection{Analytical data}

At the assessment, the absolute CD4+ T-lymphocyte count subset and HIV$1 \mathrm{VL}$ were analyzed. The laboratory procedures were not centralized and each hospital drew on its own laboratory. HIV VL was determined by realtime PCR technology: two centers used the NucliSens EasyMag system (BioMérieux, France) for extraction and NucliSens EasyQ system (BioMérieux, France) for detection and quantification (lower limit of detection, $25 \mathrm{IU} / \mathrm{mL}$ ), and the remaining centers used the Ampliprep COBAS Taqman system (Roche Diagnostics GmbH Mannheim, Germany) (lower limit of detection $20 \mathrm{IU} / \mathrm{mL}$ ).

The study of HBV and HCV infection markers did not involve any additional procedures or a significant increase in the amount of blood extracted, and was performed at one of the patient's regular follow-ups.

The following parameters were analyzed: alanine aminotransferase (ALT), aspartate aminotransferase (AST), HBV infection-related markers (surface antigen [HBsAg], antibodies against HBsAg [anti-HBs], antibodies against core antigen [anti-HBc IgG and IgM] and HBV DNA, measured by real-time PCR) and HCV markers (antibodies against HCV [anti-HCV] measured by 
enzyme immunoassay [EIA] and recombinant immunoblot assay [RIBA], and hepatitis C virus RNA [HCV RNA] measured by real-time PCR). RIBA was used to confirm infection when the antibody detection value was near the cut-off level for positive results.

Aminotransferase levels were analyzed by conventional enzymatic methods. AST and ALT values of 44 and $34 \mathrm{IU} / \mathrm{L}$ respectively were used as the upper limit of normal (ULN) for the local laboratory data. All the serological assays (HBsAg, anti-HBc IgG and anti-HBc IgM, anti-HBs and anti-HCV) were performed by commercial electrochemiluminescence EIA, including the 3600 Vitros System (Ortho Clinical Diagnostics-Johnson \& Johnson, Dorchester, NY, USA), Advia Centaur (Siemens, Germany), and Elecsys (Roche Diagnostics, Germany), which have similar analytical characteristics (sensitivity and specificity).

Anti-HBc IgM was only performed when anti-HBc IgG tested positive. In accordance with the Guidance on Vaccination of HIV-infected Children in Europe criteria, a protective antibody response to HBV vaccination was defined as a post-vaccination anti-HBs titre of $\geq 10 \mathrm{mIU} / \mathrm{mL}$ (123).

HBV DNA and HCV RNA levels (viral load) were determined by real-time PCR technology, mainly on an AmpliPrep COBAS TaqMan system (Roche Diagnostics GmbH Mannheim, Germany) with a lower limit of quantification of $20 \mathrm{IU} / \mathrm{mL}$ for HBV DNA and $15 \mathrm{IU} / \mathrm{mL}$ for HCV RNA and a 
lower limit of detection of $<10 \mathrm{IU} / \mathrm{mL}$ for both methods. The Abbot RealTime HBV and HCV Assay (Chicago, USA), which has similar analytical characteristics, was used in one center.

HBV and HCV genotyping were not included in the present study.

Additionally, noninvasive assessment of liver fibrosis was performed in all patients, classified as HIV-monoinfected, chronic HBV infected, chronic HCV infected, seronegative HCV infected or confirmed/probable OBI.

\subsection{Outcomes and definitions}

Regarding the definitions, the diagnosis of confirmed OBI was established on HBV DNA detection in serum of HBsAg-negative patients, with or without other serological markers of previous viral exposure. Probable OBI was defined on positive testing to anti-HBc IgG alone (anti-HBc alone serostatus) or to both anti-HBc and anti-HBs. HBV DNA detection in liver samples was not performed in any case.

A case of seronegative $\mathbf{H C V}$ infection was established as involving simultaneous anti-HCV negativity and a detectable HCV RNA VL, defined by HCV RNA levels of $\geq 15 \mathrm{mIU} / \mathrm{mL}$ (100).

HBV DNA and/or HCV RNA were defined as undetectable when reported as "target not detected" by the analytical system, indicating that levels were 
below the lower limit of detection $(<10 \mathrm{mlU} / \mathrm{mL})$ as explained in the previous subsection (95).

For noninvasive assessment of the liver three biochemical scores were used: the AST/ALT ratio, the APRI index and the FIB-4 score. The AST/ALT ratio was calculated as the ratio of AST to ALT values. APRI index was calculated as follows: [AST level/AST ULN] / platelet count x 100. The FIB-4 score was obtained as follows: age $\times$ AST level/platelet count $\times \sqrt{ }$ ALT. All the scores were calculated as described by other authors and pathological cutoff values were set at 1.0, 0.5 and 1.3, respectively $(111,112,127-132)$.

Vaccination against HBV was considered complete when 3 doses (at birth, at 1-2 months, and at 6 months) had been administered according to vaccination schedule of the Working Groups of the Spanish Society of Pediatric Infectious Diseases and the Advisory Committee on Vaccines of the Spanish Pediatrics Association (122).

\subsection{Statistical analysis}

The results are expressed as the median and interquartile ranges (IQR) for the quantitative variables and as percentages for the qualitative variables. When antiretroviral drugs were analyzed as risk factors, naïve patients were excluded. The quantitative variables were compared with the MannWhitney $U$ test. Fisher's exact test was used to compare categorical variables. The significance was set at a $p$ value of $<0.05$. The statistical 
analyses were performed using Stata/SE 11.2 (StataCorp College Station, TX, USA).

Besides, an explanatory model is proposed using the APRI, AST/ALT and FIB4 score data from the present study. For this purpose, the analysis was performed by lineal regression (univariate and multivariate), searching for confounding variables and modifying variables. The significance was set at a $p$ value of $<0.05$. 
IMPLEMENTATION OF OCCULT HEPATITIS SCREENING IN THE SPANISH COHORT OF

2011 HIV-INFECTED PEDIATRIC PATIENTS 


\section{RESULTS}

\subsection{Baseline characteristics}

A total of 254 out of 572 (44.4\%) HIV-infected pediatric patients included in CoRISPe who were followed-up at the outpatient clinics of 14 hospitals during 2011 were evaluated. Eight centers (126 patients) belong to Node 1 and six (128 patients) to Node 2. The data are shown in Table 1.

The median age of the participants was 14.4 years (IQR: 9.2-16.7), 55.9\% were female and $70.5 \%$ Caucasian. In $94.9 \%$ of the patients, the HIV acquisition route was MTCT. Maternal serostatus was positive for HBV in $3.9 \%$ of the children and for HCV in $24.4 \%$. However, data regarding HBV and HCV infection serostatus were missing for $44.8 \%$ and $40.6 \%$ of the mothers, respectively.

At the time of assessment, plasma HIV VL was undetectable in almost twothirds of the patients and their median CD4+ T-cell count was 840/mm3 (IQR: 577-1117). Almost one-third of the patients met the criteria for AIDS. Among the patients on HAART, past/current exposure to 3TC/FTC and TDF was $91 \%$ and 30\%, respectively. The main clinical data on the study patients are shown in Table 2. 
All the participants underwent a molecular PCR assay for HBV DNA, HCV RNA, and anti-HBs titres. HBsAg was analyzed in 239 patients (94.1\%) and anti-HBc antibodies in 216 (85\%).

\begin{tabular}{|c|c|c|c|}
\hline \multicolumn{4}{|c|}{ Participating Centers } \\
\hline $\begin{array}{l}\text { H.U. La Paz, } \\
\text { Madrid* }\end{array}$ & 37 & $\begin{array}{l}\text { H. U. San Juan, } \\
\text { Alicante* }\end{array}$ & 20 \\
\hline $\begin{array}{l}\text { H.U. Gregorio Marañón, } \\
\text { Madrid* }\end{array}$ & 16 & $\begin{array}{l}\text { H.U. Sant Joan de } \\
\text { Déu,Esplugues de } \\
\text { Llobregat, } \\
\text { Barcelona** }\end{array}$ & 79 \\
\hline $\begin{array}{l}\text { H.U. Carlos III, } \\
\text { Madrid* }\end{array}$ & 20 & $\begin{array}{l}\text { H.U. Vall d'Hebron, } \\
\text { Barcelona** }\end{array}$ & 35 \\
\hline $\begin{array}{l}\text { H.U. Miguel Servet, } \\
\text { Zaragoza* }\end{array}$ & 5 & $\begin{array}{c}\text { H.U. Germans Trias i } \\
\text { Pujol, } \\
\text { Badalona** }\end{array}$ & 5 \\
\hline $\begin{array}{l}\text { H.U. Virgen del Rocío, } \\
\text { Sevilla* }\end{array}$ & 20 & $\begin{array}{l}\text { H.U. Dr Josep Trueta, } \\
\text { Girona** }\end{array}$ & 5 \\
\hline $\begin{array}{l}\text { H.U. Carlos Haya, } \\
\text { Málaga* }\end{array}$ & 1 & H. Mataró** & 2 \\
\hline $\begin{array}{l}\text { H.U. General de } \\
\text { Castellón* }\end{array}$ & 7 & H. Granollers** & 2 \\
\hline
\end{tabular}




\begin{tabular}{|l|c|c|c|}
\hline \multicolumn{1}{|c|}{ Variable } & \multicolumn{1}{|c|}{$\begin{array}{c}\text { Study } \\
\text { cohort } \\
\mathbf{N = 2 5 4}\end{array}$} & $\begin{array}{c}\text { Remaining } \\
\text { cohort }\end{array}$ & p value \\
\hline Age*: years, mean (IQR) & $14.4(9.2-16.7)$ & $13.5(8.6-16.5)$ & 0.378 \\
\hline Female: $\mathbf{n}$ (\%) & $142(55.9)$ & $166(52.2)$ & 0.377 \\
\hline Ethnicity: $\mathbf{n}$ (\%) & $179(70.5)$ & $214(67.3)$ & 0.416 \\
\hline Caucasian & $49(19.3)$ & $65(20.4)$ & \\
\hline Black African & $18(7)$ & $28(8.8)$ & \\
\hline Latin American & $4(1.6)$ & $0(0)$ & \\
\hline Asian & $4(1.6)$ & $11(3.5)$ &
\end{tabular}

$\begin{array}{lcc}\text { Acquisition route: } \mathbf{n}(\%) & \\ \text { Vertical } & 241(94.9) & 306(96.2) \\ \text { Sexual } & 4(1.6) & 0(0) \\ \text { Transfusion } & 3(1.2) & 4(1.3) \\ \text { Unknown } & 6(2.3) & 8(2.5)\end{array}$

$\begin{array}{lll}\text { N / A } & 102(40) & 157(49.4) \\ \text { B } & 86(34) & 88(27.7) \\ \text { C (AIDS) } & 66(26) & 62(19.5)\end{array}$


2. CD4 200-499

3. CD4 $<200$ (AIDS)
$92(36.2)$

$60(23.6)$

$2(0.6)$

$13(5)$

17 (5.3)

0.903

\section{HIV infection markers}

Viral load <50 cop/mL: n (\%)

$163(64)$

$239(75.2)$

0.004

CD4+ T-cells /mm3: median

840 (577-1117)

$851(607-1105)$

0.229 (IQR)

\section{Antiretroviral therapy: $\mathbf{n}(\%)$}

Naïve patients

3TC/FTC ***

$\operatorname{TDF} * * *$
$8(3)$

$231(91)$

77 (30)

$$
5(1.6)
$$

$274(86.2)$

$90(28.3)$
0.209

0.077

0.599

Values are expressed as the median (interquartile range) except when stated otherwise.

Abbreviations: ARV, antiretroviral therapy; CDC, Centers for Disease Control and Prevention; FTC, emtricitabine; HBV, hepatitis B virus; HCV, hepatitis C virus; 3TC, lamivudine; TDF, tenofovir.

* Age is expressed as full years, ** Using standard serological methods, *** Current or past exposure, $* \star \star *$ Data from11 patients were missing in the remaining group, $* \star \star \star *$ Data from 5 patients were missing in the remaining group.

Table 2. Baseline characteristics of the CoRISPe patients included in the study $(n=254)$ at the time of assessment. Total: 572

Our study cohort represents $44 \%$ of all the children included in CoRISPe. On comparing the study cohort, the only significant clinical or epidemiological differences ( $p>0.05)$ found were in CDC clinical category 
and HIV VL $(p=0.032$ and $p=0.004$, respectively). However, these two categories do not seem to play a role when assessing $\mathrm{OBI}$ and seronegative C hepatitis, since no differences were observed in their regard.

\subsection{Prevalence of overt hepatitis B virus coinfection}

Three (1.2\%) patients were chronically infected with HBV at inclusion, they showed positive HBsAg but all were negative for HBV DNA so were classified as inactive carriers. All three were male and black Africans, two vertically-infected and one was sexually-infected. All of them showed normal aminotransferase levels with AST/ALT ratios above 1 but normality for the other two scores. Maternal serostatus was unknown in all these cases. They all had a history of current or past 3TC/FTC or TDF exposure. No cases of acute HBV infection were detected. The data are summarized in Table 3. 


\begin{tabular}{|c|c|c|c|}
\hline & Patient 1 & Patient 2 & Patient 3 \\
\hline Age (years) & 17 & 15 & 15 \\
\hline Sex & M & M & M \\
\hline Ethnicity & BA & $\mathrm{BA}$ & BA \\
\hline Transmission & $S$ & V & V \\
\hline $\begin{array}{l}\text { Current CD4+ } T \text { cell } \\
\text { count }(/ \mathrm{mm} 3)\end{array}$ & 390 & 836 & 992 \\
\hline HIV VL (cop/mL) & Undetect & Undetect & Undetect \\
\hline AIDS criteria & Yes & Yes & No \\
\hline AST (IU/mL) & 19 & 32 & 25 \\
\hline ALT (IU/mL) & 13 & 31 & 23 \\
\hline Anti-HBs & Negative & Negative & Negative \\
\hline Anti-HBc & Positive & Positive & Negative \\
\hline HBV DNA & Undetect & Undetect & Undetect \\
\hline Anti-HCV & Negative & Negative & Negative \\
\hline HCV RNA (cop/mL) & Undetect & Undetect & Undetect \\
\hline HBV vaccine & None & None & C \\
\hline 3TC/FTC exposure & Yes & Yes & Yes \\
\hline TDF exposure & Yes & Yes & Yes \\
\hline AST/ALT ratio & 1.46 & 1.03 & 1.08 \\
\hline APRI Index & 0.18 & 0.22 & 0.16 \\
\hline FIB-4 Score & 0.40 & 0.26 & 0.23 \\
\hline Maternal HBV & Unk & Unk & Unk \\
\hline Maternal HCV & Unk & Unk & Unk \\
\hline
\end{tabular}

Abbreviations: ALT, alanine aminotransferase; AST, aspartate aminotransferase; BA, Black African, C, complete; FTC, emtricitabine; HBV, hepatitis B virus; HCV, hepatitis C virus; M, male; S: sexual; TDF, tenofovir; 3TC, lamivudine; V, vertically-infected; VL, viral load; Undetect, undetectable; Unk, unknown. Figures in black are abnormal values (normal values: AST: 44 IU/L; ALT: 34 IU/L; AST/ALT ratio: 1; APRI Score: 0.5; FIB-4 Score 1.3).

Table 3. Main features of patients with overt cHBV. 


\subsection{Prevalence of overt hepatitis C virus coinfection}

Thirteen (5\%) patients were found to be coinfected with HCV when evaluated by conventional serological screening methods. Three patients showed AST elevation, ten patients had abnormal ALT levels, and three patients had elevation of both parameters. Regarding noninvasive liver fibrosis scores, five patients showed an elevated AST/ALT ratio, four patients a high APRI index and one patient a high FIB-4 score. The latter patient showed concomitant abnormalities of all three index scores and abnormal aminotransferase levels. Three patients showed some abnormal scores with normal aminotransferase levels while six patients showed elevated aminotransferases but normal scores.

The data for chronically HCV-infected children from the cohort are summarized in Table 4.

Two other patients from the cohort had spontaneously cleared HCV infection (positive anti-HCV antibodies and negative HCV RNA). Maternal coinfection data was available in one of the mothers who was HCV-positive. Data on HCV clearance was not available. Interestingly, both showed elevated ALT levels.

None of the patients had received targeted treatment for HCV. Triple HCV/HBV/HIV coinfection was not observed in any patient. 


\subsection{Occult hepatitis B virus infection}

There were six probable $\mathrm{OBI}$ cases $(2.4 \%)$ but none was proven: two patients showed a pattern of anti-HBc alone $(0.8 \%)$, while four cases were both anti-HBc and anti-HBs positive (1.6\%). HBV DNA was undetectable in all cases and only one anti-HBc/anti-HBs-positive patient showed mild raising of ALT and AST plasma levels (46 and $52 \mathrm{IU} / \mathrm{mL}$, respectively). All six patients were currently receiving at least one drug in their CART regimen with activity against HBV, all of them were on a 3TC/FTC regimen and 2 were also on TDF. None of them showed significantly lower CD4+ Tlymphocyte counts or higher plasma HIV VL when compared with the chronically HBV-infected patients. The data for probable $\mathrm{OBI}$ are summarized in Table 5. 


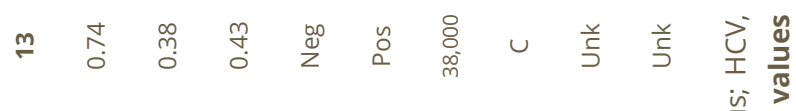

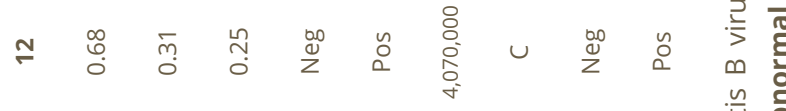

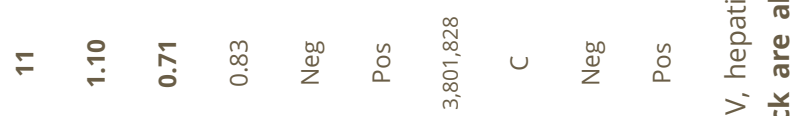

离 总

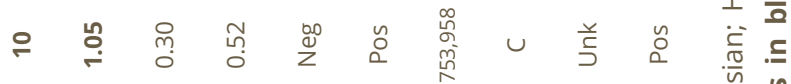

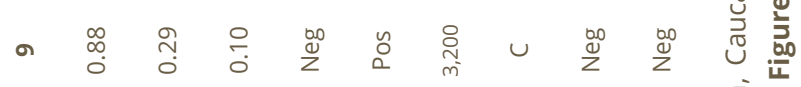

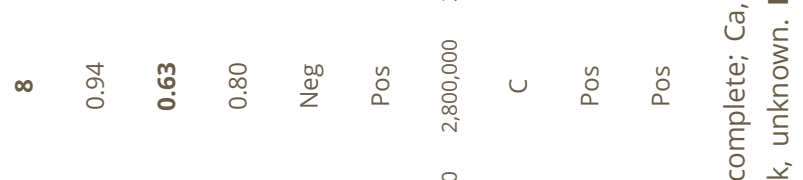

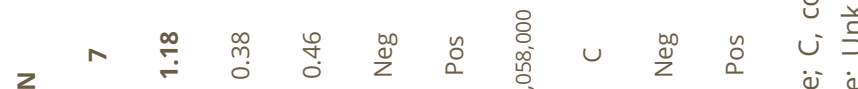

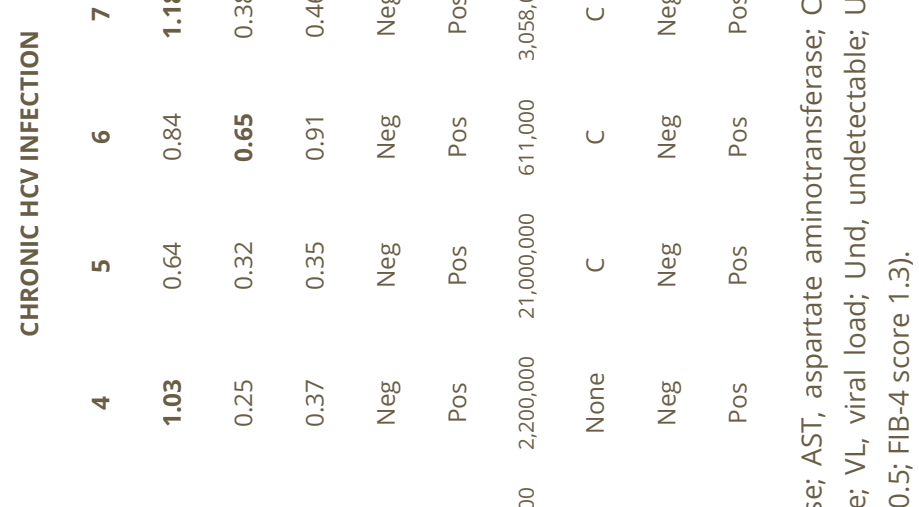

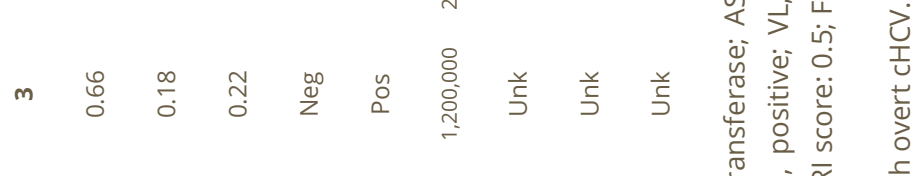

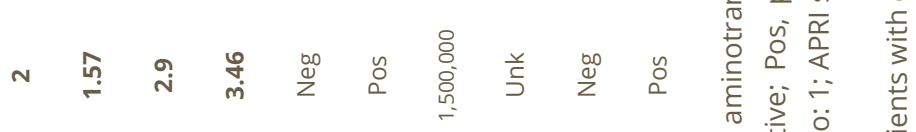

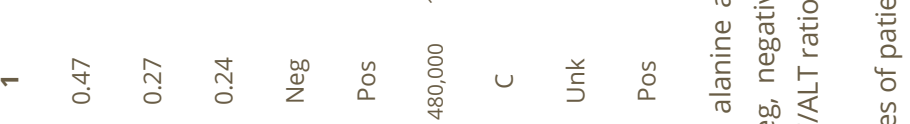

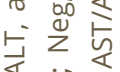

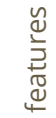

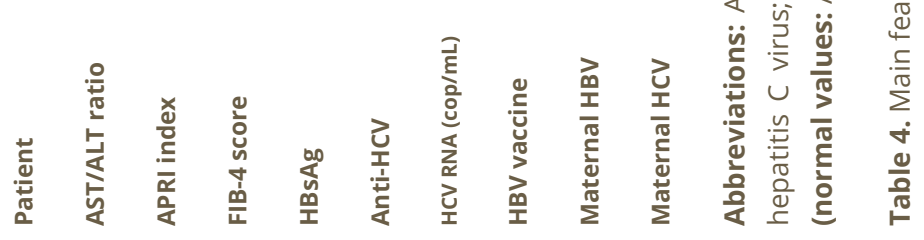




\begin{tabular}{|c|c|c|c|c|c|c|}
\hline \multicolumn{7}{|c|}{ PROBABLE OBI (2.4\%) } \\
\hline Patient & 1 & 2 & 3 & 4 & 5 & 6 \\
\hline Age (years) & 7 & 16 & 13 & 11 & 14 & 15 \\
\hline Sex & M & F & $\mathrm{F}$ & $\mathrm{F}$ & $\mathrm{F}$ & M \\
\hline Ethnicity & BA & $\mathrm{Ca}$ & $\mathrm{Ca}$ & BA & $\mathrm{Ca}$ & BA \\
\hline Transmission & T & V & V & V & V & V \\
\hline $\begin{array}{l}\text { Current CD4+ T- } \\
\text { cell count }(/ \mathrm{mm} 3)\end{array}$ & 1,088 & 574 & 750 & 910 & 466 & 734 \\
\hline HIV VL (cop/mL) & 63 & Undetect & Undetect & Undetect & 88500 & Undetect \\
\hline AIDS criteria & No & Yes & No & Yes & No & No \\
\hline AST (IU/mL) & 46 & 19 & 20 & 21 & 21 & 25 \\
\hline ALT (IU/mL) & 52 & 18 & 14 & 21 & 14 & 26 \\
\hline Anti-HBs & Positive & Undetect & Positive & Positive & Undetect & Positive \\
\hline Anti-HBc & Positive & Positive & Positive & Positive & Positive & Positive \\
\hline HBV DNA & Undetect & Undetect & Undetect & Undetect & Undetect & Undetect \\
\hline Anti-HCV & Undetect & Undetect & Undetect & Undetect & Undetect & Undetect \\
\hline $\begin{array}{ll}\text { HCV } & \text { RNA } \\
\text { (cop } / \mathrm{mL}) & \end{array}$ & Undetect & Undetect & Undetect & Undetect & Undetect & Undetect \\
\hline HBV vaccine & C & C & C & c & C & C \\
\hline $\begin{array}{l}\text { 3TC/FTC* } \\
\text { exposure }\end{array}$ & Yes & Yes & Yes & Yes & Yes & Yes \\
\hline TDF *exposure & No & Yes & No & Yes & No & No \\
\hline AST/ALT ratio & 0.88 & 1.05 & 1.42 & 1 & 1.5 & 0.96 \\
\hline APRI index & 0.52 & 0.25 & 0.17 & 0.24 & 0.31 & 0.88 \\
\hline FIB-4 score & 0.12 & 0.30 & 0.20 & 0.19 & 0.36 & 0.88 \\
\hline Maternal HBV & Unk & Positive & Unk & Unk & Unk & Positive \\
\hline Maternal HCV & Unk & Positive & Positive & Unk & Unk & Unk \\
\hline
\end{tabular}

Abbreviations: ALT, alanine aminotransferase; AST, aspartate aminotransferase; BA; Black African; Ca, Caucasian; F, female; HBV, hepatitis B virus; HCV, hepatitis C virus; M, male; OBI, occult HBV infection; T, transfusion; V, vertically-infected; VL, viral load; Undetect, undetectable; C, complete; FTC, emtricitabine; I, incomplete; TDF, tenofovir; 3TC, lamivudine; Unk, unknown. Figures in black are abnormal values (normal values: AST: 44 IU/L; ALT: 34 IU/L; AST/ALT ratio:1; APRI score: 0.5; FIB-4 score: 1.3.).

Table 5. Main features of patients with probable OBI. 


\subsection{Seronegative hepatitis C virus infection}

\begin{tabular}{|c|c|c|}
\hline \multicolumn{3}{|c|}{ SERONEGATIVE HCV INFECTION (0.8\%) } \\
\hline Patient & 1 & 2 \\
\hline Age (years) & 16 & 16 \\
\hline Sex & M & M \\
\hline Ethnicity & $\mathrm{Ca}$ & $\mathrm{Ca}$ \\
\hline Transmission & V & V \\
\hline Current CD4+ T-cell count (/mm3) & 814 & 920 \\
\hline HIV VL (cop/mL) & 150 & Undetect \\
\hline AIDS criteria & Yes & Yes \\
\hline AST (IU/mL) & 49 & 43 \\
\hline ALT $(I \mathrm{U} / \mathrm{mL})$ & 51 & 77 \\
\hline Anti-HBs & Undetect & Undetect \\
\hline Anti-HBc & Undetect & Undetect \\
\hline HBV DNA & Undetect & Undetect \\
\hline Anti-HCV & Undetect & Undetect \\
\hline HCV RNA (cop/mL) & $5,450,000$ & 45,000 \\
\hline HBV vaccine & 1 & C \\
\hline AST/ALT ratio & 0.22 & 1.79 \\
\hline APRI Index & 0.96 & 0.56 \\
\hline FIB-4 Score & 0.41 & 0.37 \\
\hline Maternal HBV & Unk & Negative \\
\hline Maternal HCV & Positive & Positive \\
\hline
\end{tabular}

Abbreviations: ALT, alanine aminotransferase; AST, aspartate aminotransferase; C, complete; Ca, Caucasian; HBV, hepatitis B virus; HCV, hepatitis C virus; I, incomplete; M, male; V, vertically-infected; VL, viral load; Undetect, undetectable; Unk, unknown. Figures in black are abnormal values (normal values: AST: 44IU/L, ALT: 34IU/L, AST/ALT ratio: 1; APRI score: 0.5; FIB-4 score 1.3).

Table 6. Main features of patients with seronegative HCV Infection. 
Seronegative HCV infection was detected in 2 patients $(0.8 \%)$, both of whom showed high ALT plasma levels (51 and $77 \mathrm{IU} / \mathrm{mL}$, respectively). There were no differences in HCV RNA levels between anti-HCV positive and anti-HCV negative cases.

The data for seronegative HCV-infected patients are summarized in Table 6. (see above)

6.6. Noninvasive assessment of liver fibrosis in overt hepatitis $B$ and $C$ virus infection

The median AST/ALT ratio, APRI index and FIB-4 score were 1.08 (IQR: 1.031.46), 0.18 (IQR: $0.16-0.22)$ and 0.26 (IQR: 0.23-0.40) respectively among the patients with overt HBV infection. The AST/ALT ratio showed mild elevation in these three patients, whereas the APRI index and FIB-4 score were within normal limits.

Among the overt HCV coinfected patients, the median AST/ALT ratio, APRI index and FIB-4 score were 0.88 (IQR: 0.68-1.05), 0.32 (IQR: 0.29-0.63) and 0.37 (IQR 0.25-0.80). The AST/ALT ratio results were found to be high in 5 of the 13 cases $(38 \%)$.

The APRI index was high in 4 patients while FIB-4 values were high in one patient. This patient showed abnormally high values of the three scores, which is consistent with some degree of fibrosis, while her AST value was $63 \mathrm{IU} / \mathrm{ml}$ with normal ALT. She was a 17-year old Caucasian girl, vertically- 
infected with both HIV and HCV, with no AIDS criteria and with good immunological and virological status (see Patient 2 in Table 4).

Median values of the three scores among patients with overt hepatitis HBV (blue) and HCV (red) are shown in Figure 15.
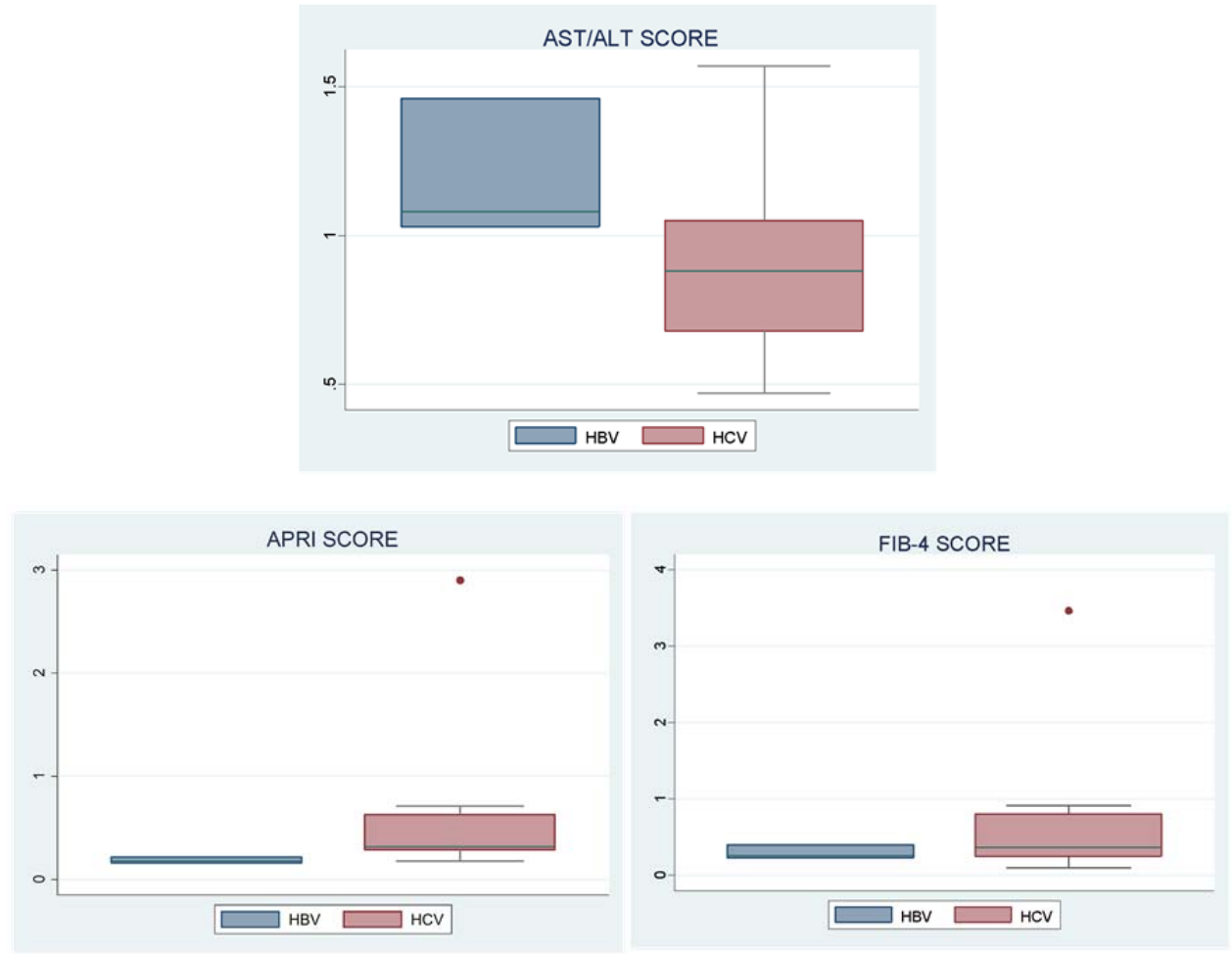

Figure 15. Biochemical score boxplots in overt HBV and HCV hepatitis. 


\subsection{Noninvasive assessment of liver fibrosis in occult hepatitis infection}

Among the probable OBI cases, the median AST/ALT ratio, APRI index and FIB-4 score were 1.03 (IQR: 0.96-1.43), 0.19 (IQR: 0.13-0.24) and 0.20 (IQR: $0.17-0.30$ ) respectively. In the probable $\mathrm{OBI}$ cases, 4 cases presented an increased AST/ALT ratio with no difference between the anti-HBc alone pattern and anti-HBc+/anti-HBs+ pattern. The APRI index was high in two patients, one of them presenting with increased levels of both aminotransferase measurements and an anti-HBc+/anti-HBs+pattern.

The aminotransferase levels were within normal values in the rest of the patients and the FIB-4 scores were within normal limits in all these patients.

Among the seronegative HCV coinfected patients, the median AST/ALT ratio, APRI index and FIB-4 score were 0.76 (IQR: 0.56-0.96), 0.45 (IQR: 0.41 0.49 ) and 0.39 (IQR: 0.37-0.41) respectively. Both patients showed raised ALT levels, one showed an elevated APRI index and in the other both AST/ALT ratio and APRI index were high. Both patients had normal FIB-4 scores. Median values of three scores among patients with occult hepatitis HBV (blue) and HCV (red) are shown in Figure 16. 

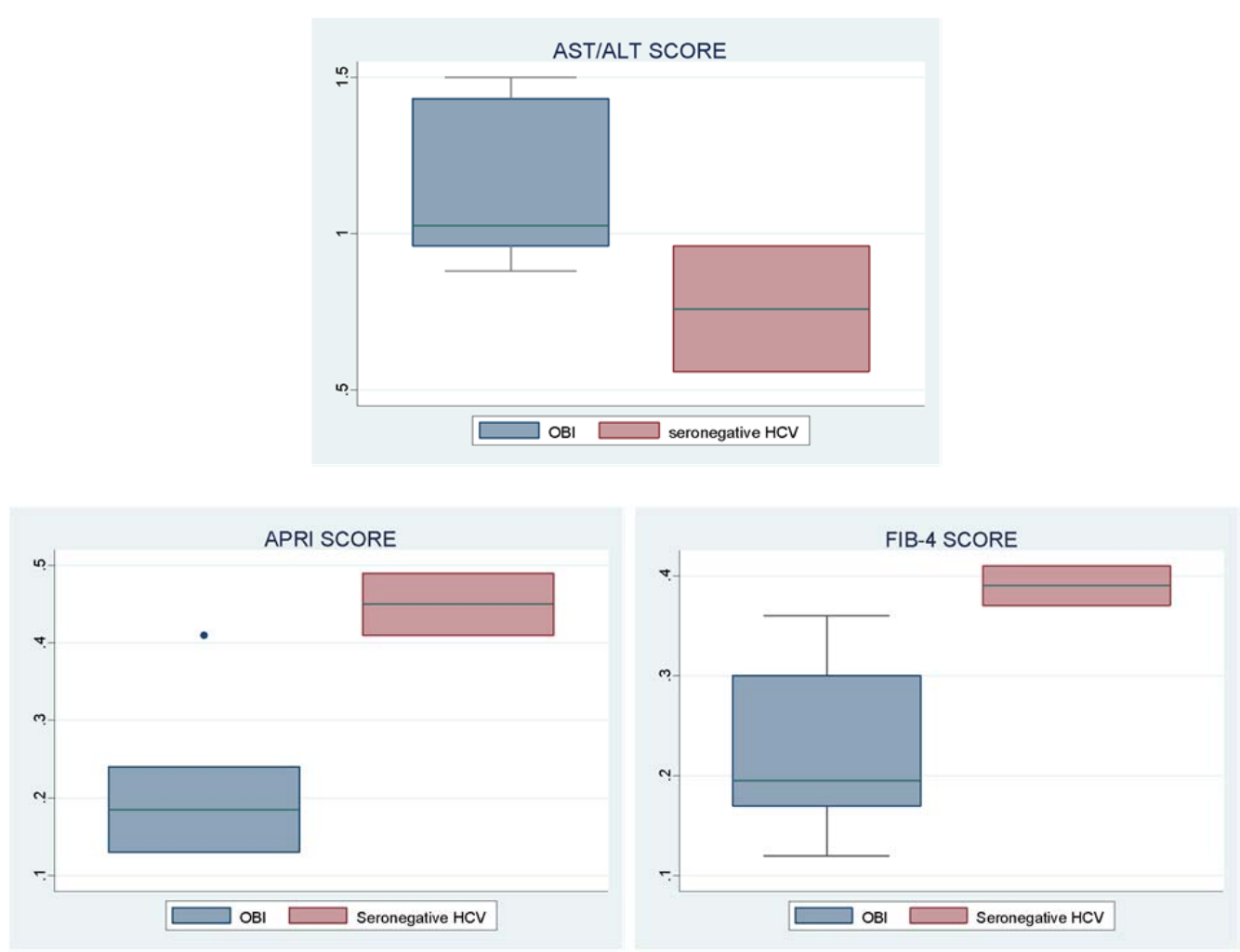

Figure 16. Biochemical score boxplots in occult hepatitis.

No significant differences were found when scores from patients with previously known HCV and HBV infection were compared with those from patients with probable $\mathrm{OBI}$ infection and seronegative HCV status. For HBV infection compared to probable OBI infection, the median AST/ALT ratios were 1.08 v. $1.03(p=0.44)$, the APRI index scores were 0.18 vs. $0.19(p=0.89)$ and the FIB-4 scores were 0.26 v. $0.20(p=0.19)$. On comparing overt HCV infection to seronegative HCV infection, the median AST/ALT ratios were 
0.88 v. $0.76(p=0.49)$, the APRI index scores were 0.32 v. $0.45(p=0.49)$ and the FIB-4 scores were 0.37 v. $0.39(p=0.93)$.

\subsection{Noninvasive assessment of liver fibrosis in HIV-monoinfected patients}

Biochemical scores for noninvasive assessment of the liver were applied to 228 patients with HIV monoinfection; the two patients with cleared HCV infection were excluded. The median ALT/AST ratio, APRI index and FIB-4 scores were 1.27 (IQR: 1-1.61), 0.20 (IQR: 018-0.27) and $0.26(0.15-0.34)$ respectively.

The univariate analysis showed that there were significant differences in the scores of each group: differences were found in the AST/ALT ratio and were statistically significant between overt hepatitis and HIV-monoinfected patients $(p=0.0035)$, being higher in the HIV non-coinfected group.

The multivariate analysis revealed that the APRI score is influenced also by the age and platelet count of the patient, showing significant differences between the overt hepatitis group and HIV-monoinfected patients $(p=0.0000)$, with the former showing a higher index. The FIB-4 score showed statistically significant differences between the three groups $(p=0.0002)$, and here too the chronic hepatitis group was the one with the higher values. Median values of three scores are compared among the three groups of patients in Figure 17. 

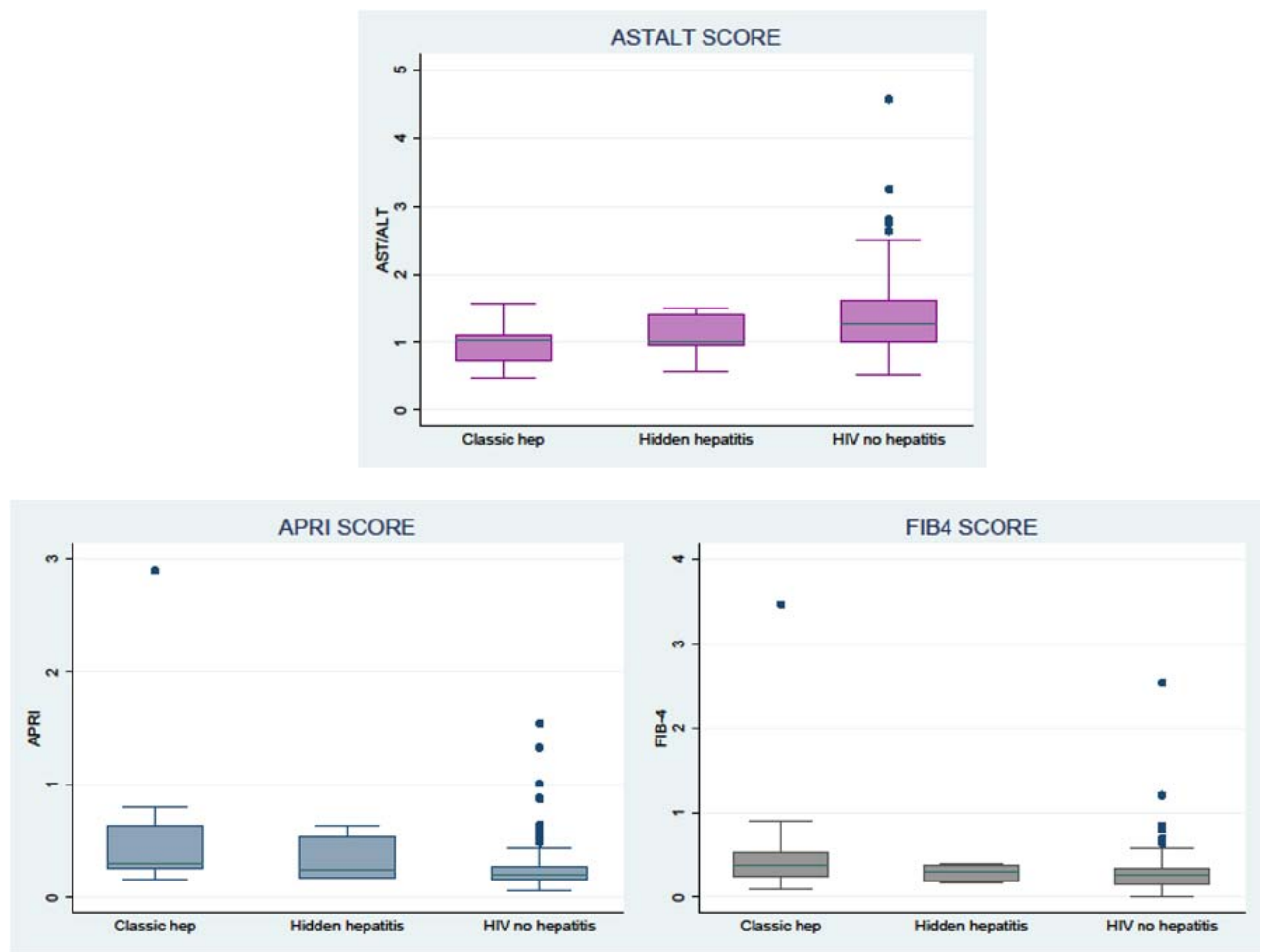

Figure 17. Biochemical score boxplot comparisons between the three groups of patients.

\subsection{Hepatitis B virus vaccine response}

Almost $90 \%$ of the patients had a complete HBV vaccination schedule, but only half of them reached protective anti-HBs levels. Data about the exact date of vaccination, booster doses, and time to response were not available. All the children with $\mathrm{cHCV}$ showed complete vaccination schedules for HBV and only one out of three with overt HBV was vaccinated. All the children with probable OBI were properly vaccinated and among the two patients with serosilent HCV infection, one showed 
complete vaccination and the other incomplete vaccination. The data are summarized in Table 7.

No significant associations were found between responsiveness to HBV vaccination and CD4+ T-lymphocyte nadir counts of <200 cells/mm3, higher viral loads, or age.

\begin{tabular}{|c|c|c|c|c|c|}
\hline \multicolumn{3}{|c|}{ CHBV } & \multicolumn{3}{|c|}{ CLEARED HCV INFECTION } \\
\hline Patient & $\begin{array}{c}\text { HBV } \\
\text { Vaccine }\end{array}$ & $\begin{array}{l}\text { Anti-HBs } \\
\text { Response }\end{array}$ & Patient & $\begin{array}{c}\text { HBV } \\
\text { Vaccine }\end{array}$ & $\begin{array}{l}\text { Anti-HBs } \\
\text { Response }\end{array}$ \\
\hline 1 & None & Negative & 1 & Complete & Negative \\
\hline 2 & None & Negative & 2 & Complete & Negative \\
\hline 3 & Complete & Negative & & & \\
\hline \multicolumn{3}{|c|}{ cHCV } & \multicolumn{3}{|c|}{ PROBABLE OBI } \\
\hline Patient & $\begin{array}{c}\text { HBV } \\
\text { Vaccine }\end{array}$ & $\begin{array}{l}\text { Anti-HBs } \\
\text { Response }\end{array}$ & Patient & $\begin{array}{c}\text { HBV } \\
\text { Vaccine }\end{array}$ & $\begin{array}{l}\text { Anti-HBs } \\
\text { Response }\end{array}$ \\
\hline 1 & Complete & Negative & 1 & Complete & Positive \\
\hline 2 & Unknown & Negative & 2 & Complete & Negative \\
\hline 3 & Unknown & Negative & 3 & Complete & Positive \\
\hline 4 & None & Negative & 4 & Complete & Positive \\
\hline 5 & Complete & Negative & 5 & Complete & Negative \\
\hline 6 & Complete & Negative & 6 & Complete & Positive \\
\hline 7 & Complete & Negative & & & \\
\hline 8 & Complete & Negative & & & \\
\hline 9 & Complete & Positive & & & \\
\hline 10 & Complete & Negative & \multicolumn{3}{|c|}{ SERONEGATIVE HCV } \\
\hline 11 & Complete & Positive & Patient & $\begin{array}{c}\text { HBV } \\
\text { Vaccine }\end{array}$ & $\begin{array}{l}\text { Anti-HBs } \\
\text { Response }\end{array}$ \\
\hline 12 & Complete & Positive & 1 & Incomplete & Positive \\
\hline 13 & Complete & Positive & 2 & Complete & Negative \\
\hline
\end{tabular}

Table 7. Vaccination status and Anti-HBs response. 


\section{DISCUSSION}

With the advent of the cART era, HIV has become a long-lasting chronic disease in which liver disease has emerged as one of the most common non-AIDS-related causes of death among HIV-infected adult patients. HBV and HCV are known to be cofactors for HIV disease progression and the risk of drug-related liver toxicity due to ART is increased in patients with coinfection. Viral hepatitis is now the principal liver entity that clinicians taking care of these patients will have to face and it is time to focus on liver disease in the routine care of this population from an early age (133).

Whether coinfected children share the same clinical pattern as adults and the effect of hepatitis coinfection in HIV still remain unclear, and controversial. Although liver dysfunction prevalence in HIV-infected children has traditionally seemed low, it shows an upward trend with age and warrants further consideration, evaluation and follow-up.

\subsection{HBV/HIV coinfection in children}

Data on HVB/HIV coinfection in children are limited and the prevalence of $\mathrm{CHBV}$ is still not well characterized. Extrapolating from HBV/HIV coinfection data on the adult population, coinfected children are prone to faster liver progression and fibrosis $(7,8,16,37,65)$. 
The present study tries to shed light on this prevalence, which is erratic depending on HBV endemicity. The recent literature review by Healy et al. found two longitudinal cohorts of HBV/HIV coinfected children in addition to several cross-sectional observational studies from small cohorts. One of these was an African cohort of 34 vertically-infected HIV children, 26\% of whom presented an unusual HBeAg-positive/anti-HBe-positive pattern with detectable HBV DNA, showing poor viral control, especially in those with greater immunosuppression at baseline. Another cohort comprised 161 Romanian adolescents, $43 \%$ of whom showed HBsAg positivity with $23 \%$ of HBeAg positivity, and $78 \%$ had positive anti-HBc, similar to the African cohort; the adolescents with higher rates of immunosuppression showed lower rates of anti-HBe seroconversion (69).

The present study showed a $1.2 \%$ rate of HBV/HIV coinfection, half the prevalence reported by Aurpibul et al. in a cohort of $521 \mathrm{HIV}$-infected Thai children, probably because vaccination against HBV in children is not a universal policy in their country. OBI was not detected as long as molecular techniques were only applied in HBsAg-positive patients. However, HBV DNA testing was performed in all the participants in that study. In addition, it found a protective antibody rate of $18 \%$, much less than in the present study, which could be explained by the worse immunological status and higher mean age of the children (71). 
Summarizing coinfection seems to be lower in Spain than in endemic HBV areas. This low prevalence probably hampers a better approach to understanding HBV/HIV coinfection in nonendemic countries.

\subsection{HCV/HIV coinfection in children}

More prolific data on HCV/HIV coinfection in children have become available in the past decade, since the remarkable strides made in HCV treatment to achieve sustained virological response and cure. Although traditionally the course of HCV infection in children was thought to be more benign than in adulthood, the data are controversial and there is a growing concern about liver disease in coinfected children, in whom CART may also contribute to increasing the hepatotoxicity risk.

Regarding data from Madrid, Micheloud et al. conducted a retrospective study on 23 vertically HIV/HCV-infected children from a cohort of 480 HIVinfected children with a group control of 30 HIV-infected children. The prevalence of $\mathrm{HIV} / \mathrm{HCV}$ coinfection was 5\%. Interestingly, HIV/HCV coinfected patients showed a slower progression to AIDS than the control group, not completely explained by the authors. In fact, the same group found a similar response in immunological and virological markers during long-term cART, independent of CD4+ T-cell values at baseline, in 19 HIV/HCV coinfected children compared to 25 vertically HIV-monoinfected controls. However, the coinfected patients showed a worse evolution for biochemical markers of liver function and $25 \%$ of them showed fibrosis on 
liver biopsy. Claret et al. conducted a prospective observational study on the effect of HIV coinfection on the progression of HCV-related liver disease in a cohort of 70 Catalan MTCT/HCV-infected children. They found a HIV/HCV coinfection rate of $18 \%$ and HIV/HCV coinfected children were less prone to spontaneous HCV clearance. Although $75 \%$ of the entire cohort showed a chronic active state regarding HCV which leads to liver disease progression, HIV/HCV coinfected children showed worse surrogate markers of liver function. (134-137).

While England et al. mentioned HCV/HIV global coinfection rates of 4-10\% in children worldwide, the Spanish cohort showed 5\% of HCV/HIV coinfection, similar to the figures of Claret et al. and the most common pattern of HCV infection was a chronic active phase, with 10 patients out of 13 showing raised aminotransferase levels. However, in the present study, other two cases anti-HCV was positive and HCV RNA undetectable, which could indicate a spontaneously cleared infection and was analyzed as such. This is not surprising, because children are more likely to present spontaneous clearance than adults, with reported rates of between $25 \%$ and $40 \%$ depending on the genotype, particularly among genotype 3 infections. Clearance often occurs at 24 months, and in some others at 7 years of age, but afterwards the rate drops to $6-12 \%$. In one patient the HCV RNA remained negative on subsequent assessment; the other patient was lost to follow-up $(3,34,138)$ 
Interestingly, $70 \%$ of the HCV/HIV children in the present study were female, denoting that probably there are sex-related factors, hormonal or genetic, which reflect different susceptibilities to infection, as suggested by the European Paediatric Hepatitis C Virus Network (46).

Genotyping was not addressed in the present study. However, interestingly, Bortolotti et al. described HCV genotypes 3 and 4 as being are more frequently found in vertically-infected children and genotypes 1 and 2 in transfusion-related infections. Genotype 3 was also related to spontaneous clearance (138).

Recent data on treatment for $\mathrm{CHCV}$ in HCV/HIV coinfection and HCV monoinfection in children from the European Pregnancy and Paediatric HIV Cohort Collaboration in EuroCoord have led to reassessing the urgent need for an early diagnosis and HCV treatment due to the progression to liver fibrosis in approximately a quarter of all patients. Recent results from this collaboration found that $12 \%$ of coinfected HIV/HCV children and adolescents showed advanced liver fibrosis, assessed by liver biopsy or TLE and also those with shorter HCV infection were more likely to successful treatment outcomes $(137,139,140)$.

This scenario justifies the hypothesis of implementing reliable screening tests for viral hepatitis in the immunosuppressed patient, such as PCR, in addition to classic serological screening, especially with new direct-acting antivirals on the horizon for HCV treatment. 


\subsection{Occult hepatitis in HIV-positive children}

As mentioned before, just as the burden of non-AIDS morbidity and mortality has changed in the CART era, the possibility of viral liver disease that pediatricians are likely to encounter in their young patients may also change. $\mathrm{OBI}$ and HCV seronegative infection arise as challenging situations that have significant clinical implications and, as stated above, may be missed when assessing hepatitis coinfection by routine methods. The real significance of these entities remain controversial, with conflicting data regarding their prevalence and clinical repercussion (141-146).

\subsubsection{Occult hepatitis B virus infection}

Occult HBV hepatitis has proved relevant in different clinical scenarios besides HIV infection: blood donation, stem cell and solid organ transplantation, LDUO and cryptogenetic chronic liver disease, HCC, and even MTCT, because occult infection can be transmitted through the same pathways as classic hepatitis infections. Indeed, OBI has major implications for transmission and blood donation: if surface antigens are the only serologic marker of CHBV infection routinely screened for, OBI infective cases might be underdiagnosed, increasing the risk of blood-borne transmission $(28,85,94,95,141,142,147)$.

HBV reactivation is well understood in $\mathrm{HBsAg}$-positive individuals in different stem cell transplantation and immunosuppressive therapy 
settings, and preemptive therapy is unanimously accepted. Corticosteroids are a well-known risk factor for HBV reactivation, and regimes for lymphoma in patients with HBsAg positivity are known to be a risk in $36 \%$ of cases. Corticosteroids used in other non-malignant conditions are still a risk factor, especially in long therapies with over $20 \mathrm{mg}$ of prednisolone. Patients under treatment with anti-CD20 monoclonal antibodies (rituximab and ofatumumab) are also at risk, estimated at a 5-fold increase, and alarming HBV reactivation can occur even after one year of cessation. Patients with other non-malignant conditions such as inflammatory bowel disease or rheumatoid arthritis who are on anti-TNF treatment (infliximab, adalimumab, etanercept) are also at risk, with 35\% of HBV reactivation (148).

HBsAg-negative/HBcAg-positive patients are known to be at risk of reactivation also, as recently demonstrated in a prospective study of patients on rituximab who showed a reactivation rate of up to $43 \%$ (149).

In view of the foregoing, and taking into consideration the complexity of the HBV life cycle, assessed in a review by Raimondo et al. (see Figure 13), and the not always easy interpretation of HBV serology dynamics, as stated by Mortensen et al. (see Figure 14 and 15), diagnosis is challenging. The particularity of HBV DNA/host interaction lies in the presence of cccDNA in $\mathrm{OBI}$, which persists in the nucleus of infected hepatocytes. This DNA is able to replicate and synthesizes an amount of antigens that, although undetectable, are able to generate a specific T-cell immune response. As stated by Raimondo et al., even physicians who correctly order HBV 
serology tests that include surface antigen and core antigen may miss OBI $(28,91)$.

This is why, although remarkable strides have been made in understanding the natural history and pathogenesis of HBV, and despite numerous articles, the first published almost 10 years ago, there is still a lack of information regarding $\mathrm{OBI}$, especially in pediatric patients $(91,93,141,150,151)$.

In March 2008, the European Association for the Study of the Liver (EASL) Expert Panel on OBI held in Taormina, Italy, focused on producing a number of statements and recommendations that provide the basis for a better approach to this clinical dilemma (Statements of Taormina). A consensus was reached on defining $\mathrm{OBI}$ as the presence of HBV DNA in the liver (with detectable or undetectable HBV DNA in the serum) of HBsAgnegative individuals. When detectable, the amount of HBV DNA in serum is very low $<200 \mathrm{IU} / \mathrm{ml}$. Thus, liver biopsy becomes the gold standard for OBI diagnosis. On the basis of the HBV antibody profile, OBI may be classed as seropositive (anti-HBc and/or anti-HBs positive) or seronegative (anti-HBc and anti-HBs negative). False OBI cases are those with HBV DNA levels in serum comparable to those in overt HBV infections, usually due to infection by escape mutants: HBV variants with mutations in the $\mathrm{S}$ gene that produce a modified HBsAg which is not recognized by conventional commercial tests (95). 
Previous studies on OBI have reported discordant prevalence rates in adult HIV-infected patients, ranging from $0 \%$ to $89 \%$. In a recent paper, Mortensen et al. found a $0.3 \%$ prevalence of OBI among 1,887 samples of HBsAg-negative patients attending a dental clinic. Interestingly, 2.2\% of these were anti-HBc alone or anti-HBc/anti-HBs-positive. The same paper, a literature review, found that 1 million HBsAg-negative patients who were tested for HBV DNA showed an OBI rate of $0.15 \%$, with detectable HBV DNA among HBcAg-positive patients ranging between $8 \%$ and $12 \%$ $(28,79,146,150-153)$.

The present study found no cases of confirmed OBI based on positive HBV DNA analysis, the only reliable noninvasive diagnostic marker of $\mathrm{OBI}$ in clinical practice. Since OBI status is dependent on long-lasting persistence of viral genomes in the hepatocytes in the form of cccDNA, analysis of liver extracts is considered the diagnostic method of reference for OBI (88).

Liver samples were not available in this study, therefore OBI cannot be definitely excluded in these patients. In addition, another possible explanation for the absence of positive samples in the present study is that HBV DNA detection in serum can fluctuate over time. Moreover, when it is detectable, the amount of HBV DNA serum is usually very low $(<200 \mathrm{IU} / \mathrm{mL})$ in $\mathrm{OBI}$ cases. Thus, the use of a highly sensitive and specific test, like HBV nucleic acid amplification testing by PCR techniques with detection limits of $<10$ copies HBV DNA per reaction, is recommended in all cases. The latest- 
generation real-time PCR diagnostic method applied in the present study to avoid any lack of sensitivity meets this criterion.

Lastly, all the patients with probable OBI were receiving antiretroviral therapy with activity against HBV (3TC/FTC and/or TDF), which might have controlled HBV replication to below the detection limits $(76,78,82,102)$

According to the definitions in the consensus recommendations based on the HBV antibody profile, HBV infection markers may be negative in up to $20 \%$ of chronically infected patients, possibly due to progressive loss of specific antibodies. This justifies including HBV DNA detection in the regular screening for HBV infection in both HIV-infected adult and pediatric patients, as other authors have suggested $(76,79,95,153,154)$.

On the other hand, false $\mathrm{OBI}$ results can also occur, as some commercially available detection assays do not recognize positive HBV DNA and negative HBsAg due to viral escape mutants that express a modified HBsAg. In the present study the latest real-time PCR diagnostic method was used in order to achieve the highest sensitivity as state before, but the latter was not assessed $(79,155)$.

The risk of $\mathrm{OBI}$ associated with the "anti-HBc alone" serological profile has been extensively demonstrated, and an antibody response to HBcAg can be considered a surrogate marker of $\mathrm{OBI}$ in selected patients and circumstances. This was the case in 2 of the 6 patients with probable OBI in 
the present series. On the other hand, four patients were both anti-HBc and anti-HBs positive, a serological pattern that traditionally has been associated with immunity due to past infection. However, when immunosuppression occurs, this interpretation warrants consideration because although very uncommon, there is an increased risk of fulminant liver failure if reactivation occurs, so in this case anti-HBs positivity might not exclude OBI definitely (see Figure 17) $(76,83,147,154-157)$.

As stated above, considerations with regard to occult hepatitis infections are not only relevant for HIV-positive patients. In general, they pose a risk to immunocompromised hosts and are of particular interest in liver transplantation, where the receiver can develop a HBV infection if the donor was anti-HBc alone positive, so might harbor an occult infection. Indeed, prophylaxis with 3TC is recommended for HBsAg-negative/antiHBc-positive children under rituximab therapy, or with combined regimes for hematological malignancies, or undergoing bone marrow or stem cell transplantation (48).

In a recent paper evaluating the prevalence of $\mathrm{OBI}$ in children who were born to HBsAg-positive mothers in Egypt and received immunoprophylaxis at birth, the researchers found one case of OBI with negative HBsAg and a Iow level of positive HBV DNA with positivity for anti-HBs. However, this situation is exceedingly rare due to the efficiency of perinatal prophylaxis, and further follow-up is needed anyway due to the young age of the patient (158). 
Thus, serology interpretation under the occult hepatitis lens might lead to anticipating such reactivations and establishing preemptive therapy for HBV, for instance. Traditional serologic test results have to be interpreted carefully in the immunocompromised patient. The review by Maldonado et al. encourages including $\mathrm{OBI}$ in regular $\mathrm{HBV}$ screening in certain risk populations (159).

In contrast to the results of other authors, patients with probable $\mathrm{OBI}$ included in the present study did not show significantly lower CD4+ Tlymphocyte counts or higher plasma HIV VL, and probable OBI was neither associated with younger age nor with HCV coinfection. However, the results are not conclusive since liver biopsy for HBV DNA intrahepatic detection was not performed, and children participating in the study showed a high median age and good clinical and immunological status, as good as those in similar studies. Thus, the interpretation of the HBV marker profile in the 6 patients with probable OBI in the present study remains controversial in terms of its being a surrogate marker for HBV/HIV coinfection, or possibly not in the event of additional immunosuppresion $(144,152,157,160)$.

\subsubsection{Seronegative hepatitis C virus infection}

Seronegative HCV infection is defined by detectable serum HCV RNA in the context of negative anti-HCV serology. It has been extensively related to immunosuppression conditions, in particular to HIV infection $(81,100,161)$. 
This condition has been also reported in uninfected HIV subjects as well considered of high-risk for HCV infection such as hemodialysis patients, hemophiliacs or subjects in need of blood product and clotting transfusions, and patients with cryptogenetic liver disease with persistent abnormality on basic liver function tests. However, in this group of HIVnegative individuals, occult hepatitis $\mathrm{C}$ infection $(\mathrm{OCI})$ has been described rather than seronegative HCV infection $(162,163)$.

OCl, defined by Castillo et. al in 2004, is defined by negativity of both antiHCV serologic tests and conventional serum HCV RNA PCR but with intrahepatic HCV RNA PCR. OCI patients' profile has been studied in those with persistent elevated aminotransferase levels once excluded any other potential cause of liver disease such as alcohol and drug toxicity, HBV and HIV infection, autoimmunity, metabolic and genetic disorders. Castillo et. al found HCV RNA in liver biopsy samples from 57 of 100 patients who were anti-HCV antibodies negative and serum HCV RNA, and of these 57 subjects, 70\% had viral RNA in their peripheral-blood mononuclear cells. A matter of concern, subjects with $\mathrm{OCl}$ were more likely to have necroinflammatory activity and fibrosis in the liver histology (163).

Furthermore, a study searching for $\mathrm{HCV}$ infection in family members of $\mathrm{OCl}$ patients revealed the transmissibility of this entity, showing a prevalence rate of HCV infection among relatives of patients with $\mathrm{OCl}$ similar to that found among family members of patients with overt CHCV (164). 
In addition, these patients show a different pattern of cellular immune response compared to overt HCV infection, with a disbalance of Th2-type cytokine (IL-4 and IL-10) response which has been attributed to HCV infection persistence, that has been related to lymphoproliferative disorders, a fact that highlights the relevancy of this otherwise controverted entity (162).

$\mathrm{OCl}$ was not addressed in the present study because liver biopsy was not conducted for obvious ethical implications.

Coming back to the setting of HCV/HIV coinfection, HIV-infected individuals are known to be at risk for HCV seronegative infection due to the immunosuppression that impairs a proper immune response with antiHCV antibody titers that are detectable by standard serodiagnostic tests. Besides, in addition to the immunosuppression conferred by HIV virus itself, it is known that HCV may cause humoral dysfunction when vertical or early childhood infection has occurred. As stated by Papaeva et al., serology may underestimate the rate of HCV coinfection and PCR would be the method of choice for perinatal HCV infection, particularly in HIVinfected children $(22,165)$.

In the present study, the prevalence of HCV seronegative infection $(0.8 \%)$ was low in comparison with previous research, estimated to be between $0 \%$ and $13 \%$ in HIV-positive individuals. This may be related to the good overall immunological status of the study cohort or to the development of 
immune tolerance in the first years of life. In contrast to Chamie et al. who found a prevalence of HCV seronegative infection of 3.2\% among 1,174 anti-HCV-negative HIV-infected adult patients, in the present study there was no significant association with high ALT levels or CD4+ T-lymphocyte cell counts of $<200$ cells/mm3 $(81,100)$.

Off note, one of the mothers of the HCV/HIV vertically-infected children screened negative for HCV antibodies in the present study. In this context performing a HCV RNA PCR for maternal HCV seronegative infection detection would be appropriate. However, this was not possible because the mother had passed away.

In order to increase sensitivity, as indicated by George et al., latestgeneration real-time PCR processing of whole-blood specimens was used in the present study. Besides, as reported by García et al., follow-up sampling is strongly recommended and it would be advisable to check seronegative patients for viremia at least twice at 6-monthly intervals, including molecular techniques $(97,100)$.

\subsection{Liver fibrosis assessment}

With regard to liver fibrosis assessment, biochemical markers are appealing because of their simplicity, low cost and feasibility and have emerged and have been validated as a promising diagnostic alternative for adult patients. The fact of being an accessible surrogate marker of liver dysfunction makes these scores a potential universal screening method for 
liver abnormalities in the general population. This is of even greater value in the pediatric population, in which it is highly recommended not to use invasive diagnostic methods that entail general anesthesia and the risk of unexpected events which, although very rare, can lead to bleeding complications and even death. Another advantage of these NITs is the fact that the data would be collected from routine blood tests as a standard of care and would not require additional cost or effort $(105,106,114,128,129,132,166-168)$.

Regarding noninvasive liver assessment specifically in HIV-positive pediatric patients, three recent publications have addressed this question, which will be discussed further on this thesis. Two of them analyze the usefulness of the APRI index in the North American and Latin American populations, respectively, while the third assesses the validity of the AST/ALT ratio, the APRI index and the FIB-4 score in a large cohort of Asian children $(23,116,117)$.

\subsubsection{AST/ALT ratio}

AST and ALT are widely available and commonly requested in the liver function test panel and the ratio between AST and ALT was the first noninvasive liver function test released in the 50 s by De Ritis and is considered a surrogate marker of hepatocellular damage. Although first used in alcohol-related hepatitis, its use has been extended to other liver pathologies such as acute and chronic hepatitis and NAFLD. In chronic 
hepatitis, AST/ALT ratios are normally below 1.0. Ratios above this value are seen particularly when progression to fibrosis and cirrhosis occurs. It should be noted that in newborn infants, physiologically, the AST/ALT ratio is typically over 3.0 and falls over the first week(127).

There is no current consensus regarding the AST/ALT ratio cut-off value, and several have been proposed for the adult population. Botros et al. suggested a cut-off ratio of 1 but Abdollahi et al. set it at 0.7 ; both studies were performed in adults and neither in HIV-positive patients. Among the pediatric population, Mansoor et al. found a ratio of 0.7 to be a poor predictor of liver fibrosis in young children with NAFLD. Interestingly, the ALT/AST ratio proved to perform better in the adolescent group when compared to other age groups. Aurpibul et al. also attempted to address this question among 1,930 HIV-infected children from the TREAT Asia Pediatric HIV Observational Database and almost all patients showed an AST/ALT ratio $>0.7$, including the $4.7 \%$ of $\mathrm{HBV}$ and $3.5 \% \mathrm{HCV}$ infected, respectively, denoting a possible underlying liver dysfunction. The explanation could be the less virological control and worst CDC clinical category of children even before starting $\operatorname{CART}(23,110,127,132)$.

In the present study, 3.0\% of patients with chronic hepatitis were identified as having ratios above 1: including the three with chronic HBV and 5 out of the 13 with chronic HCV infection. Among the probable OBI cases, 4 out of 6 also showed abnormal ratios. One of the two seronegative HCV patients showed a raised ratio as well. However, taking all the data together, HIV- 
monoinfected children showed a significantly higher median AST/ALT ratio than those with chronic hepatitis or occult hepatitis hinting at the role in liver toxicity of HIV itself and CART among the possible factors.

The AST ULN value used in the present study was $44 \mathrm{IU} / \mathrm{mL}$, as used by the laboratory of reference. If a lower AST ULN value of $40 \mathrm{IU} / \mathrm{mL}$ had been used, as other authors have proposed, there would have been no significant differences between the two APRI indexes(111).

Although an isolated value is not a reliable predictor, combination with other noninvasive serum markers and the possibility of liver imaging with elastography-based methods might have greater accuracy. This is the reason why the APRI index and FIB-4 score were calculated as well.

\subsubsection{AST-to-Platelet ratio index}

The APRI index is inherently limited by the use of a standard ULN value and by its lack of sensitivity to mild to moderate fibrosis. Recently published studies have shown that the sensitivity of the APRI index depends on the etiology of the chronic liver disease: its accuracy is acceptable for assessing liver fibrosis in patients with CHCV and NAFLD, but not for $\operatorname{cHBV}(129,131,169,170)$.

In a recent study by Mansoor et al. the AST/ALT ratio, the APRI index and the FIB-4 score were evaluated in ninety-two children with biopsy-proven NAFLD. Although no marker was considered the ideal predictor of liver 
fibrosis, only the APRI index showed good performance in both the advanced and initial stages of liver fibrosis and also showed reproducibility. Diaz et al. obtained similar results when assessing the usefulness of the APRI index, compared to liver biopsy, for detecting liver fibrosis in children with intestinal failure and a history of long-term parenteral nutrition. They found that the APRI index could significantly predict cirrhosis but not fibrosis $(110,171)$.

In the present study, using a cut-off value of 0.5 for the APRI index as suggested by McGoogan et al., 4 patients with CHCV, 2 patients with probable $\mathrm{OBI}$ and the 2 patients with seronegative HCV infection would be at risk for liver fibrosis. Among HIV-monoinfected patients, 22 showed elevated APRO index values. If an APRI cut-off value of 1.5 was used, as other authors have suggested, only one HCV-infected child would have shown high scores $(23,111)$.

For this reason, the present study, in which screening was given preference, used an APRI cut-off of 0.5 . With this value, $12 \%$ of the whole cohort showed a high APRI index, compared to almost $40 \% \%$ for the HCV/HIV-infected children.

Siberry et al. found 3\% prevalence of abnormal APRI index values in a cohort of 1,012 perinatally HIV-infected Latin American children, taking an abnormal APRI cut-off of 1.5. They found that high APRI index value were associated with HBV not HCV, with higher HIV VL, with lower current and 
nadir CD4+ T-lymphocyte counts and with the absence of CART. Interestingly protease inhibitor-based cART was protective $(111,116)$.

These findings are in keeping with HIV children under CART who have achieved viral suppression having less risk of liver fibrosis. However, as stated above, the longer lifetime means more possible exposure to other hepatotoxic drugs, so the statement that in general cART is protective must be made with caution.

When comparing Siberry's Latin American cohort with the Spanish cohort, the former had a lower mean age (6.3 vs. 14.4 years) and a lower prevalence of HCV-coinfection (0.6\% vs. 5\%). Although the median CD4+ Tlymphocyte median count (893 vs. 840 cells/mm3) and CDC clinical category (N/A $35.2 \%$ vs. $40 \%$ ) were similar, the percentage of children with viral suppression was significantly lower in his cohort (35.3\% vs. 64\%) (116).

In contrast, the present results are in agreement with the findings of another paper published by Siberry et al. on this topic in a cohort of 397 perinatally HIV-infected North American children in whom $0.8 \%$ showed a baseline abnormal APRI index when a $>1.5$ cut-off value was selected and $6.5 \%$ when lowered to 0.5 (117).

\subsubsection{Fibrosis-4 score}

The FIB-4 score differs from the APRI index because it includes the patient's age in the calculation. In studies in HIV-infected adults, it has been found to 
be a useful predictor of liver disease, HCC and even risk of mortality. In children, the FIB-4 score has not been validated although a few studies among children with NAFLD and HIV have been published $(23,110,128$ $131,172)$.

In the present study, a 17-year old girl with CHCV who did not met AIDS criteria and had restored sustained immunological recovery and good virological control showed an abnormal FIB-4 value, and also the highest AST/ALT ratio and APRI index values. This patient was an outlier case, showing abnormality in the three scores, with values of 1.57, 2.9 and 3.46 respectively (see Patient $\mathbf{2}$ in Table 4). According to the suggestion of Shah et al., in their paper on noninvasive liver fibrosis assessment in adults with NAFLD, a value of $>2.68$ has $80 \%$ positive predictive value, making the presence of fibrosis in this child very likely(128).

Interestingly, TLE was performed on this patient and showed a result of 15.30 $\mathrm{KPa}$, also strongly suggesting the presence of liver fibrosis. Accordingly, this patient received a course of 12 week treatment with ledipasvir/sofosbuvir plus ribavirin at the age of 22 years with sustained viral response.

In comparison with an Asian cohort of HIV-infected children, the prevalence of impaired liver function in the present study is very low. Aurpibul et al. found $32 \%$ of patients with abnormal APRI values with a cutoff value of $>0.5$ and $8.5 \%$ when a $>1.5$ cut-off was selected, together with $2.7 \%$ of patients with a pathological FIB-4 score. This significant number of 
patients with liver disease could be explained by the higher prevalence of HBV infection (4.7\%), poorer virological control (61\% with detectable HIV VL) and immunological status (median CD4+ T-lymphocyte 171 vs. 840 cells/mm3). Curiously, HCV infection was 3.5\%, lower than in the present study (23).

In view of the heterogeneity of the tests, scores and threshold values, further studies are needed to validate these NITs in children, using ageappropriate cut-off points with better sensitivities without any loss of specificity to make a prompt diagnosis of liver fibrosis.

\subsection{Hepatitis B virus vaccine response}

Despite the use of CART, the response to vaccines in HIV-infected children is poor and is not sustained over time. Antibody response to HBV vaccination is impaired in HIV-infected children, especially in older patients or those with CD4+T-lymphocyte counts below 200 cells/mm3 but it is known that continuing vaccination after achieving immune recovery and complete virologic control leads to protective responses. For this reason, although anti-HBs titres $>10 \mathrm{mIU} / \mathrm{mL}$ are considered protective in the general population, the optimal response in HIV-infected patients is established at a $>100 \mathrm{mIU} / \mathrm{mL}$ threshold according to European HIV pediatric guidelines and van den Berg et al., who classify response to hepatitis B vaccination in HIV seropositive patients as hyporesponsiveness 
(anti-HBs 10-100 mlU/mL) or non-responsiveness (anti-HBs $<10 \mathrm{mlU} / \mathrm{mL}$ ) $(123,125)$.

Although $90 \%$ of patients in the present study showed a complete HBV vaccination schedule, agreeing with the results of Kim et al., only half of them showed optimal anti-HBs levels, and no significant associations were found between responsiveness to HBV vaccination and CD4+ T-lymphocyte nadir counts of $<200$ cells/mm3, higher VL, or age (124).

In an unpublished study conducted in Spain, Velasco et al. assessed the long-term response to hepatitis B virus vaccination in HIV-infected children, in some of whom planned CART interruption was effected. Despite vaccination, only $34 \%$ of the cohort showed protective anti-HBs levels. Vaccination before CART, younger age at vaccination, detectable HIV VL, CART interruption and longer time since vaccination at the time of assessment were related to poorer responses (173).

It should be noted that quantitative data were not available in this study, vaccine response was not assessed immediately after vaccination and there is no record of vaccination date or type of vaccine administered, which is an additional limitation.

A recent study has reported that strong immunological memory after a primary course of HBV vaccination persists for more than 10 years after immunization in healthy infants and adolescents. Hence, reevaluation of 
seroconversion over time may be warranted in the general population and even more so in the immunosuppressed population (174-178).

The present findings underline the importance of confirming seroconversion after HBV vaccination in HIV-infected patients, as Akarsu et al. suggested, and it would be wise to vaccinate patients who have the anti$\mathrm{HBC}$ alone pattern and negative HBV DNA to determine whether they have $\mathrm{OBI}$ or a cleared infection, since anti-HBs response to HBV vaccine in such individuals is generally accepted as proof of resolved infection $(74,76,153-$ 155).

Consequently, it may be assumed that the 4 anti-HBc/anti-HBs-positive patients had cleared infections but as mentioned before, a controversial aspect is the fact that detection of naturally acquired antibodies to HBsAg (anti-HBs) does not necessarily exclude the existence of occult infection: $0.5 \%$ to $21 \%$ of these patients still test positive for serum HBV DNA $(73,78,103,179)$.

It is not only HBV vaccination response that is sub-optimal in HIV-infected children. Alsina et al. compared the cellular immune response of 13 perinatally HIV-infected children and found a strong cellular response to cytomegalovirus as compared to tetanus toxoid, suggesting that repeated exposure to CMV could maintain an effective response whereas tetanus toxoid would need revaccination (180). 
Therefore, as immune reconstitution after CART does not restore anti-HBV immunity completely in the majority of children, the response to revaccination is variable and careful follow-up is required so that HIV patients start and complete vaccination schedules, including booster doses, not only for HBV but also probably for other vaccine antigens. 


\section{STUDY LIMITATIONS}

The novelty of this study is that it is the first to search for occult hepatitis coinfection in a large cohort of HIV-infected pediatric patients. The crosssectional design is an obvious limitation as is the lack of information about some parameters such as HBsAg, analyzed in 239 out of 254 patients (94.1\%), and anti-HBc antibodies, studied in $216(85 \%)$ of the total, thus a case of chronic HBV infection with negative plasmatic VL and/or an anti$\mathrm{HBc}$ alone pattern could be overlooked.

The lack of participation of the rest of the 318 patients in the entire pediatric cohort is another undesirable circumstance, as they could have shed more light on liver disease among HIV-infected pediatric patients in this attempt to approach, understand and maybe prevent or at least try to reduce liver disease. However, the percentage of inclusion is similar to other previously published papers on the CoRISPe population, reducing the importance of this limitation $(181,182)$.

Other constraints were the fact of no hepatitis D virus coinfection in the HBV-infected patients and that no HCV genotyping was performed.

The retrospective recording of data about HBV vaccination is another limitation, since there are no data about the exact time of vaccination -a factor that could interfere with the evaluation of vaccine response- and no possibility of intervening. Missing data regarding maternal HBV and HCV infection also entails less accuracy. 
The CART history was not recorded in the present study except for treatments with effect on HBV replication, nor were drug resistanceassociated HBV mutations such as with 3TC, as the three patients with cHBV had undetectable HBV DNA. However, this consideration opens a door to further research among the cohort in this regard. Potential hepatotoxic non-cART medication was not recorded either. This would increase the information about possible causes and correlations of liver dysfunction.

The fact of not performing TLE and/or biopsy on occult coinfected children also diminishes the accuracy of the study (because intrahepatic VHB DNA is the gold standard for $\mathrm{OBI}$ ). Although this was not among the aims of the study, it would shed light on the cases with high noninvasive assessment scores for liver fibrosis. Studies on this direction are currently being performed among the HBV and HCV coinfected HIV children from CoRISPe. It would be desirable to include all these patients with occult and seronegative infections.

Despite the above limitations, this study can be considered a novel snapshot of the current prevalence of classic and occult hepatitis infection among children living with HIV in Spain and provides a starting point for further research and action on this issue in the pediatric population, in which liver disease may become one of the leading causes of morbidity and death. 


\section{CONCLUSIONS}

- The study data show that HIV-infected children and young adolescents living in Spain present a similar rate of HBV and HCV coinfection to those of previous reports. However, although some interesting studies on this topic are ongoing, accurate prospective national data are still missing.

- The study cohort includes a $44 \%$ of all the children included in CoRISPe without significant clinical or epidemiological differences. Therefore, our conclusions could be extrapolated to the global cohort of HIV-infected children in Spain.

- This study presents a similar rate of occult HBV and seronegative coinfection to that reported in large studies in adults and in other settings where the prevalence of hepatitis virus infection differs, especially for HBV. Further work is needed to clarify the clinical significance of occult hepatitis infection and its pathogenic consequences, reactivation and progression to chronic liver disease and hepatocellular carcinoma, in this unique population of growing children.

- These data reinforce the need to increase diagnostic accuracy by implementing occult hepatitis screening through sensitive molecular assays for both HBV DNA and HCV RNA in the routine care of HIV-infected children, who may even present with some 
grades of liver fibrosis despite their young age, in accordance with the recommendations of the recent PENTA and SEIP guidelines. Since this type of hepatitis has been shown to be transmissible, implementing molecular viral hepatitis screening in routine HIV care would be in agreement with the WHO objective of a $90 \%$ reduction in HBV and HCV infection by 2030.

- It is essential to keep an open mind on how to interpret traditional HBV serology as for anti-HBs positivity in immunocompromised patients, not only for HIV.

- Noninvasive liver assessment should be considered a reasonable and feasible first grade diagnostic tool that applies not only to coinfected hepatitis-HIV children but also to HIV-monoinfected children, in order to detect and monitor liver toxicity following CART.

- The present findings underline the importance of confirming seroconversion after HBV vaccination. Careful follow-up is required in order to start, complete and booster vaccination schedules in HIV patients, not only for HBV but probably also for other vaccine antigens. 


\section{FURTHER RESEARCH}

In our opinion, it would be advisable to conduct a study of noninvasive liver fibrosis assessment within CoRISPe database, including both serum markers and transient elastography in all types of coinfected patients, and maybe in HIV-monoinfected patients too, in order to have a snapshot of liver dysfunction in HIV-infected children living in Spain.

It would be also desirable to include vaccine status in the CoRISPe database in order to record vaccine doses and trademarks, dates and preferably, vaccine responses.

Accordingly, it would be interesting to create a national cohort of viral hepatitis-infected children, including HBV, HDV and HCV-infected patients, as well as recording vaccinal status and liver function assessment and undertaking periodic monitoring, especially in this era of the emergence of new treatments. 
IMPLEMENTATION OF OCCULT HEPATITIS SCREENING IN THE SPANISH COHORT OF 2011 HIV-INFECTED PEDIATRIC PATIENTS 


\section{DISCLOSURES}

$\checkmark$ This study was supported by the Red de Investigación en Sida (RIS) RD06/0006 of ISCIII. S.J.d.O. received financial support from the Red Temática de Investigación Cooperativa Sanitaria of ISCIII (RED RIS RD06/0006/0035 and RD0/0006/0021) and FIPSE (36910/10).

$\checkmark$ This study has received a non-financial bursary from the Language Service of the Universitat Autònoma of Barcelona for writing the PhD thesis in English, November 2013.

$\checkmark$ This study has been awarded the Manuel Barrera Award for the best scientific publication of a member of the Colegio Oficial de Médicos de Castellón, Spain, July 2015.

$\checkmark$ Part of the study was presented as a poster at the 29th Annual Meeting of the European Society for Paediatric Infectious Diseases (ESPID) as "Occult Hepatitis Screening in the Catalan Cohort of HIVInfected Pediatric Patients (CoRISPe-CAT)". The Hague, The Netherlands, June 7-11, 2011.

$\checkmark$ The preliminary report of the study was presented as an oral communication at the 8th International Workshop on HIV \& Hepatitis Co-infection. Madrid, Spain, 30thMay - 1st June, 2012. 
$\checkmark$ The preliminary report of the study was published in The Pediatric Infectious Disease Journal as "Implementation of occult hepatitis screening in the Spanish cohort of HIV-infected pediatric patients". Pediatr Infect Dis J. 2013; 32: e377-3779. The article is reproduced as Appendix 3. 


\section{REFERENCES}

1. Fauci A, Lane C. Human immunodeficiency virus (HIV) diseases: AIDS and related disorders. In: McGraw-Hill, Braundwals E, Fauci AS, Kasper DL, Hauser SL, Longo DL JJ, editor. Harrison's principles of Internal Medicine. 18th ed. McGraw-Hill; 2012.

2. Gray L, Newell ML, Thorne C, Peckham C, Levy J. Fluctuations in symptoms in human immunodeficiency virus-infected children: the first 10 years of life. Pediatrics. 2001;108(1):116-22.

3. England K, Thorne C, Newell M. Vertically acquired paediatric coinfection with HIV and hepatitis C virus. Lancet Infect Dis. 2006;6(2):83-90.

4. Branch A, Natta M Van, Vachon M, Dieterich D, Meinert C, Jabs D, et al. Mortality in hepatitis C virus-infected patients with a diagnosis of AIDS in the era of combination antiretroviral therapy. Clin Infect Dis. 2012;55(1):137-44.

5. Price J, Thio C. Liver Disease in the HIV-Infected Individual. Clin Gastroenterol Hepatol. 2010;8(12):1002-12.

6. Jaén A, Esteve A, Miró J, Tural C, Montoliu A, Ferrer E, et al. Determinants of HIV progression and assessment of the optimal time to initiate highly active antiretroviral therapy: PISCIS Cohort (Spain). J Acquir Immune Defic Syndr. 2008;47(2):212-20.

7. Rosenthal E, Poirée M, Pradier C, Perronne C, Salmon-Ceron D, Geffray L, et al. Mortality due to hepatitis C-related liver disease in HIV-infected patients in France (Mortavic 2001 study). AIDS. 2003;17(12):1803-9. 
8. Masiá M, Padilla S, Álvarez D, López JC, Santos I, Soriano V, et al. Risk, predictors, and mortality associated with non-AIDS events in newly diagnosed HIV-infected patients. AIDS. 2013;181-9.

9. Mallon P. Aging with HIV: osteoporosis and fractures. Curr Opin HIV AIDS. 2014;9(4):428-35.

10. Tsoukas C. Immunosenescence and aging in HIV. Curr Opin HIV AIDS. 2014;9(4):398-404.

11. Maida I, Núñez M, Ríos M, Martín-Carbonero L, Sotgiu G, Toro C, et al. Severe liver disease associated with prolonged exposure to antiretroviral drugs. J Acquir Immune Defic Syndr. 2006;42(2):177-82.

12. Rivero-Juárez A, Camacho A, Merchante N, Pérez-Camacho I, Macias J, OrtizGarcia C, et al. Incidence of liver damage of uncertain origin in HIV patients not co-infected with HCV/HBV. PLoS One. 2013;8(7):e68953.

13. Bonacini M, Louie S, Bzowej N, Wohl A. Survival in patients with HIV infection and viral hepatitis B or C: a cohort study. AIDS. 2004;18(15):203945.

14. Coffin CS, Osiowy C, Myers RP, Gill MJ. Virology and clinical sequelae of longterm antiviral therapy in a North American cohort of hepatitis B virus (HBV)/human immunodeficiency virus type 1 (HIV-1) co-infected patients. J Clin Virol. 2013;57(2):103-8.

15. Ioannou G, Bryson C, Weiss N, Miller R, Scott J, Boyko E. The Prevalence of Cirrhosis and Hepatocellular Carcinoma in Patients with Human Immunodeficiency Virus Infection. Hepatology. 2013;57(1):249-57. 
16. Kourtis A, Bulterys M, Hu D, Jamieson D. HIV-HBV Coinfection - A Global Challenge. N Engl J Med. 2012;10(19):1749-52.

17. Peters L, Mocroft A, Lundgren J, Grint D, Kirk O, Rockstroh J. HIV and hepatitis C co-infection in Europe, Israel and Argentina: a EuroSIDA perspective. BMC Infect Dis. 2014;14(Suppl 6):S13.

18. EASL recommendations on treatment of hepatitis C 2014. J Hepatol. 2014;61(2):373-95.

19. Matthews G V., Rockstroh J. HIV and hepatitis C coinfection. Curr Opin HIV AIDS. 2011;6(6):449-50.

20. HepHIV 2014: Cómo mejorar el diagnóstico temprano del VIH y las hepatitis víricas [Internet]. Available from: http://gttvih.org/actualizate/la_noticia_del_dia/06-10-14. Accessed October 2014. Spanish.

21. Nigro G, D’Orio F, Catania S, Badolato MC, Livadiotti S, Bernardi S, et al. Mother to infant transmission of coinfection by human immunodeficiency virus and hepatitis C virus: prevalence and clinical manifestations. ArchVirol. $1997 ; 142(3): 453-7$.

22. Papaevangelou V, Pollack H, Rochford G, Kokka R, Hou Z, Chernoff D, et al. Increased transmission of vertical hepatitis C virus (HCV) infection to human immunodeficiency virus (HIV)-infected infants of HIV- and HCV-coinfected women. J Infect Dis. 1998;178(4):1047-52.

23. Aurpibul L, Bunupuradah T, Sophan S, Boettiger D, Wati DK, Nguyen L V., et al. Prevalence and Incidence of Liver Dysfunction and Assessment of 
Biomarkers of Liver Disease in HIV-Infected Asian Children. Pediatr Infect Dis J. 2015;34(6):e153-8.

24. Global Health Sector Strategy on viral hepatitis , 2016 - 2021. 2016; Available from: http://www.who.int/hiv/draft-hep-strategy-20162021_en.pdf. Accessed May 152016.

25. Soriano V, Labarga P, de Mendoza C, Peña JM, Fernández-Montero J V., Benítez L, et al. Emerging Challenges in Managing Hepatitis B in HIV Patients. Curr HIVIAIDS Rep. 2015;12(3);344-52.

26. Muñoz-Gámez JA, Salmerón J. Prevalencia de la hepatitis B y C en España : Rev Esp Enferm Dig. 2013;105(5):245-8. Spanish.

27. ECDC. European Centre for Disease Prevention and Control. Hepatitis B and $C$ in the EU neighbourhood: prevalence, burden of disease and screening policies. Stockholm: ECDC; 2010. [Internet]. Stockholm: ECDC. Available from:

http://scholar.google.com/scholar?hl=en\&btnG=Search\&q=intitle:Hepatitis+ B+and+C+in+the+EU+neighbourhood+:+prevalence+,+burden+of+disease+ and+screening+policies\#1 \nhttp://scholar.google.com/scholar?hl=en\&btnG $=$ Search\&q=intitle:Hepatitis+B+and+C+in+the+EU+ne. Accessed July 28 2014.

28. Mortensen E, Kamali A, Schirmer PL, Lucero-Obusan C, Winston CA, Oda G, et al. Are current screening protocols for chronic hepatitis B virus infection adequate? Diagn Microbiol Infect Dis. 2016; 85(2):159-67.

29. Report S. European Centre for Disease Prevention and Control. Hepatitis B and surveillance in Europe. 2012. Stockholm: ECDC; 2014. [Internet]. 2012. Available from: 
http://ecdc.europa.eu/en/publications/Publications/hepatitis-b-csurveillance-europe-2012-july-2014.pdf. Accessed July 282014.

30. Salleras L, Bruguera M, Vidal J, Taberner J, Plans P, Bayas J, et al. Prevalence of HBV markers in the population of catalonia Rational for universal vaccination of adolescents. Eur J Epidemiol. 1992; 8 (5): 640-4.

31. Solà R, Cruz De Castro E, Hombrados M, Planas R, Coll S, Jardí R, et al. [Prevalence of hepatitis $B$ and hepatitis $C$ viruses in different counties of Catalonia, Spain: cross-sectional study]. Med Clin (Barc). 2002;119(3):90-5. Spanish.

32. Salleras L, Domínguez A, Bruguera M, Plans P, Costa J, Cardeñosa N, et al. Declining prevalence of hepatitis B virus infection in Catalonia (Spain) 12 years after the introduction of universal vaccination. Vaccine. 2007;25(52):8726-31.

33. Platt L, Easterbrook P, Gower E, McDonald B, Sabin K, McGowan C, et al. Prevalence and burden of HCV co-infection in people living with HIV: a global systematic review and meta-analysis. Lancet Infect Dis. 2016;16(7):797-808.

34. Mack C, González-Peralta R, Gupta N, Leung D, Narkewicz M, Roberts E, et al. NASPGHAN Practice Guidelines: Diagnosis and Management of Hepatitis C Infection in Infants, Children, and Adolescents. J Pediatr Gastroenterol Nutr. 201254(6):838-55.

35. Berenguer J, Carmena J, Castro M, Gonzalez J, Guardiola J, Labarga P, et al. MANEJO DE LAS HEPATITIS VIRALES EN PACIENTES INFECTADOS POR EL VIH Guía de Práctica Clínica de GeSIDA. Available from: http://www.gesida- 
seimc.org/contenidos/guiasclinicas/2015/gesida-guiasclinicas-2015Manejo_Hepatitis_Virales.pdf. Accessed May 102015.

36. Who. Guidelines for the screening, care and treatment of persons with hepatitis C infection. 2014;(April):124.

37. Clausen LN, Lundbo LF, Benfield T. Hepatitis $C$ virus infection in the human immunodeficiency virus infected patient. World J Gastroenterol. 2014;20(34):12132-43.

38. Hoffmann C, Mashabela F, Cohn S, Hoffmann J, Lala S, Martinson N, et al. Maternal hepatitis B and infant infection among pregnant women living with HIV in South Africa. J Int AIDS Soc. 2014;22:18871.

39. Babik JM, Cohan D, Monto A, Hartigan-O'Connor DJ, McCune JM. The human fetal immune response to hepatitis C virus exposure in utero. J Infect Dis. 2011;203(2):196-206.

40. Salleras L, Domínguez A, Bruguera M, Plans P, Espuñes J, Costa J, et al. Seroepidemiology of hepatitis B virus infection in pregnant women in Catalonia (Spain). J Clin Virol. 2009;44(4):329-32.

41. Hepatitis B. Capítulo 29. 2015;1-11. Available from: http://vacunasaep.org/documentos/manual/cap-29\#7. Accessed June 10 2015. Spanish.

42. Ruiz-Extremera A, López-Garrido M a., Barranco E, Quintero MD, Ocete-Hita E, Muñoz De Rueda P, et al. Activity of hepatic enzymes from week sixteen of pregnancy. Am J Obstet Gynecol. 2005;193(6):2010-6.

43. Ward C, Tudor-Williams G, Cotzias T, Hargreaves S, Regan L, Foster GR. Prevalence of hepatitis C among pregnant women attending an inner 
London obstetric department: uptake and acceptability of named antenatal testing. Gut. 2000;47(2):277-80.

44. Cordero JL, Fernández-reyes MJ, Ma A, Arroyo JE. Prevención de las infecciones víricas en el recién nacido. 2008; Available from: https://www.aeped.es/sites/default/files/documentos/55.pdf. Accessed June 10 2015. Spanish.

45. Pembrey L, Newell ML, Tovo PA, Amoroso A., Bevilaqua E, Asensi-Botet F, et al. The management of HCV infected pregnant women and their children European paediatric HCV network. J Hepatol. 2005;43(3):515-25.

46. European Paediatric Hepatitis C Virus Network. A significant sex but not elective cesarean section effect on mother-to-child transmission of hepatitis C virus infection. J Infect Dis. 2005;192(11):1872-9.

47. PACIENTE COINFECTADO POR VIH Y VIRUS DE LAS HEPATITIS A , B Y C ( Septiembre de 2009 ) Panel de expertos de Gesida, Secretaría del Plan Nacional sobre el Sida ( SPNS ) y Asociación Española para el Estudio del Hígado ( AEEH ). 2009;1-90. Spanish.

48. Sokal EM, Paganelli M, Wirth S, Socha $P$, Vajro $P$, Lacaille $F$, et al. Management of chronic hepatitis B in childhood: ESPGHAN clinical practice guidelines: Consensus of an expert panel on behalf of the European Society of Pediatric Gastroenterology, Hepatology and Nutrition. J Hepatol. 2013;59(4):814-29.

49. Who. Guidelines for the screening, care and treatment of persons with hepatitis B infection. 2015;124. 
50. Dumas L, Vergani D, Mieli-Vergani G. Hepatitis B virus: something old, something new. J Pediatr Gastroenterol Nutr. 2007;44(1):14-7.

51. Della Corte C, Nobili V, Comparcola D, Cainelli F, Vento S. Management of chronic hepatitis B in children : An unresolved issue. J Gastroenterol Hepatol. 2014;29:912-9.

52. Marx G, Martin SR, Chicoine J-F, Alvarez F. Long-term follow-up of chronic hepatitis B virus infection in children of different ethnic origins. J Infect Dis. 2002;186(3):295-301.

53. Chang M. Natural history and clinical management of chronic hepatitis B virus infection in children. Hepatol Int. 2008;2(Supplement 1):28-36.

54. Choe H-J. What physicians should know about the management of chronic hepatitis B in children: East side story. World J Gastroenterol. 2014;20(13):3582.

55. Dienstag JL, Delemos AS. Viral Hepatitis. In: Mandell, Douglas and Bennett's Principles and practice of infectious disease. $8^{\text {th }}$ ed. Philadelphia: Churchill, Livingstone, Elsevier; 2015.; p.1442-1468.

56. Clemente MG, Vajro P. An update on the strategies used for the treatment of chronic hepatitis B in children. Expert Rev Gastroenterol Hepatol. 2016; 10(5):649-58.

57. Chiu Y-C, Liao S-F, Wu J-F, Lin C-Y, Lee W-C, Chen H-L, et al. Factors Affecting the Natural Decay of Hepatitis B Surface Antigen in Children with Chronic Hepatitis B Virus Infection during Long-Term Follow-Up. J Pediatr. 2014;165(4):767-72.e1. 
58. Zacharakis G, Koskinas J, Kotsiou S, Pouliou E, Papoutselis M, Tzara F, et al. Natural history of chronic hepatitis B virus infection in children of different ethnic origins: a cohort study with up to 12 years' follow-up in northern Greece. J Pediatr Gastroenterol Nutr. 2007;44(1):84-91.

59. Wen W, Chang M, Hsu H, Ni Y, Chen H. The Development of Hepatocellular Carcinoma Among Prospectively Followed Children with Chronic Hepatitis B Virus Infection. J Pediatr. 2004;144(3):397-9.

60. Hsu H-Y, Chang M-H, Lee C-Y, Chen J-S, Hsu H-C, Chen D-S. Spontaneous loss of HBsAg in children with chronic hepatitis B virus infection. Hepatology. 1992;15(3)382-6.

61. Rodrigue JR, Balistreri W, Haber B, Jonas MM, Mohan P, Molleston JP, et al. Impact of Hepatitis C Virus Infection on Children and their Caregivers: Quality of Life, Cognitive, and Emotional Outcomes. 2010;48(3):341-7.

62. Baker RD, Baker SS. Hepatitis C in children in times of change. Curr Opin Pediatr. 2015;27(5):614-8.

63. Bamford a., Turkova a., Lyall H, Foster C, Klein N, Bastiaans D, et al. Paediatric European Network for Treatment of AIDS (PENTA) guidelines for treatment of paediatric HIV-1 infection 2015: Optimizing health in preparation for adult life. HIV Med. 2015;44:1-42.

64. Documento de consenso sobre TAR en niños y adolescentes con infección por el virus de la inmunodeficiencia humana (Enero 2016). Panel de expertos de la Sociedad Española de Infectología Pediátrica (SEIP) y del Plan Nacional sobre el SIDA (PNS). Spanish. Available from: http://www.msssi.gob.es/va/ciudadanos/enfLesiones/enfTransmisibles/sida 
/publicaciones/profSanitarios/GuiasTAR_octubre2015completasFinal13_10_ 15.pdf. Accessed July 26 2016. Spanish.

65. Matthews P, Geretti A, Goulder P, Klenerman P. Epidemiology and impact of HIV coinfection with Hepatitis B and Hepatitis C viruses in Sub-Saharan Africa. J Clin Virol. Elsevier B.V.; 2014 Jun 5;61(1):1-14.

66. Konopnicki D, Mocroft A, de Wit S, Antunes F, Ledergerber B, Katlama C, et al. Hepatitis B and HIV: prevalence, AIDS progression, response to highly active antiretroviral therapy and increased mortality in the EuroSIDA cohort. AIDS. 2005;19(6):593-601.

67. Ikpeme E, Etukudo O, Ekrikpo U. Seroprevalence of HBV and HIV coinfection in children and outcomes following highly active antiretroviral therapy ( HAART ) in Uyo, South-South Nigeria. Afr Health Sci. 2013;13(4):955-61.

68. Ruta S, Matusa R, Sultana C, Manolescu L, Kozinetz C, Kline M, et al. High Prevalence of Hepatitis B Virus Markers in Romanian Adolescents With Human Immunodeficiency Virus Infection. MedGenMed. 2005;7(1):68.

69. Healy S, Gupta S, AJ Melvin. HIV / HBV coinfection in children and antiviral therapy. Expert Rev Anti Infect Ther. 2013;11(3):251-63.

70. Toussi SS, Abadi J, Rosenberg M, Levanon D. Prevalence of hepatitis B and C virus infections in children infected with HIV. Clin Infect Dis. 2007;45(6):7958.

71. Aurpibul L, Lumbiganon P, Kolasaraksa P, Hansudewechakul R, SaNguanmoo P, Taeprasert P, et al. HIV and Hepatitis B coinfection among 
perinatally HIV-infected Thai adolescents. Pediatr Infect Dis J. 2012;31(9):943-7.

72. Abad C, Fortuny C, Almendros P, Soler P, Navarro M. Progressive liver disease in patients with vertically-acquired HIV / HCV co-infection in Spain. Spanish Cohort of HIV-infected children (CoRISPe). Available from: http://regist2.virology-education.com/2013/5hivped/docs/27_Rojo.pdf. Accessed February 152015.

73. Said Z. An overview of occult hepatitis B virus infection. World J Gastroenterol WJG. 2011;17(15):1927-38.

74. Akarsu M, Kantar FU, Sayiner a A. Occult hepatitis B: Evolving challenges and new perspectives. Hepat Mon. 2011;11(6):475-6.

75. Chemin I, Trépo C. Clinical impact of occult HBV infections. J Clin Virol. 2005;34(Suppl.1):S15-21.

76. Ocana S, Casas ML, Buhigas I, Lledo JL. Diagnostic strategy for occult hepatitis B virus infection. World J Gastroenterol. 2011;17(12):1553-7.

77. Komori M, Yuki N, Nagaoka T, Yamashiro M, Mochizuki K, Kaneko a, et al. Long-term clinical impact of occult hepatitis B virus infection in chronic hepatitis B patients. J Hepatol. 2001;35(6):798-804.

78. Cardona N, Loureiro C, Garzaro D, Duarte M, Garcia D, Pacheco M, et al. Unusual presentation of hepatitis B serological markers in an Amerindian community of Venezuela with a majority of occult cases. Virol J. 2011 Jan;8:527.

79. Torbenson M, Thomas D. Occult hepatitis B. Lancet Infect Dis. 2002;2(8):479-86. 
80. Carreño V, Bartolomé J, Castillo I, Quiroga JA. Occult hepatitis B virus and hepatitis C virus infections. Rev Med Virol. 2008;18(3):139-57.

81. Chamie G, Bonacini M, Bangsberg D, Stapleton J, Hall C, Overton E, et al. Factors Associated with Seronegative Chronic Hepatitis C Virus Infection in HIV Infection. Clin Infect Dis. 2007;44(4):577-83.

82. Lledó J, Fernández C, Gutiérrez M, Ocaña S. Management of occult hepatitis B virus infection: An update for the clinician. World J Gastroenterol. 2011;17(12):1563-8.

83. Gärtner B, Jung W, Welsch C, Fischinger J, Schubert J, Zeuzem S, et al. Permanent loss of anti-HBc after reactivation of hepatitis $B$ virus infection in an anti-HBs and anti-HBc-positive patient after allogeneic stem cell transplantation. J Clin Virol. 2007 ;38(2):146-8.

84. Walz A, Wirth S, Hucke J, Gerner P. Vertical Transmission of Hepatitis B Virus (HBV) from Mothers Negative for HBV Surface Antigen and Positive for Antibody to HBV Core Antigen. J Infect Dis. 2009;200(8):1227-31.

85. Kwon C, Hwang S, Shin S, Chang S, Kim S, Ko K, et al. Occult hepatitis B virus infection in pregnant woman and its clinical implication. Liver Int. 2008;28(5):667-74.

86. Awerkiew S, Däumer M, Reiser M, Wend UC, Pfister H, Kaiser R, et al. Reactivation of an occult hepatitis B virus escape mutant in an anti-HBs positive, anti-HBc negative lymphoma patient. J Clin Virol. 2007;38(1):83-6.

87. Navarro-Gómez ML, Salvador-Resino S, González-Sánchez MI, MuñozFernández MA. Immune restoration syndrome secondary to hepatitis C 
virus infection in an HIV-infected pediatric patient. Med Clin (Barc). 2006;126(13):518-9.

88. Clark SJ, Creighton S, Horner M, Smith HM, Portmann B, Taylor C, et al. Reactivation of latent hepatitis B virus infection with HIV-related immunosuppression. Int J STD AIDS. 2006;17(1):67-9.

89. Bloquel B, Jeulin H, Burty C, Letranchant L, Rabaud C, Venard V. Occult Hepatitis B Infection in Patients Infected With HIV: Report of Two Cases of Hepatitis B Reactivation and Prevalence in a Hospital Cohort. J Med Virol. 2010;82(2):206-12.

90. Said ZNA, El-Sayed MH, El-Bishbishi IA, El-Fouhil DF, Abdel-Rheem SE, ElAbedin MZ, et al. High prevalence of occult hepatitis B in hepatitis Cinfected Egyptian children with haematological disorders and malignancies. Liver Int. 2009;29(4):518-24.

91. Raimondo G, Pollicino T, Cacciola I, Squadrito G. Occult hepatitis B virus infection. J Hepatol. 2007;46(1):160-70.

92. Zerbini A, Pilli M, Boni C, Fisicaro P, Penna A, Di Vincenzo P, et al. The Characteristics of the Cell-Mediated Immune Response Identify Different Profiles of Occult Hepatitis B Virus Infection. Gastroenterology. 2008;134(5):1470-81.

93. Cacciola I, Pollicino T. Occult hepatitis B virus infection in patients with chronic hepatitis C liver disease. New EngI J Med Med. 1999;341(1):22-6.

94. Pollicino T, Squadrito G, Cerenzia G, Cacciola I, Raffa G, Crax̀ı A, et al. Hepatitis B virus maintains its pro-oncogenic properties in the case of occult HBV infection. Gastroenterology. 2004;126(1):102-10. 
95. Raimondo G, Allain J-P, Brunetto MR, Buendia M-A, Chen D-S, Colombo M, et al. Statements from the Taormina expert meeting on occult hepatitis B virus infection. J Hepatol. 2008 Oct;49(4):652-7.

96. Bassett SE, Brasky KM, Lanford RE. Analysis of hepatitis C virus-inoculated chimpanzees reveals unexpected clinical profiles. J Virol. 1998;72(4):258999.

97. García F, ML M, García-Valdecasas J, Teruel J, Bernal C, Fernández-Lucas M. Relevance of investigating the presence of hepatitis C virus RNA in HCV antibody-negative hemodialysis patients. Am J Nephrol. 2000;20(2):166-77.

98. Stramer SL, Glynn S a., Kleinman SH, Strong DM, Caglioti S, Wright DJ, et al. Detection of HIV-1 and HCV infections among antibody-negative blood donors by nucleic acid-amplification testing. N Engl J Med. 2004;351(8):7608.

99. Neau D, Winnock M, Jouvencel A, Faure M, Castéra L, Legrand E, et al. Occult Hepatitis B Virus Infection in HIV-Infected Patients with Isolated antibodies to hepatitis B core Antigen: Aquitaine cohort, 2002-2003. Clin Infect Dis. 2005;40(5):750-3.

100. George S, Gebhardt J, Klinzman D, Foster M, Patrick K, Schmidt W, et al. Hepatitis C Virus Viremia in HIV-Infected Individuals With Negative HCV Antibody Tests. J Acquir Immune Defic Syndr. 2002;31(2):154-62.

101. Seetharam A, Perrillo R, Gish R. Immunosuppression in Patients with Chronic Hepatitis B. Curr Hepatol reports. 2014 Jan;13:235-44. eCollection 2014. 
102. Schmeltzer P, Sherman K. Occult Hepatitis B-Clinical Implications and Treatment Decisions. Dig Dis Sci. 2010;55(12):3328-35.

103. Gupta S, Singh S. Occult hepatitis B virus infection in ART-naive HIV-infected patients seen at a Tertiary Care Centre in North India. BMC Infect Dis. 2010;10:53.

104. Franciscus A. Grading and Staging a Liver Biopsy. October [Internet]. 2007;(October):1-2. Available from: http://hcvadvocate.org/hepatitis/factsheets_pdf/grade_stage.pdf. Accesed June 102013.

105. Castera L. Noninvasive Assessment of Liver Fibrosis. Dig Dis. 2015;33(4): 498-503.

106. Tsochatzis E a., Castera L. Assessing liver disease in HIV-HCV coinfected patients. Curr Opin HIV AIDS. 2015;10(5):316-22.

107. Park LS, Tate JP, Justice AC, Lo Re V 3rd, Lim JK, et al. FIB-4 index is associated with hepatocellular carcinoma risk in HIV-infected patients. Cancer Epidemiol Biomarkers Prev. 2011;20:2512-7.

108. Nobili V, Alisi A, Vania A, Tiribelli C, Pietrobattista A, Bedogni G. The pediatric NAFLD fibrosis index: a predictor of liver fibrosis in children with nonalcoholic fatty liver disease. BMC Med. 2009;7:21.

109. Mansoor S, Collyer E, Alkhouri N. A Comprehensive Review of Noninvasive Liver Fibrosis Tests in Pediatric Nonalcoholic Fatty Liver Disease. Curr Gastroenterol Rep.2015;17(6):23. 
110. Mansoor S, Yerian L, Kohli R, Xanthakos S, Angulo P, Ling S, et al. The Evaluation of Hepatic Fibrosis Scores in Children with Nonalcoholic Fatty Liver Disease. Dig Dis Sci. 2015;60(5):1440-7.

111. McGoogan K, Smith B, Choi S, Berman W, Jhaveri R. Performance of the AST to Platelet Ratio Index (APRI) as a Noninvasive Marker of Fibrosis in Pediatric Patients with Chronic Viral Hepatitis. J Pediatr Gastroenterol Nutr. 2010;50(3):344-6.

112. Lebensztejn D, Skiba E, Sobaniec-Lotowska M, Kaczmarski M. A simple Noninvasive Index (APRI) Predicts Advanced Liver Fibrosis in Children With Chronic Hepatitis B. Hepatology. 2005 Jun;41(6):1434-5.

113. Nobili V, Parkes J, Bottazzo G, Marcellini M, Cross R, Newman D, et al. Performance of ELF Serum Markers in Predicting Fibrosis Stage in Pediatric Non-Alcoholic Fatty Liver Disease. Gastroenterology. 2009;136(1):160-7.

114. EASL-ALEH Clinical Practice Guidelines: Non-invasive tests for evaluation of liver disease severity and prognosis. J Hepatol [Internet]. 2015; Available from: $\quad$ http://linkinghub.elsevier.com/retrieve/pii/S0168827815002597. Accessed May 102016.

115. Castera L. Hepatitis B: are non-invasive markers of liver fibrosis reliable? Liver Int. 2014;34 (Suppl 1):91-6.

116. Siberry G, Cohen RS, Harris R, Cruz MS, Oliveira R, Peixoto M, et al. Prevalence and Predictors of Elevated Aspartate Aminotransferase-toPlatelet Ratio Index in Latin American Perinatally HIV-infected Children. Pediatr Infect DIs J. 2011;76(6):1358-75. 
117. Siberry G, Patel K, Pinto J, Puga A, Mirza A, Miller T, et al. Elevated Aspartate Aminotransferase-to-Platelet Ratio Index in Perinatally HIV-infected Children in the United States. Pediatr Infect DIs J. 2014;33(8):855-7.

118. Rubio A, Monpoux F, Huguon E, Truchi R, Triolo V, Rosenthal-Allieri M-A, et al. Noninvasive procedures to evaluate liver involvement in HIV-1 vertically infected children. J Pediatr Gastroenterol Nutr. 2009;49(5):599-606.

119. Ministerio de Sanidad SS e I. Coberturas de vacunación. Datos estadísticos. [Internet]. Available from: http://www.msssi.gob.es/profesionales/saludPublica/prevPromocion/vacun aciones/home.htm. Accessed February 16 2015. Spanish.

120. Arístegui J, Díez-domingo J, Marés J, Torres M. Vacunación frente a la hepatitis B. Impacto de los programas desde su utilización en España . Impacto de los programas de vacunación tras 20 años ¿Es tiempo de cambios? Enferm Infec Microbiol Clin. 2015;33(2):113-8. Spanish.

121. Moreno-Pérez D, Álvarez-García F, Cilleruelo-Ortega M, Corretger-Rauet J, García-Sánchez N, Hernández-Merino A, et al. Calendario de vacunaciones de la Asociación Española de Pediatría (CAV-AEP): recomendaciones 2016. An Pediatr (Barc). 2016;84(1): 60. e1-13. Spanish.

122. Mellado Peña MJ, Moreno-Pérez D, Ruíz Contreras J, Hernández-Sampelayo Matos T, Navarro Gómez M, AEP grupo de colaboradores del D de CS-C de la. Consensus document by the Spanish Society of Paediatric Infectious Diseases and the advisory committee on vaccines of the Spanish Paediatrics Association on vaccination in immunocompromised children. An Pediatr (Barc). 2011;75(6):413.e1-22. Spanish. 
123. Menson E, Mellado M, Bamford A, Castelli G, Duiculescu D, Marczynska M, et al. Guidance on vaccination of HIV-infected children in Europe. HIV Med. 2012;13(6):333-6; e1-14.

124. Kim H, Harrington R, Van-Rompaey S, Kitahata M. Independent clinical predictors of impaired response to hepatitis B vaccination in HIV-infected persons. Int J STD AIDS. 2008;19(9):600-4.

125. Van den Berg R, van Hoogstraten I, van Agtmael M. Non-responsiveness to hepatitis B vaccination in HIV seropositive patients; possible causes and solutions. AIDS Rev. 2009;11(3):157-64.

126. CDC 1994. 1994 Revised Classification System for Human Immunodeficiency Virus Infection in Children Less Than 13 Years of Age Official Authorized Addenda : Human Immunodeficiency Virus and Official Guidelines for. MMWR Morb Mortal Wkly Rep. 1994;43:1-10.

127. Botros M, Sikaris KA, Pathology M, Parade V. The De Ritis Ratio : The Test of Time. Clin Biochem Rev. 2013;34:117-30.

128. Shah A, Lydecker A, Murray K, Tetri B, Contos M, Sanyal A, et al. Use of the Fib4 Index for Non-Invasive Evaluation of Fibrosis in Nonalcoholic Fatty Liver Disease. Clin Gastroenterol Hepatol. 2009;7(10):1104-12.

129. Portilla J, López-Burgos A, Saiz-De-La-Hoya-Zamácola P, Sánchez-Payá J, Bedía-Collantes M, Faraco-Atienzar I, et al. Utility of 2 biochemical models predictive of liver fibrosis grade in prison inmates with hepatitis C. Gastroenterol Hepatol. 2009;32(6):387-94. 
130. Iacobellis A, Marcellini M, Andriulli A, Perri F, Leandro G, Devito R, et al. Non invasive evaluation of liver fibrosis in paediatric patients with nonalcoholic steatohepatitis. World J Gastroenterol. 2006;12(48):7821-5.

131. Yang H, Kim H, Kim M, Ko J, Seo J. Noninvasive Parameters and hepatic fibrosis scores in children with nonalcoholic fatty liver disease. World J Gastroenterol. 2012;18(13):1525-30.

132. Abdollahi M, Pouri A, Ghojazadeli M, Estakhri R, Somi M. Non-invasive serum fibrosis markers: A study in chronic hepatitis. Bioimpacts. $2015 ; 5(1): 17-23$.

133. Martinez E, Milinkovic A, Buira E, De Lazzari E, Leon A, Larrousse M, et al. Incidence and causes of death in HIV-infected persons receiving highly active antiretroviral therapy compared with estimates for the general population of similar age and from the same geographical area. HIV Med. 2007;8(4):251-8.

134. Micheloud D, Jensen J, Bellón J, Gurbindo D, José M de, Moreno D, et al. Slow Progression of Human Immunodeficiency Virus and Hepatitis C Virus Disease in a Cohort of Coinfected Children. Pediatr Infect Dis J. 2007;26(9):845-6.

135. Micheloud D, Jensen J, Bellon JM, Gonzalez R, Mellado MJ, Navarro ML, et al. Long-term response to highly active antiretroviral therapy in human immunodeficiency virus and hepatitis C virus coinfected children: 6 years of follow-up. Pediatr Infect Dis J. 2007;26(11):1061-4.

136. Claret-Teruel G, Noguera-Julian A, Esteva C, Muñoz-Almagro C, Sánchez E, Jiménez R, et al. Impact of human immunodeficiency virus coinfection on 
the progression of mother-to-child transmitted hepatitis C virus infection. Pediatr Infect Dis J. 2011;30(9):801-4.

137. Turkova A, Giacomet V, Goetghebuer T, Miloenko M, Nicolini LA, Noguerajulian A, et al. HCV treatment in children and young adults with HIV / HCV co-infection in Europe. J viral Erad. 2015;1:179-84.

138. Bortolotti F, Verucchi G, Camma C, Cabibbo G, Zancan L, Indolfi G, et al. Long-Term Course of Chronic Hepatitis C in Children: From Viral Clearance to End-Stage Liver Disease. Gastroenterology. 2008;134(7):1900-7.

139. Thorne C. European Paediatric HIV/HCV Co-infection Study Group in the European Pregnancy and Paediatric HIV Cohort Collaboration. HIV/HCV coinfection in children and young people in Europe: results from cohort collaboration. In: Annual Meeting of the European Pediatric Society of Paediatric Infectious Diseases (ESPID) May 2014 Dublin, Ireland Abstract 682. 2014.

140. Mohan P, Barton B a., Narkewicz MR, Molleston JP, Gonzalez-Peralta RP, Rosenthal P, et al. Evaluating progression of liver disease from repeat liver biopsies in children with chronic hepatitis C: A retrospective study. Hepatology. 2013;58(5):1580-6.

141. Raimondo G. Occult hepatitis B virus infection and liver disease: fact or fiction? J Hepatol. 2001;34(3):471-3.

142. Raimondo G, Pollicino T, Squadrito G. What is the clinical impact of occult hepatitis B virus infection? Lancet. 2005;365(9460):638-40.

143. Bréchot C, Thiers V, Kremsdorf D, Nalpas B, Pol S, Paterlini-Bréchot P. Persistent Hepatitis B Virus Infection in Subjects Without Hepatitis B Surface 
Antigen: Clinically Significant or Purely "Occult"? Hepatology. 2001;34(1):194-203.

144. Neau D, Winnock M, Galpérine T, Jouvencel A, Castéra L, Legrand E, et al. Isolated antibodies against the core antigen of hepatitis B virus in HIVinfected patients. HIV Med. 2004;5(3):171-3.

145. Lo Re V, Frank I, Gross R, Dockter J, Linnen JM, Giachetti C, et al. Prevalence, Risk factors, and Outcomes for Occult Hepatitis B Virus Infection Among HIV-Infected Patients. J Acquir Immune Defic Syndr. 2007;44(3):315-20.

146. Filippini P, Coppola N, Pisapia R, Scolastico C, Marrocco C, Zaccariello A, et al. Impact of occult hepatitis B virus infection in HIV patients naive for antiretroviral therapy. AIDS. 2006;20(9):1253-60.

147. Sagnelli E, Pistauro M, Martini S, Filippini P, Sagnelli C, Coppola N. Clinical impact of occult hepatitis B virus infection in immunosuppressed patients. World J Hepatol. 2014;6(6):384-93.

148. Seto W-K. Hepatitis B virus reactivation during immunosuppressive therapy: Appropriate risk stratification. World J Hepatol. 2015;7(6):825-30.

149. Seto WK, Chan TSY, Hwang YY, Wong DKH, Fung J, Liu KSH, et al. Hepatitis B reactivation in patients with previous hepatitis $B$ virus exposure undergoing rituximab-containing chemotherapy for lymphoma: A prospective study. J Clin Oncol. 2014;32(33):3736-43.

150. Santos E a, Yoshida CFT, Rolla VC, Mendes JM, Vieira IF, Arabe J, et al. Frequent Occult Hepatitis B Virus Infection in Patients Infected with Human Immunodeficiency Virus Type 1. Eur J Clin Microbiol Infect Dis. 2003;22(2):92-8. 
151. Hofer M, Joller-Jemelka HI, Grob PJ, Lüthy R, Opravil M. Frequent chronic hepatitis B virus infection in HIV-infected patients positive for antibody to hepatitis B core antigen only. Swiss HIV Cohort Study. Eur J Clin Microbiol Infect Dis. 1998;17(1):6-13.

152. Pérez-Rodríguez M, Sopeña B, Crespo M, Rivera A, González-del-Blanco T, Ocampo A, et al. Clinical significance of "anti-HBc alone" in human immunodeficiency virus-positive patients. World J Gastroenterol WJG. 2009;15(10):1237-41.

153. Shire NJ, Rouster SD, Stanford SD, Blackard JT, Martin CM, Fichtenbaum CJ, et al. The Prevalence and Significance of Occult Hepatitis B Virus in a Prospective Cohort of HIV-Infected Patients. J Acquir Immune Defic Syndr. 2007;44(3):309-14.

154. Pondé R, Cardoso D, Ferro M. The underlying mechanisms for the "anti-HBc alone" serological profile. Arch Virol. 2010;155(2):149-58.

155. Urbani S, Fagnoni F, Missale G, Franchini M. The role of anti-core antibody response in the detection of occult hepatitis B virus infection. Clin Chem Lab Med. 2010;48(1):23-9.

156. Grob P, Jilg W, Bornhak H, Gerken G, Gerlich W, Günther S, et al. Serological Pattern "anti-HBc alone": Report on a Workshop. J Med Virol. 2000;62(4):450-5.

157. Marque-Juillet S, Benghalia K, Monnier S, Fernand-Laurent C, Mazeron M, Harzic M. Should patients infected with HIV be screened for occult hepatitis B? Pathol Biol (Paris). 2010;58(2):e39-42. French. 
158. Foaud H, Maklad S, Mahmoud F, El-Karaksy H. Occult hepatitis B virus infection in children born to HBsAg-positive mothers after neonatal passiveactive immunoprophylaxis. Infection. 2015;43(3):307-14.

159. Maldonado-Rodriguez A, Cevallos AM, Rojas-Montes O, Enriquez-Navarro K, Alvarez-Muñoz MT, Lira R. Occult hepatitis B virus co-infection in human immunodeficiency virus-positive patients: A review of prevalence, diagnosis and clinical significance. World J Hepatol. 2015;7(2):253-60.

160. Cohen-Stuart J, Velema M, Schuurman R, Boucher C, Hoepelman A. Occult hepatitis B in persons infected with HIV is associated with low CD4 counts and resolves during antiretroviral therapy. J Med Virol. 2009;81(3):441-5.

161. Bonacini $M$, Lin $H$, Hollinger F. Effect of Coexisting HIV-1 Infection on the Diagnosis and Evaluation of Hepatitis C Virus. J Acquir Immune Defic Syndr. 2001;26:340-4.

162. Rezaee-Zavareh MS, Hadi R, Karimi-Sari H, Hossein Khosravi M, Ajudani R, Dolatimehr F, et al. Occult HCV Infection: The Current State of Knowledge. Iran Red Crescent Med J. 2015;17(11):e34181.

163. Castillo I, Pardo M, Bartolome J, Ortiz-Movilla N, Rodriguez-Inigo E, de Lucas $S$, et al. Occult hepatitis $C$ virus infection in patients in whom the etiology of persistently abnormal results of liver-function tests is unknown. J Infect Dis. 2004;189(1):7-14.

164. Castillo C, Bartolome J, Quiroga J, Barril G, V Carreño. Hepatitis C virus infection in the family setting of patients with occult hepatitis C. J Med Virol. 2009;81:1198-12. 
165. Bortolotti F, Vajro P, Barbera C, Crivellaro C, Zancan L, Giacchino R, et al. Patterns of antibodies of HCV and HCV replication in children with chronic nonA nonB hepatitis.J Pediatrics. 1994; 125 (6 Pt1):916-8..

166. Giannini E, Risso D, Botta F, Chiarbonello B, Fasoli A, Malfatti F, et al. Validity and clinical utility of the aspartate aminotransferase-alanine aminotransferase ratio in assessing disease severity and prognosis in patients with hepatitis C virus-related chronic liver disease. Arch Intern Med. 2003;163(2):218-24.

167. Sterling RK, Lissen E, Clumeck N, Sola R, Correa MC, Montaner J, et al. Development of a simple noninvasive index to predict significant fibrosis in patients with HIV/HCV coinfection. Hepatology. 2006;43(6):1317-25.

168. Castera L, Bedossa P. How to assess liver fibrosis in chronic hepatitis C: serum markers or transient elastography vs. liver biopsy? Liver Int. 2011;31 Suppl 1(s1):13-7.

169. Yilmaz Y, Yonal O, Kurt R, Bayrak M, Aktas B, Ozdogan O. Noninvasive assessment of liver fibrosis with the aspartate transaminase to platelet ratio index (APRI): Usefulness in patients with chronic liver disease: APRI in chronic liver disease. Hepat Mon. 2011;11(2):103-6.

170. Sebastiani G, Vario A, Guido M, Alberti A. Sequential algorithms combining non-invasive markers and biopsy for the assessment of liver fibrosis in chronic hepatitis B. World J Gastroenterol. 2007;13(4):525-31.

171. Díaz JJ, Gura KM, Roda J, Perez-Atayde AR, Duggan C, Jaksic T, et al. Aspartate aminotransferase to platelet ratio index correlates with hepatic cirrhosis but not with fibrosis in pediatric patients with intestinal failure. J Pediatr Gastroenterol Nutr. 2013;57(3):367-71. 
172. Mendeni M, Focà E, Gotti D, Ladisa N, Angarano G, Albini L, et al. Evaluation of liver fibrosis: concordance analysis between noninvasive scores (APRI and FIB-4) evolution and predictors in a cohort of HIV-infected patients without hepatitis C and B infection. Clin Infect Dis. 2011;52(9):1164-73.

173. Velasco E, Noguera-Julian A, Alsina L, Juncosa T, Muñoz-Almagro C, Sánchez E, et al. Respuesta vacunal al virus de la hepatitis B en el niño con infección VIH.Influencia de la interrupción de tratamiento. In:IX Curs d'Infectologia Pediàtrica, Hospital Universitari Vall d'Hebron. February 9 2012. Spanish.

174. Petersen KM, Bulkow LR, McMahon BJ, Zanis C, Getty M, Peters $H$, et al. Duration of Hepatitis B Immunity in Low Risk Children Receiving Hepatitis B Vaccinations From Birth. Pediatr Infect Dis J. 2004;23(7):650-5.

175. Hammitt LL, Hennessy TW, Fiore AE, Zanis C, Hummel KB, Dunaway E, et al. Hepatitis B immunity in children vaccinated with recombinant hepatitis $B$ vaccine beginning at birth: a follow-up study at 15 years. Vaccine. 2007;25(39-40):6958-64.

176. Zanetti AR, Mariano A, Romanò L, D'Amelio R, Chironna M, Coppola RC, et al. Long-term immunogenicity of hepatitis B vaccination and policy for booster: an Italian multicentre study. Lancet. 2004;366(9494):1379-84.

177. Samandari T, Fiore AE, Negus S, Williams JL, Kuhnert W, McMahon BJ, et al. Differences in Response to a Hepatitis B Vaccine Booster Dose Among Alaskan Children and Adolescents Vaccinated During Infancy. Pediatrics. 2007;120(2):e373-81.

178. Elrashidy H, Elbahrawy A, El-Didamony G, Mostafa M, George NM, Elwassief A, et al. Antibody levels against hepatitis B virus after hepatitis B vaccination 
in Egyptian diabetic children and adolescents. Hum Vaccines Immunother. 2013;9(9):2002-6.

179. Gandhi RT, Wurcel A, Lee H, McGovern B, Shopis J, Geary M, et al. Response to hepatitis B vaccine in HIV-1-positive subjects who test positive for isolated antibody to hepatitis B core antigen: implications for hepatitis B vaccine strategies. J Infect Dis. 2005;191(9):1435-41.

180. Alsina L, Noguera-Julian A, Fortuny C. Impaired cellular immune response to tetanus toxoid but not to cytomegalovirus in effectively HAART-treated HIVinfected children. Vaccine 2013;31(20):2417-9.

181. Dapena M, Jiménez B, Noguera-Julian A, Soler-Palacín P, Fortuny C, Lahoz R, et al. Metabolic disorders in vertically HIV-infected children: Future adults at risk for cardiovascular disease. J Pediatr Endocrinol Metab. 2012;25(56):529-35.

182. Espiau M, Yeste D, Noguera-julian A, González-tomé MI, Falcón-neyra L, Gavilán C, et al. Metabolic syndrome in children and adolescents living with HIV. Pediatr Infect Dis J. 2016;35(6):e171-6. 


\section{APPENDIX 1: INFORMATION SHEET FOR PARENTS/GUARDIANS}

\section{OCCULT HEPATITIS B VIRUS INFECTION AND SERONEGATIVE HEPATITIS}

\section{VIRUS INFECTION STUDY IN A NATIONAL COHORT OF HIV-INFECTED}

\section{PEDIATRIC PATIENTS (CORISPe)}

\section{INFORMATION SHEET FOR PARENTS/GUARDIANS}

Hepatitis B virus and Hepatitis c virus (HBV and HCV) coinfection is frequently seen in patients who live with the human immunodeficiency virus (HIV), mainly due to shared transmission routes. As you may know, one of the main ways they are acquired is mother-to-child transmission, especially in the perinatal period. If this occurs and HBV transmission takes place during infancy, there is a higher risk it may become chronic. In addition, HIV patients present a higher risk of progression and chronic liver damage.

Two different or special situations, occult hepatitis B virus infection and seronegative hepatitis C virus infection, can be missed with the regular screening methods. Early detection of these infections would make it easier to take a series of preventive measures to prevent or stop their progression to liver damage and the development of complications.

For all these reasons, the doctor who is informing you, an expert in the management of pediatric HIV infection, considers it appropriate for you to take part in the Implementation of Occult Hepatitis Screening in the 
Spanish Cohort of HIV-Infected Pediatric Patients study that is going to be carried out in several Spanish pediatric hospitals.

Consent to take part in this study would not entail any additional procedure during or outside existing routine periodic assessments or any significant increase in the volume of routine blood extractions. If HBV or VHC coinfection is detected, the appropriate treatment will be recommended and in the event of poor vaccine response the possibility of reimmunization will be offered.

In accordance with Law 15/1999 on the Protection of Personal Data (LOPD), the personal data obtained will be only those that are strictly necessary for the purposes of the study. Your name will not appear in any study report, and your identity will not be disclosed to any person other than the researchers except in the case of medical emergency or legal requirement.

Any personal information that may be identifiable will be kept by secure computerized methods.

According to current legislation, you are entitled to be informed of relevant health information obtained during the course of the study. This information will be communicated as desired. Should you prefer not to be informed, your decision will be respected.

If you need more information about this study please contact the principal researcher (see below) at the Infectious Diseases and Immunodeficiencies 
Unit, Phone:

934893140.

Your participation in this project is voluntary. You have the right to participate or withdraw your consent after the study has started. If you choose not to participate you will receive all necessary medical care and the relationship with the medical team treating you will not be affected.

Yours faithfully,

Pere Soler Palacín Marta Dapena Archilés

Pediatric Infectious Diseases and Immunodeficiencies Unit

Hospital Universitari Vall d'Hebron, Barcelona 
IMPLEMENTATION OF OCCULT HEPATITIS SCREENING IN THE SPANISH COHORT OF 2011 HIV-INFECTED PEDIATRIC PATIENTS 


\section{APPENDIX 2: INFORMED CONSENT}

\section{INFORMED CONSENT (MINORS)}

I,

$\mathrm{Mr} / \mathrm{Mrs}$

(Name of the father, mother or legal guardian)

with National Identity Card number:

declare that:

Dr.

as a specialist doctor in Pediatric Infectious Diseases at. Hospital, has informed me about the characteristics of the Implementation of Occult Hepatitis Screening in the Spanish Cohort of HIV-Infected Pediatric Patients study in a detailed and understandable way.

I have read the information sheet that was given to me.

I was able to ask questions about the study.

I freely give my approval for

of whom I am the parent or legal guardian, to be included in this study. 
I am aware that participation in this study is voluntary and I may withdraw from it at any time I wish, and that waiver of participation in it will not alter the clinical management of the illness of my child or ward. 


\section{INFORMED CONSENT (MATURE MINOR)}

I,

with National Identity Card number:

and born on (date).

declare that:

Dr.

as a specialist doctor in Pediatric Infectious Diseases at

Hospital, has informed me about the characteristics of the Implementation of Occult Hepatitis Screening in the Spanish Cohort of HIV-Infected Pediatric Patients study in a detailed and understandable way in the presence of my parents or legal guardians.

I have read the information sheet that was given to me.

I was able to ask questions about the study.

I have been invited to take part in this study and I accept the invitation. I am aware that my participation in this study is voluntary and I may withdraw whenever I wish, and that waiver of participation in it will not alter the clinical management of my disease. 
IMPLEMENTATION OF OCCULT HEPATITIS SCREENING IN THE SPANISH COHORT OF

2011 HIV-INFECTED PEDIATRIC PATIENTS 


\title{
Implementation of Occult Hepatitis Screening in the Spanish Cohort of HIV-infected Pediatric Patients
}

\author{
Marta Dapena, MD, * Concepción Figueras, MD, PhD, *Antoni Noguera-Julian, MD, PhD, $\hat{T}$ \\ Clàudia Fortuny, MD, PhD, † Maria Isabel de José, MD, PhD, † Maria José Mellado, MD, PhD, $\S$ \\ César Gavilán, MD, 7 Maria Dolores Falcón-Neyra, MD, \| Maria Luisa Navarro, MD, PhD, ** \\ Santiago Jiménez de Ory, MSc, t广 Carmen López, MD, łł Lluis Mayol, MD, PhD, \$§ Maria Méndez, MD, 99

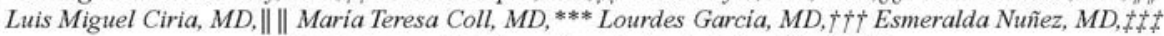 \\ Maria Espiau, $M D$, * and Pere Soler-Palacin, $M D, P h D^{*}$
}

\begin{abstract}
Regular sereening methods may miss the diagnosis of occult hepatitis $B$ infection and seronegative hepatitis $C$ virus infection in immunocompromised patients. A cross-sectional study within a Spanish cohort of HIV-infected children yielded 6 of $254(2.4 \%)$ possible occult hepatitis B infection cases and 2 of $254(0.8 \%)$ seronegative hepatitis $\mathrm{C}$ virus-infected patients, Implementation of occult hepatitis screening in the routine care of these children may be warranted.
\end{abstract}

Key Words: hepatitis $B$ core antigens, hepatitis $C$ infection, hepatitis $B$ vaccines, HIV, pediatrics

(Pediatr Infect Dis J 2013:32: e377-e379)

ust as the burden of non-AIDS morbidity and mortality has changed in the era of highly active antiretroviral therapy, liver hisease has emerged as one of the most common non-AIDS-related causes of death among HIV-infected adults.' Occult hepatitis B virus $(\mathrm{HBV})$ infection $(\mathrm{OBI})^{2}$ and seronegative or serosilent hepatitis $\mathrm{C}$ virus ( $\mathrm{HCV}$ ) infection ${ }^{3}$ may not be detected by current screening methods but may pose a risk for later hepatic failure when

From the "Hospital Universitari Vall d'Hebron, Pediatric Infectious Diseases and Immmoseficiencies Unit, Universitat Autonoma de Barcelona: 9 Department of Pediatrics, Hospital Sant Joan de Déu, Infectious Diseases Unit, Universitat de Barcelona, Barcelona; †Department of Pediatrics, Hospital Universitario La Paz, Infectious Diseases Unit; \$Department of Pediatrics, Hospital Universitario Carlos III, Infectious Diseases Unit, Madrid; Tepartment of Pediatrics, Hospital San Joan d'Alacant, Infectious Diseases Unit, Alacant: Department of Pediatrics, Hospital Virgen del Rocio, Infectious Diseases Unit, Sevilla; " "Department of Pediatrics, Hospital General Universitanio Gregorio Marañon, Infectious Diseases Unit; \# Haboratorio de Inmunobiologia Molecular, Hospital General Universitario Gregorio Maraf́ón, Madrid; \#Department of Pediatrics, Hospital General de Castello, Infectious Diseases Unit, Castelló; \$ \$Department of Pediatrics, Hospital Josep Trueta, Infectious Diseases Unt, Girona; १1Department of Pediatrics, Hoopital Germans Trias i Pujol, Infecticus Diseases Unit, Badalona, Barcelona; III Department of Pediatrics, Hospital Infantil Universitario Mignel Servet, Infectious Diseases Unit, Zaragoza; ${ }^{2}$. Department of Pediatrics, Hospital Asil de Granollers, Infections Diseases Unit, Granollers; f f P Department of and t+tDepartment of Pediatrics, Hospital Carlos Haya, Infectious Diseases Unit, Malaga, Spain.

This study was supported by Red de Imvestigacion en Sida (RIS) RD06/0006 from ISCII. SJ.d.O. received financial support from Red Tematica de Imvestigación Cooperativa Sanitaria ISCIII (RED RIS RD06/0006/0035 and RD06/0006/0021) and FIPSE (36910/10). The authors have no other funding or conflicts of interest to disclose.

Address for correspondence: Pere Soler-Palacin, MD, PhD, Pediatric Infectious Diseases and Immunodeficiencies Unit, Hospital Universitari Vall d'Hebron, Universitat Autonoma de Barcelona, Passeig de la Vall d'Hebron, 119-129, 08035, Barcelona, Spain. E-mail: psoler@vhebronnet

Copyright O 2013 by Lippincot

DOI: $10.1097 /$ INF $06013 \mathrm{e} 31828 \mathrm{e} 969$ additional immunosuppression or for a highly active antiretroviral therapy switch for immunovirological failure occurs.

A large body of information has been produced in recent years regarding occult hepatitis in adults, but data in HIV-infected children are lacking. This study was designed to investigate the value of including $\mathrm{OBI}$ and $\mathrm{HCV}$-seronegative infection markers in our routine hospital screening protocols for HIV-infected pediatric patients by assessing the prevalence of these entities in a large cohort of vertically HIV-infected Spanish children.

\section{METHODS}

The Spanish Cohort of HIV-infected Children (CoRISpe) is a national registry of HIV-infected Spanish patients aged 18 years or younger, and currently includes 838 patients in 75 centers. This report represents a cross-sectional study of all vertically HIV-infected children and adolescents from 14 hospitals in CoRISpe during 2011. At assessment, CD4 + T-lymphocyte absolute count and HIV-1 viral load (VL) were analyzed. HIV-VL was determined by real-time polymerase chain reaction (PCR) technology: 2 centers used the NucliSens EasyMag system (BioMérieux, Marcy LEtoile, France) for extraction and NucliSens EasyQ system (BioMérieux) for detection and quantification (lower limit of detection, 25 copies $/ \mathrm{mL}$ ), and the remaining centers used the Ampliprep COBAS Taqman system (Roche Diagnostics GmbH, Mannheim, Germany; lower limit of detection, 20 copies $/ \mathrm{mL}$ ).

Alanine aminotransferase, aspartate aminotransferase, HBV infection-related markers (surface antigen [HBsAg], antibodies against $\mathrm{HBsAg}$ [anti-HBs], antibodies against core antigen [anti$\mathrm{HBc} \mathrm{IgG}$ and IgM] and HBV DNA by real-time PCR) and HCV markers (antibodies against $\mathrm{HCV}$ [anti-HCV] by enzyme immunoassay and recombinant immunoblot assay, and HCV RNA by realtime PCR) were analyzed. Recombinant immunoblot assay was used to confirm infection when the antibody detection was near the cutoff value for positive results.

All serological assays ( $\mathrm{HBsAg}$, anti- $\mathrm{HBc} \mathrm{IgG}$ and anti- $\mathrm{HBc}$ $\mathrm{IgM}$, anti-HBs and anti-HCV) were performed by commercial electrochemiluminescence enzyme immunoassays, including the 3600 Vitros System (Ortho Clinical Diagnostics-Johnson \& Johnson, Dorchester, NY), Advia Centaur (Siemens, Munich, Germany) and Elecsys (Roche Diagnostics), which had similar analytical characteristics (sensitivity and specificity).

HBV-DNA and HCV-RNA levels (VL) were determined by real-time PCR technology, mainly on an AmpliPrep COBAS TaqMan system (Roche Diagnostics $\mathrm{GmbH}$ ) with a lower limit of quantification of $20 \mathrm{IU} / \mathrm{mL}$ for HBV-DNA and $15 \mathrm{IU} / \mathrm{mL}$ for HCVRNA and a lower limit of detection of $<10 / \mathrm{IU} \mathrm{mL}$ for both methods. The Abbot Real-Time HBV and HCV Assay (Chicago, IL), which has similar analytical characteristics, was used in 1 center. 
The diagnosis of confirmed OBI was established on HBVDNA detection in the serum of HBsAg-negative patients, with or without other serologic markers of previous viral exposure. ${ }^{4}$ We defined possible $\mathrm{OBI}$ as positive testing to anti-HBc IgG alone (anti-HBc alone serostatus) or to both anti-HBc and anti-HBs but no HBV-DNA detected. HBV-DNA detection in liver samples was not performed in any case. A case of seronegative or serosilent $\mathrm{HCV}$ infection was defined as simultaneous anti-HCV negativity and detectable ( $215 \mathrm{IU} / \mathrm{mL}) \mathrm{HCV}-\mathrm{RNA}$ VL.

Results are expressed as the median and interquartile range for quantitative variables and as a percentage for qualitative variables. When antiretroviral drugs were analyzed as risk factors, naive patients were excluded. Comparisons between quantitative variables were performed with the Mann-Whitney $U$ test. The Fisher exact test was used to compare categorical variables. Significance was set at a $P$ value of $<0.05$. Statistical analyses were performed using Stata/SE 11.2 (StataCorp., College Station, TX).

\section{RESULTS}

Of 838 HIV-infected pediatric patients, 254 were evaluated ( $30 \%$ patients from the total of the cohort, $18 \%$ of centers). No significant differences were observed when comparing our population with the general cohort..$^{5}$ Median age was 14.4 years (interquartile range: $9.2-16.7), 55.6 \%$ of participants were female, and $69.3 \%$ were white. In $95 \%$ of patients, the route of HIV acquisition was mother-to-child transmission. Maternal serostatus was positive in $3.9 \%$ for $\mathrm{HBV}$ and in $24.4 \%$ for $\mathrm{HCV}$; however, data regarding HBV and HCV infection serostatus were missing for $44.8 \%$ and $40.6 \%$ of the mothers, respectively.

Plasma HIV-VL was undetectable in two thirds, and median CD4+ T-cell count was $840 / \mathrm{mm}^{3}$ (interquartile range: $577-1117$ ), Almost one third of patients met the criteria for AIDS. Among patients on highly active antiretroviral therapy, ever/current exposure to drugs with anti-HBV activity were $91 \%$ and $30 \%$ for lamivudine/emtricitabine and tenofovir disoproxil fumarate, respectively.

Almost $90 \%$ of patients had completed the $\mathrm{HBV}$ vaccination schedule, but only one half of them achieved protective anti-HBs levels. No association was found between responsiveness and CD4+ T-lymphocyte nadir counts $<200$ cells $/ \mathrm{mm}^{3}$, higher VL or age.

Three $(1.3 \%)$ patients were chronically infected with HBV at inclusion ( $\mathrm{HBsAg}^{+}$, anti-HBc IgM+, anti-HBs-), HBV-DNA was negative but all of them received HIV/HBV-active drugs. No cases of acute $\mathrm{HBV}$ infection were detected.

Six possible OBI cases $(2.4 \% ; 95 \%$ confidence interval: $0.8-5.1$ ), but no confirmed case were detected: 2 patients showed an anti-HBc alone pattern $(0.8 \%)$ whereas 4 cases were both anti$\mathrm{HBc}$ and anti-HBs positive $(1.6 \%)$. HBV-DNA was undetectable in all cases and only 1 anti-HBc/anti-HBs-positive patient showed mild elevation of alanine aminotransferase and aspartate aminotransferase plasma levels (46 and $52 \mathrm{IU} / \mathrm{mL}$, respectively). Five of these 6 patients were currently receiving at least 1 antiretroviral drug with activity against $\mathrm{HBV}$, and did not show significantly lower CD4+ T-lymphocyte counts or higher plasma HIV-VL when compared with chronically HBV-infected patients.

Fifteen $(6 \%)$ patients were coinfected with $\mathrm{HCV}$ when evaluated by conventional serological screening methods. Two of them had spontaneously cleared HCV infection. All of them were HBV-DNA negative. Triple HCV-HBV-HIV coinfection was not observed in any patient

Seronegative $\mathrm{HCV}$ infection was detected in 2 patients $(0.8 \% ; 95 \%$ confidence interval: $0.1-2.8)$, both of whom showed elevated alanine aminotransferase plasma levels (51 and 77 IU/ $\mathrm{mL}$, respectively). There were no differences in HCV-RNA levels between anti-HCV positive and anti-HCV negative cases.

Data from possible OBI and seronegative HCV-infected patients are summarized in Table 1 .

\section{DISCUSSION}

Although remarkable strides have been made in understanding the natural history and pathogenesis of viral hepatitis, there is still a lack of information regarding occult hepatitis infection, especially in children.

We found no cases of confirmed OBI based on positive HBV-DNA analysis, the only reliable noninvasive diagnostic

TABLE 1. Main Features of Patients With Possible Occult HBV Infection and Seronegative HCV Infection

\begin{tabular}{|c|c|c|c|c|c|c|c|c|}
\hline & \multicolumn{6}{|c|}{ Poszible OBI (2.4\%) } & \multicolumn{2}{|c|}{$\begin{array}{r}\text { Seronegative } \mathrm{HCV} \\
\text { Infection }(0.8 \%)\end{array}$} \\
\hline & Patient 1 & Patient 2 & Patient 3 & Patient 4 & Patient 5 & Patient 6 & Patient 7 & Patient 8 \\
\hline Age, $y \mathbf{y r}$ & 7 & 16 & 13 & 11 & 14 & 15 & 16 & 16 \\
\hline Sex & M & $\mathrm{F}$ & $\mathrm{F}$ & $\mathbf{F}$ & $\mathbf{F}$ & M & $\mathrm{M}$ & M \\
\hline Ethnicity & A & $\mathrm{w}$ & w & A & $\mathrm{W}$ & $\mathrm{A}$ & $\mathrm{w}$ & $\mathrm{W}$ \\
\hline Transmiввion & $\mathrm{T}$ & $\mathrm{v}$ & $\mathrm{v}$ & $\mathrm{v}$ & $\mathrm{v}$ & $\mathrm{v}$ & $\mathrm{v}$ & $\mathrm{v}$ \\
\hline Current CD $4+\mathrm{T}$ coll count $\left(/ \mathrm{mm}^{3}\right)$ & 1088 & 574 & 750 & 910 & 466 & 734 & 814 & 920 \\
\hline HIV VL (cop/mL) & 63 & Undetect & Undetect & Undetect & 88,500 & Undetect & 150 & Undetect \\
\hline AIDS criteria & No & Yess & No & Yes & No & No & Yes & Yes \\
\hline ALT $(I U / m L)$ & 46 & 19 & 20 & 21 & 21 & 25 & 49 & 43 \\
\hline AST (IU/mL) & 52 & 18 & 14 & 21 & 14 & 26 & 51 & 77 \\
\hline Anti-HBs IgG & Positive & Undetect & Positive & Positive & Undetect & Positive & Undetect & Undetect \\
\hline Anti-HBc IgG & Positive & Positive & Positive & Positive & Positive & Positive & Undetect & Undetect \\
\hline HBV DNA & Undetect & Undetect & Undetect & Undetect & Undetect & Undetect & Undetect & Undetect \\
\hline Anti-HCV & Undetect & Undetect & Undetect & Undetect & Undetect & Undetect & Undetect & Undetect \\
\hline HCV RNA (cop/mL) & Undetect & Undetect & Undetect & Undetect & Undetect & Undetect & $5,450,000$ & 45,000 \\
\hline HBV vaccine & C & C & $\mathrm{C}$ & $\mathrm{C}$ & C & $\mathrm{C}$ & I & $\mathrm{C}$ \\
\hline 3TC/FTC ${ }^{*}$ exposure & Yeв & Yeв & Yes & Yes & Yeв & Yes & Yes & Yeв \\
\hline $\mathrm{TDF}^{*}$ exровите & No & Yes & No & Yes & No & No & Yes & No \\
\hline Maternal HBV & Unk & Positive & Unk & Unk & Unk & Positive & Unk & Negative \\
\hline Maternal HCV & Unk & Positive & Positive & Unk & Unk & Unk & Positive & Positive \\
\hline
\end{tabular}

Current or ever exposure. TDF, tenofovir disoproxil fumarate, 3TC, lamivudine; V, vertically infected; Undetect, undetectable; Unk, unknown. 
marker of $\mathrm{OBI}$ in clinical practice. As OBI status is dependent on longlasting persistence of viral genomes in the hepatocytes, ${ }^{2}$ analy. sis of liver extracts is considered the reference standard diagnostic method for OBI. Liver samples were not available in our study, however; hence, OBI cannot be definitely excluded in our patients. In addition, HBV-DNA detection in serum can fluctuate over time, another possible explanation for the absence of positive samples in our study. ${ }^{6}$ A major limitation of the survey is that most patient: with "possible occult $\mathrm{HBV}$ " were receiving antiretroviral treatment active against HBV (ie, lamivudine/emtricitabine and/or tenofovir disoproxil fumarate), which might have suppressed HBV replication below the detection limits. Thus, it is highly recommendable to perform the screening for viral hepatitis before starting on antiretroviral treatment, including HBV-DNA and HCV-RNA.

Using the definitions in the consensus recommendations ${ }^{4}$ based on the HBV antibody profile, HBV infection markers may be negative in up to $20 \%$ of patients, possibly due to progressive loss of specific antibodies. ${ }^{2}$ In our opinion, this justifies implementation of HBV-DNA detection in the regular screening methods for HBV infection in HIV-infected children, as other authors have suggested. ${ }^{4}$ On the other hand, false OBI results can also occur, with positive $\mathrm{HBV}-\mathrm{DNA}$ and negative $\mathrm{HBsAg}$ caused by viral escape mutants that express a modified $\mathrm{HBsAg}$ not (or poorly) recognized by commercially available detection assays ${ }^{2}$

The risk of $\mathrm{OBI}$ associated with the "anti-HBc alone" serological profile has been extensively demonstrated, and an antibody response to $\mathrm{HBc}$ can be considered a surrogate marker of $\mathrm{OBI}{ }^{8}$ This was the case in 2 of 6 patients with possible OBI in our study.

In our study, the prevalence of HCV seronegative infection $(0.8 \%)$ was low in comparison with previous studies, ${ }^{2}$ a fact that may be related to the good overall immunological status of our cohort or the development of immune tolerance in the first years of life. In 2 cases, anti-HCV was positive and HCV-RNA undetectable, which could indicate cleared infection. In 1 of them, HCV. RNA remained negative along subsequent assessment; the other patient was lost to further follow-up. As was reported by Garcia et al, ${ }^{7}$ follow-up sampling is strongly recommended, and we suggest checking seronegative patients for viremia on at least 2 time points, 6 months apart.

The novelty of this study is that it is the first to search for occult hepatitis coinfection in a large cohort of HIV-infected pediatric patients. The cross-sectional design is an obvious limitation, but it can be considered a snapshot of the current prevalence of occult hepatitis infection among children living with HIV in our country.

In conclusion, our data reinforce the need for the recent Spanish pediatric HIV guidelines recommendation to implement occult hepatitis screening (sensitive molecular assays for both
HBV-DNA and HCV-RNA) in the routine care of these children. 9.10 Further work is needed to clarify the clinical significance of occult hepatitis infection and its pathogenic consequences in this unique growing population

\section{ACKNOWLEDGMENTS}

The authors are grateful to the children who participated in this study and their families. The authors also thank Samtiago Pérez Hoyos (Statistics Department, Hospital Universitari Vall d'Hebron, Barcelona) for performing the statistical analysis, Francisco Rodriguez-Frias (Liver Pathology Unit, Biochemistry Department, Hospital Universitari Vall d'Hebron, Barcelona and CIBER (Carlos III Institute of Health) who kindly revised the article drafts and Celine Cavallo for English language revision

\section{REFERENCES}

1. Rosenthal E, Poirce M, Pradier C, et al.; GERMIVIC Joint Study Group, Mortality due to hepatitis C-related liver disease in HIV-infected patients in France (Mortavic 2001 study). AIDS. 2003;17:1803-1809.

2. Torbenson M, Thomas DL. Oceult hepatitis B. Lancet Infect Dis. 2002;2:479-486.

3. Chamie G, Bomacini M, Banssberg DR, et al. Factors associated with seronegative chronic bepatitis C virus infection in HIV infection. Clin Infect Dis. 2007:44:577-583.

4. Raimondo G, Allain JP, Brunetto MR, et al. Statements from the Taormina expert meeting on oecult hepatitis B vims infection. $J$ Hepato $L$ $2008 ; 49 ; 652-657$,

5. de Jose MI, Jiménez de Ory S, Espian M, et al.: working groups of CoRISpe and HIV HGM BioBank. A new tool for the paediatric HIV research: general data from the Cohort of the Spanish Paediatric HIV Network (CoRISpe). BMC Infect Dis. 2013:13:2

6. Cardona NE, Loureiro CL, Garzaro DJ, et al. Unusual presentation of hepatitis B serological markers in an Amerindian community of Venezuela with a majority of occult cases. Virol J.2011;8:527.

7. Garcia F, Mateos ML, Garcia-Valdecasas J, et al. Relevance of investigating the presence of hepatitis C virus RNA in HCV antibody-negative hemodi. alysis patients. Am $J$ Nephrol. 2000;20:166-167.

8. Marque-Juillet S, Benghalia K, Monnier S, et al. Should patients infected with HIV be screened for occult hepatitis B? Pathol Biol. 2010;58:e39-e42.

9. Menson EN, Mellado MJ, Bamford A, et al.; Paediatric European Network for Treatment of AIDS (PENTA) Vaccines Group; PENTA Steering The Children's HIV Association (CHIVA) Guidance on vaccintion of HIV.infected children in Europe. HIV Med. 2012:13:333-336; el.

10. Expert Panel Spanish Collaborative for Pediatric HIV Infection (CEVIHP), Spanish Society of Pediatric Infections Disenses (PFIC) of the Spanish Association of Pediatrics (AEP) and Secretariat of the National AIDS Plan consensus document CEVIHP/SEIP/AEP/SNS regarting antiretroviral treatment in children and adolescents infected with HIV. Available at: http: www.seipweb_es/images/stories/pdf/docu_oficiales/2012/GuiasTARNinos Adolescentes23 Marzol2, pif. Accessed March 25, 2013. 